\title{
Katalyse und Elektronentransfer in helikalen De-novo-
}

\section{Gerïststrukturen}

Tyler B. J. Pinter, Karl J. Koebke und Vincent L. Pecoraro*

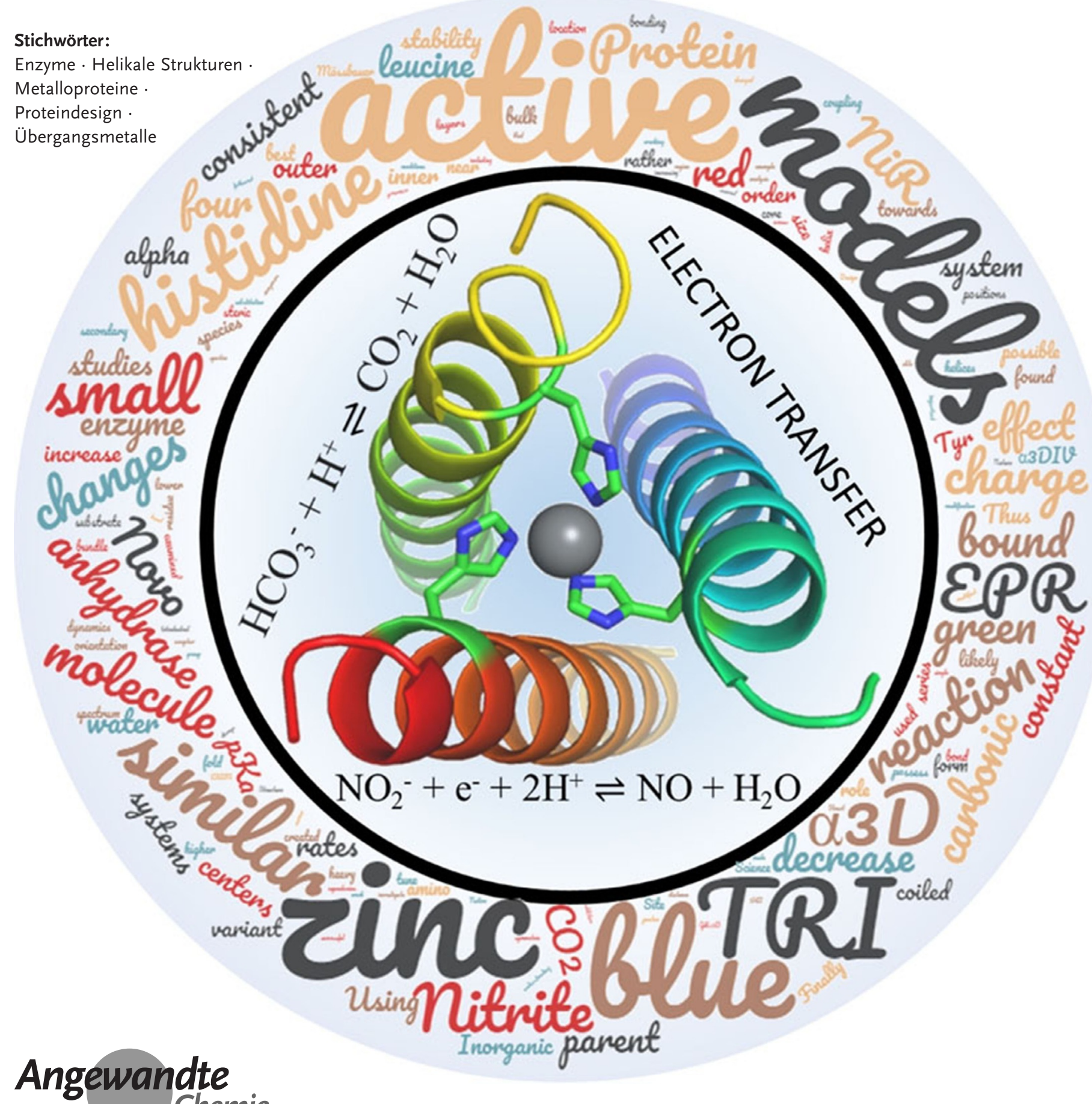

Enzyme - Helikale Strukturen

Uergangsmetalle 
Die Frage nach der Beziehung zwischen der Struktur und der

Funktion von Proteinen ist eines der größten Rätsel der Biochemie.

Das De-novo-Design von Metalloproteinen bietet die Möglichkeit, neu zu bestimmen, was nötig ist, um von Grund auf Funktionalität in einer Struktur aufzubauen, die nicht von der Struktur des natürlichen Vorbilds abgeleitet ist. Dieser Aufsatz konzentriert sich auf Arbeiten zum Proteindesign, die De-novo-Metalloproteine innerhalb alphahelikaler Gerüststrukturen liefern. Beispiele umfassen De-novo-Proteine mit Carboanhydrase- oder Nitritreduktaseaktivität, sowie Systeme, in denen die spektroskopischen Eigenschaften einzigartiger Elektronentransferzentren von Cupredoxinen oder Rubredoxinen nachgebildet werden. Diese Arbeiten demonstrieren die Vielseitigkeit von alpha-Helices als Gerüststrukturen im Design von Metalloproteinen und die Fortschritte, die durch rationales Design möglich sind. Unsere Arbeiten belegen die Unabhängigkeit der Carboanhydraseaktivität von der Gerüststruktur und Position des aktiven Zentrums, verfeinern unsere Cupredoxinmodelle und erhöhen die Aktivität unserer Nitritreduktase um bis zu das 1000-Fache.

\section{Aus dem Inhalt}

1. Einleitung
$\begin{aligned} & \text { 2. De-novo-Design von } \\
& \text { Metallopeptiden für die } \\
& \text { Katalyse }\end{aligned}$
$\begin{aligned} & \text { 3. Entwicklung von Kupferzentren } \\
& \text { als Modelle für die } \\
& \text { Nitritreduktaseaktivität }\end{aligned}$
$\begin{aligned} & \text { 4. Design von } \\
& \text { Elektronentransferzentren in } \\
& \text { De-novo-Gerüsten }\end{aligned}$
\begin{tabular}{l} 
5. Zusammenfassung und Ausblick 7770 \\
\hline
\end{tabular}

search. Daher stellt dieser Aufsatz aktuelle Entwicklungen im Einsatz von reinen $\alpha$-helikalen Strukturen in den Mittelpunkt, speziell von dreisträngigen Coiled-Coil-Peptiden (3SCCs)

\section{Einleitung}

Metalloproteine und -peptide vermitteln eine immense Zahl wichtiger biochemischer Reaktionen, die essentiell für alle Lebensformen sind. ${ }^{[1]} \mathrm{Zu}$ den bedeutendsten Beispielen zählen der Transfer von Elektronen innerhalb biologischer Systeme durch redoxaktive Metallzentren und die proteingestützte, metallvermittelte Katalyse. ${ }^{[1,2]}$ Diese Bedeutung unterstreicht, wie weitläufig die Forschung zu Metallzentren in biologischen Systemen ist und wie viele Inspirationen sie für das Design von de novo entwickelten Strukturen bietet.

Das De-novo-Proteindesign nutzt einen Bottom-upAnsatz zur Entwicklung funktioneller Proteine in Gerüsten, die sich von denen der nativen Systeme vollständig unterscheiden. ${ }^{[3]}$ Diese Strategie hat zwei parallele und gleichermaßen wichtige Ziele. Erstens werden durch die Nachbildung der natürlichen Metallbindungsstellen in De-novo-Gerüsten, die üblicherweise eine signifikant andere Sekundärstruktur als das natürliche System haben, die Genauigkeit und Vollständigkeit unseres Verständnisses der chemischen Prinzipen und Eigenschaften, die die Funktion von Metalloproteinen bestimmen, auf den Prüfstand gestellt. Dieser Ansatz ermöglicht es, die grundlegenden Voraussetzungen der jeweils untersuchten Funktion ohne den „evolutionären Ballast“ zu betrachten, der in Studien an den nativen Proteinen immer vorhanden ist und diese verkompliziert. ${ }^{[4]}$ Das zweite Ziel ist die Synthese neuer Katalysatoren mit verbesserten Eigenschaften für katalytische Anwendungen. ${ }^{[5]}$ Heute stehen bereits eine Vielzahl von Ansätzen zum De-novo-Design von Metalloproteinen und eine noch größere Zahl von künstlichen Gerüststrukturen zur Verfügung, mit denen gearbeitet werden kann. ${ }^{[6]}$ Zum Design von Metalloproteinen für die Katalyse sind bereits viele Aufsätze erschienen, ${ }^{[3]}$ unter anderem eine gesamte Ausgabe von Accounts of Chemical Re- und Drei-Helix-Bündel-Peptiden (3HBs), mit einem Fokus auf den Arbeiten unserer Gruppe.

3SCC- und 3HB-Systeme bieten eine Reihe von Vorteilen. ${ }^{[7]}$ Die 3SCCs der TRI-Familie wurden ausgehend von CoilSer $^{[8]}$ entwickelt, das wiederum ausgehend von dem von Hodges et al. zur Nachbildung des Coiled-Coils Tropomycin beschriebenen Polyheptapeptids entwickelt wurde. ${ }^{[9]}$ TRI besteht aus wiederholenden Heptaden (abcdefg) mit Leucinresten an der ersten (Position $a$ ) und vierten Position (Position $d) .{ }^{[10]}$ An den weiteren Positionen finden sich helixinduzierende (Ala, Position $c$ ), geladene und/oder salzverbrückende Reste (Lys an Positionen $b$ und $g$ und Glu an Positionen $e$ und $f$ ). Die Geometrie einer Super-Coiled-alphaHelix mit 3.5 Aminosäureresten pro Windung richtet die Leucinreste auf einer Seite der alpha-Helix aus, wodurch eine amphiphile Struktur erreicht wird. Das kristallographische TRI-Analogon CoilSer ist in Abbildung $1 \mathrm{~A}$ gezeigt. In TRI sind drei alpha-Helices parallel miteinander assoziiert und die Leucinreste dabei derart zusammengelagert, dass ein hydrophober Innenraum aus den $a$ - und $d$-Resten gebildet wird. Diese Struktur wird zusätzlich durch Salzbrücken zwischen den $e$ - und $f$-Aminosäureresten benachbarter Stränge stabilisiert. Zur Verbesserung der Stabilität der Coiled-CoilStrukturen wird der N-Terminus amidiert und der C-Terminus acyliert. Die durch diese räumliche Anordnung geschaffenen Schichten von Leucinresten im hydrophoben Inneren der Struktur können durch metallbindende Aminosäurereste

[*] Dr. T. B. J. Pinter, Dr. K. J. Koebke, Prof. V. L. Pecoraro Department of Chemistry, University of Michigan Ann Arbor, Michigan, 48109-1055 (USA) E-Mail:vlpec@umich.edu

(D) Die Identifikationsnummern (ORCIDs) der Autoren sind unter https://doi.org/10.1002/anie.201907502 zu finden. 

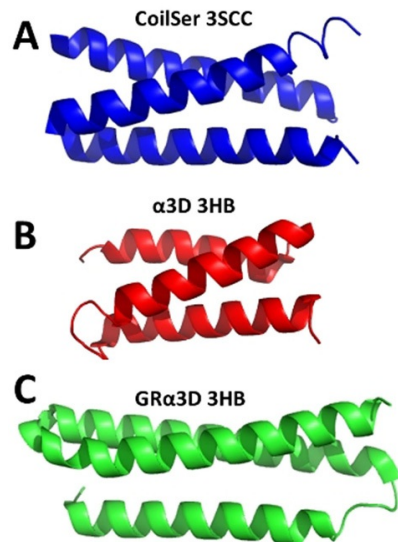

Abbildung 1. Strukturen der in diesem Aufsatz diskutierten Peptide und Proteingerüste: kristallographisches TRI-Analogon CoilSer (A; PDB: 3PB $\left.{ }^{[12]}\right), \alpha_{3} \mathrm{D}$ (B; PDB: $2 \mathrm{MTQ}^{\left[{ }^{[13]}\right)}$ und $\mathrm{GR} \alpha_{3} \mathrm{D}$ (C; PDB: 6DS9[1]).

ersetzt werden, wodurch Bindungsstellen für Metalle im Inneren des TRI-Gerüsts geschaffen werden. Tabelle 1 listet die Sequenzen der CS- und TRI-Peptide auf, die in diesem Aufsatz diskutiert werden.

Zur Bildung einer Metallbindungsstelle müssen in einem TRI/CS-System drei parallele und unabhängige Stränge assoziieren. Darin unterscheiden sich diese Systeme signifikant von natürlichen Systemen, in denen die zur Metallbindung benötigten chelatisierenden Aminosäurereste alle von einem einzigen Strang stammen. Daher wurde ein zweites Gerüst entwickelt, in dem die drei alpha-Helices miteinander verknüpft werden. Dabei ermöglichen flexible Schleifen die Bildung von $\alpha_{3} \mathrm{D}$, einem antiparallelen 3HB-Protein, wie in
Abbildung 1B dargestellt. Die De-novo-Designstrategie ist dabei jedoch die gleiche wie im Fall von TRI: Hydrophobe Aminosäurereste, Aminosäurereste in der Nähe der flexiblen Schleifen oder in den flexiblen Schleifen selbst werden zur Erzeugung von Metallbindungsstellen durch metallbindende Aminosäurereste ersetzt. Ein weiterer Unterschied zwischen TRI und $\alpha_{3} \mathrm{D}$ besteht darin, dass in TRI nur symmetrische Bindungsstellen erzeugt werden können, da TRI durch Assoziation dreier identischer Stränge gebildet wird. In $\alpha_{3} \mathrm{D}$ kann hingegen jede Aminosäure unabhängig mutiert werden und dadurch eine vollständige Kontrolle der Aminosäurereste sowohl in der Umgebung als auch in der Metallbindungsstelle selbst erreicht werden. Zur Erhöhung der Stabilität des 3HB-Gerüsts bei steigender Anzahl destabilisierender Mutationen am Ausgangsgerüst $\alpha_{3} \mathrm{D}$ entwickelten wir schließlich die verlängerte Version Grand $\alpha_{3} \mathrm{D}\left(\mathrm{GR} \alpha_{3} \mathrm{D}\right.$; Abbildung $1 \mathrm{C}) .{ }^{[1]}$ In diesem Aufsatz diskutieren wir die Fortschritte, die wir beim rationalen Design sowohl von katalytischen Metallbindungsstellen als auch von Metallbindungszentren zum Elektronentransfer in unseren TRI- (einschließlich TRI, GRAND und CoilSer-Peptiden) und $\alpha_{3} \mathrm{D}$ Gerüststrukturen (einschließlich $\alpha_{3} \mathrm{D}$ und Grand $\alpha_{3} \mathrm{D}$ ) erzielt haben.

\section{De-novo-Design von Metallopeptiden für die Katalyse}

In biologischen Systemen katalysieren Metalle vielfältigste Reaktionen. ${ }^{[14]}$ Dabei kann ein und dasselbe Metall in unterschiedlichen Peptidumgebungen deutlich unterschiedliche Aktivitäten und unterschiedliche chemische Eigenschaf-

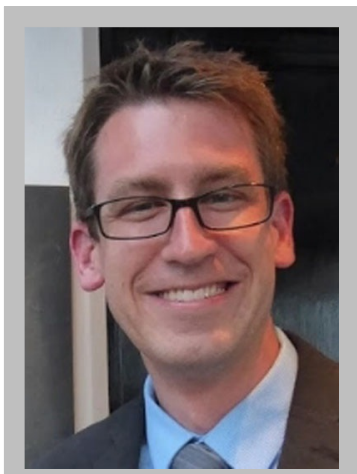

Tyler B. J. Pinter promovierte an der University of Western Ontario (London, Ontario, Kanada) unter Anleitung von Prof. Martin Stillman zu den mittels Massenspektrometrie untersuchten, metallbindenden Eigenschaften von Metallothionein. Derzeit arbeitet er als NSERC-Research-Fellow mit Prof. Vincent Pecoraro an der Entwicklung von De-novo-Modellen für Metallbindungszentren.

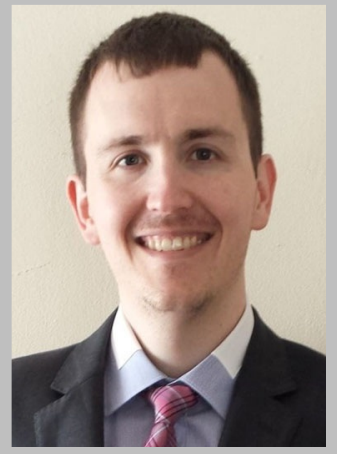

Karl J. Koebke promovierte an der University of Wisconsin - Milwaukee (USA) unter Anleitung von Prof. Andy Pacheco zur Kinetik der Dioxygenierung von Stickstoffmonoxid in Häm-Proteinen. Anschließend war er drei Jahre als Postdoktorand bei Prof. Vincent Pecoraro tätig und entwickelte eine Vielzahl maßgeschneiderter De-novo-Gerüste einschließlich Mimetika für die Nitritreduktase und Cupredoxin. Nachdem er ein Jahr mit Prof. Timothy Stemmler (Wayne State University) zur mitochondrialen FeS-Cluster-Biogenese forschte, arbeitet er nun mit Prof. Neil Marsh (University of Michigan) an Protein-Nanokäfigen durch Selbstorganisation.

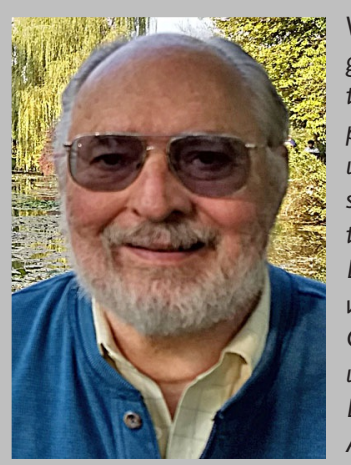

Vincent L. Pecoraro ist John T. Groves Collegiate Professor of Chemistry an der University of Michigan, Ann Arbor (USA). Er ist Experte auf dem Gebiet der bioanorganischen und supramolekularen Chemie und hat substanzielle Beiträge zum Verständnis der photosynthetischen Wasseroxidation und der Biochemie von Vanadium geleistet. In den vergangenen Jahren war er führend auf dem Gebiet des Designs von Metalloproteinen und Metallakronen für die biomolekulare Bildgebung. Er war mehr als 20 Jahre lang Associate Editor für Inorganic Chemistry und ist Fellow der ACS und AAAS. 
Tabelle 1: Liste der Peptidsequenzen der in diesem Aufsatz diskutierten Ausgangspeptide.

\begin{tabular}{lcccccc}
\hline Peptid $^{[a]}$ & \multicolumn{1}{l}{ abcdefg } & abcdefg & \multicolumn{2}{l}{ abcdefg } & \multicolumn{2}{l}{ abcdefg } \\
\hline TRI & AC-G & WKALEEK & LKALEEK & LKALEEK & LKALEEK & G-NH $_{2}$ \\
CS & AC-E & WEALEKK & LAALESK & LQALEKK & HEALEHG & $-\mathrm{NH}_{2}$ \\
\hline Protein $^{[b]}$ & Schleife & abcdefg & abcdefg & abcdefg & Schleife \\
\hline$\alpha_{3} D$ & MGS & WAEFKQR & LAAIKTR & LQAL & GGS \\
& EAE & LAAFEKE & IAAFESE & LQAY & KGKG \\
& NPE & VEALRKE & AAAIRDE & LQAYRHN & \\
\hline
\end{tabular}

[a] N- und C-Terminus sind acyliert bzw. amidiert. [b] Rekombinant aus E. coli. hergestellt.
$\mathrm{HCO}_{3}{ }^{-}+\mathrm{H}^{+} \rightleftharpoons \mathrm{CO}_{2}+\mathrm{H}_{2} \mathrm{O}$

Zwar wird durch das Einbringen zweier Schichten metallbindender Aminosäurereste die Struktur gegenüber jener des ursprünglichen TRI destabilisiert, durch das Einführen einer Bindungsstelle für ein Schwermetallion ist diese Struktur aber insgesamt stabiler als die unmutierte Form. Es konnte gezeigt werden, dass die strukturell wichti-

ge Bindungsstelle die Stabilität des ten aufweisen und dementsprechend unterschiedliche Reaktionen vermitteln. So spielt Eisen eine Schlüsselrolle bei der Speicherung und dem Transport von Sauerstoff, beim Elektronentransfer sowie bei vielen Hydroxylierungen, Dioxygenierungen, Oxidationen und Hydrolysereaktionen. Die jeweilige Chemie des Eisenzentrums wird dabei ausschließlich durch die spezifische Proteinumgebung des Metallions moduliert. ${ }^{[15]}$ Dementsprechend können in unseren De-novoGerüsten durch approximative Nachbildung der Position der spezifischen konservierten Aminosäurereste, die die natürliche Metallbindungsstelle umgeben, die jeweils gewünschten katalytischen Aktivitäten erreicht werden. Bisher waren unsere Arbeiten auf dem Gebiet dreier Funktionen besonders erfolgreich, nämlich bei der zinkkatalysierten Hydrolyse- und Nitritreduktase-Aktivität sowie beim Elektronentransfer.

\subsection{Entwicklung von Zinkzentren als Modelle der hydrolytischen Carboanhydraseaktivität}

Aufbauend auf unserem fundierten Verständnis der Bindung von Schwermetallionen in den Tris(cystein)-Bindungsstellen unserer de novo entwickelten Gerüste ${ }^{[16]}$ widmeten wir unsere Aufmerksamkeit der komplexeren Aufgabe der Nachahmung katalytischer Metallzentren. Dieses Vorhaben ist deutlich ambitionierter, da das Design der Metallbindungsstelle nicht nur die primären koordinierenden Liganden nachbilden muss, sondern für eine effektive Katalyse auch den Zugang des Substrats zum aktiven Zentrum ermöglichen muss. Bei unserem ersten Versuch, ein katalytisch aktives Metall in unsere Gerüste einzubringen, nahmen wir die symmetrische Tris(histidin)-Koordinationsumgebung der Carboanhydrase (CA) zum Vorbild. CA katalysiert die reversible Hydrierung von $\mathrm{CO}_{2}$, Reaktion (1), und ist essentiell für das Puffersystem des Blut-pH-Werts und die Atmung. Die native CA stellt aufgrund der relativ einfachen Metallbindungsstelle und ihrer hohen katalytischen Aktivität ein geeignetes Ziel dar. ${ }^{[17]}$ Durch Mutation von zwei verschiedenen Leucinschichten im TRI-Gerüst an jedem Ende des CoiledCoils, einmal durch Cystein in der Nähe des N-Terminus und einmal durch Histidin in der Nähe des C-Terminus, wird TRIL9CL23H erhalten. Kristallographisch konnten wir zeigen, dass die Tris(cystein)-Bindungsstelle ein für die strukturelle Stabilität wichtiges $\mathrm{Hg}^{\mathrm{II}}$-Ion bindet, während in der Tris(histidin)-Bindungsstelle das für die katalytische Aktivität notwendige Zinkion gebunden wird. ${ }^{[12]}$
3SCC durch Bildung einer trigonalen $\mathrm{Hg}^{\mathrm{II}}-\mathrm{Cys}_{3}$-Struktur signifikant erhöht. Der Vergleich kristallographischer Daten ergab, dass die Geometrie des Zinkzentrums dem der nativen CA stark ähnelt, einschließlich der Koordination eines exogenen Wassermoleküls oder Hydroxids an das Zinkzentrum, wenngleich die Orientierung der koordinierenden Imidazole vom natürlichen Vorbild abweicht (Abbildung 2).

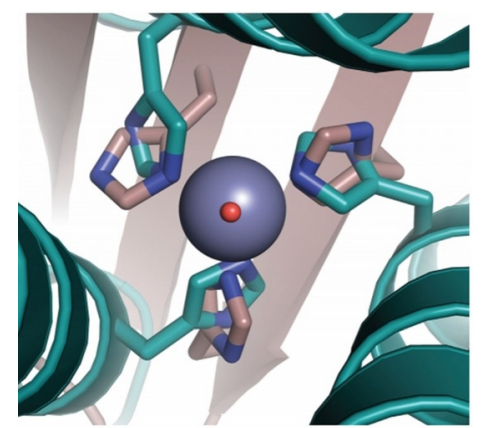

Abbildung 2. Überlagerung des $\mathrm{Zn}^{\prime \prime} \mathrm{N}_{3} \mathrm{O}$-Zentrums in $\left[\mathrm{Hg}^{\prime \prime}\right]_{S}\left[\mathrm{Zn}^{\prime \prime}\right.$. $\left.\left(\mathrm{H}_{2} \mathrm{O}\right)\right]_{\mathrm{N}}(\mathrm{CSL9PenL} 23 \mathrm{H})_{3}$ mit dem aktiven Zentrum der menschlichen CAII. CS in Cyan (PDB: $3 \mathrm{~PB})^{[12]}$ ) und CAll in Beige (PDB: 2CBA ${ }^{[17]}$ ). Das Lösungsmittelmolekül in CS ist in Rot abgebildet, das Lösungsmittelmolekül aus Call liegt unter dem Zinkion. Wiedergabe mit Genehmigung aus Lit. [12]. Copyright 2012 Nature Publishing Group.

Wir untersuchten anschließend die Aktivität von $\left[\mathrm{Hg}^{\mathrm{II}}\right]_{\mathrm{S}^{-}}$ $\left[\mathrm{Zn}^{\mathrm{II}}\right]_{\mathrm{N}}$ TRIL9CL23H (tiefgestellte Zeichen stehen für metallkoordinierende Proteinliganden $-\mathrm{HgS}_{3}$ und $\mathrm{ZnN}_{3}$ ) in der Hydrolyse von $p$-Nitrophenolacetat (pNPA) und der Hydrierung von $\mathrm{CO}_{2}$. Die Hydrolyse von pNPA ist gut untersucht, da die Bildung von $p$-Nitrophenolat wegen seiner Farbigkeit gut verfolgt werden kann. Unser CA-Modell $\left[\mathrm{Hg}^{\mathrm{II}}\right]_{\mathrm{S}^{-}}$ $\left[\mathrm{Zn}^{\mathrm{II}}\right]_{\mathrm{N}}$ TRIL9CL23H zeigte eine $\mathrm{pH}$-abhängige Aktivität (Abbildung 3; $\mathrm{p} K_{\mathrm{a}}$ der Hydrolyse ca. 8.8), wobei der Maximalwert für $k_{\text {cat }} / K_{\mathrm{M}}$ bei pH 9.5 erreicht wurde und etwa das 100-Fache des entsprechenden Wertes von CAII (der Isoform mit der höchsten pNPA-Aktivität) betrug. Tabelle 2 vergleicht die Aktivitäten unserer Modellgerüste in der pNPAHydrolyse. Bemerkenswerterweise zeigt unser CA-Modell unter unseren Bedingungen keine Produktinhibierung, wie sie sonst häufig für niedermolekulare CA-Modelle beobachtet wird. ${ }^{[18]}$

Diesem Modell fehlt die wichtige sekundäre Koordinationsumgebung, die in CAII eine wichtige Rolle bei der Er- 


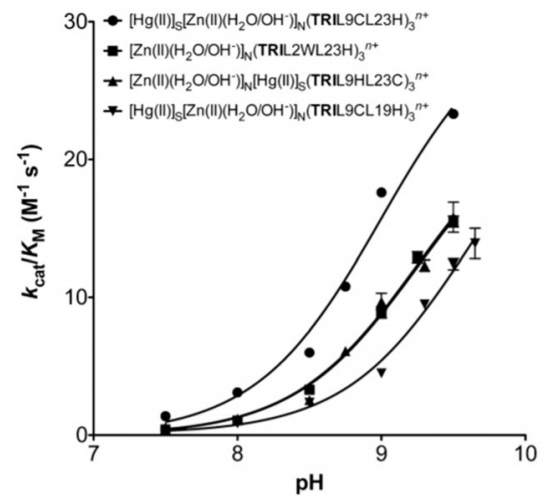

Abbildung 3. $\mathrm{pH}-\mathrm{Abhängigkeit} \mathrm{der} \mathrm{katalytischen} \mathrm{Effizenz} \mathrm{der} \mathrm{pNPA-Hy-}$ drolyse durch Zn"-bindende TRI-Peptide: $\left[\mathrm{Hg}^{\prime \prime}\right]_{S}\left[\mathrm{Zn}^{\prime \prime}\right]_{N} \operatorname{TRIL9CL23H}(\bullet)$,

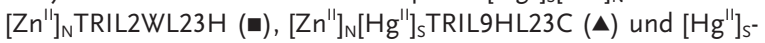
$\left.\left[Z n^{\prime \prime}\right)\right]_{N}$ TRIL9CL19H ( $)$. Wiedergabe mit Genehmigung aus Lit. [12]. Copyright 2013 American Chemical Society.

Tabelle 2: Kinetische Parameter der Hydrolyse von pNPA durch Zn-TRIPeptide.

\begin{tabular}{llll}
\hline Peptid & $p K_{\mathrm{a}}$ & $\begin{array}{l}k_{\text {cat }} / K_{\mathrm{M}}(\max ) \\
\left(\mathrm{M}^{-1} \mathrm{~s}^{-1}\right)^{[a]}\end{array}$ & $\begin{array}{l}k_{\text {cat }} \text { (max) } \\
\left(\mathrm{s}^{-1}\right)\end{array}$ \\
\hline$[\mathrm{Zn}]_{N}(\mathrm{TRIL2WL23H})$ & 9.2 & 25 & 0.055 \\
{$[\mathrm{Hg}]_{S}[\mathrm{Zn}]_{N}(\mathrm{TRIL9CL23H})$} & 9.0 & 31 & 0.053 \\
{$[\mathrm{Zn}]_{N}[\mathrm{Hg}]_{S}(\mathrm{TRIL9HL23C})$} & 9.2 & 24 & 0.030 \\
{$[\mathrm{Hg}]_{S}[\mathrm{Zn}]_{N}(\mathrm{TRIL9CL19H})$} & 9.6 & 27 & 0.076 \\
\hline
\end{tabular}

[a] Durch Angleichung an die $\mathrm{pH}$-abhängigen $k_{\mathrm{cat}} / K_{\mathrm{M}}$-Werte gegen den $\mathrm{pH}$-Wert erhalten.

höhung der $\mathrm{CO}_{2}$-Hydrierungsgeschwindigkeit spielt. In T199A-Mutanten von CAII fehlt der Akzeptor einer Wasserstoffbrücke, der im Mechanismus der Hydrolyse nachweislich zur Aktivierung des zinkgebundenen Wassermoleküls dient. ${ }^{[19]}$ Dadurch wird die Aktivität gegenüber jener des nativen Systems um das etwa 100-Fache gesenkt und liegt so etwa im Bereich der in unserem CA-Modell beobachteten Geschwindigkeitskonstanten. Da das von uns beschriebene $\left[\mathrm{Hg}^{\mathrm{II}}\right]_{S}\left[\mathrm{Zn}^{\mathrm{II}}\right]_{\mathrm{N}}$ TRIL9CL23H nur die erste Koordinationssphäre nachbildet, stellt es im Grunde genommen ein Modell der Aktivität von CAIIT199A dar.

In unseren Untersuchungen zur Geschwindigkeitskonstante der $\mathrm{CO}_{2}$-Hydrierungsaktivität, der natürlichen Reak- tion von CAII, zeigte $\left[\mathrm{Hg}^{\mathrm{II}}\right]_{\mathrm{S}}\left[\mathrm{Zn}^{\mathrm{II}}\right]_{\mathrm{N}}$ TRIL9CL23H bei $\mathrm{pH} 9.5$ Umsatzgeschwindigkeiten im Bereich des 500-Fachen des nativen Enzyms und übertraf die Aktivität des besten niedermolekularen CA-Modells um mehr als das 70-Fache (Tabelle 3). Seit dem Erscheinen unserer Arbeit wurden Modelle mit höherer pNPA-Aktivität beschrieben, beispielsweise MID1, das bei pH 9 eine maximale Aktivität von $k_{\text {cat }} / K_{\mathrm{M}}$ von $660 \mathrm{M}^{-1} \mathrm{~s}^{-1}$ erreichte. ${ }^{[20]}$ Bis heute ist $\left[\mathrm{Hg}^{\mathrm{II}}\right]_{\mathrm{S}^{-}}$ $\left[\mathrm{Zn}^{\mathrm{II}}\right]_{\mathrm{N}}$ TRIL9CL23H das Modell mit der höchsten Aktivität in der $\mathrm{CO}_{2}$-Hydrierung. Diese Arbeit stellte einen Meilenstein dar, der deutlich machte, was allein durch Nachbildung der ersten Koordinationssphäre in unseren De-novo-Gerüsten erreicht werden kann.

\subsection{Einfluss der Position der Zinkbindungsstelle auf die Hydrolyseaktivität}

Es ist denkbar, dass die Gegenwart des zweiten Metallzentrums $\left[\mathrm{Hg}^{\mathrm{II}}\right]_{\mathrm{S}}$ durch Veränderung der Beweglichkeit oder der ,atmenden“ Anordnung der einzelnen Stränge des 3SCC die Aktivität unserer CA-Modells erhöht. Daher entwickelten wir entsprechende Modelle, in denen das stabilisierende Tris(cystein)-Motiv zur Bindung von Schwermetallen fehlt. ${ }^{[21]}$ TRIL23H-Denaturierungsstudien ergaben, dass die 3SCCStruktur in Abwesenheit der Cysteinschicht weniger stabil war, die Affinität für Zink aber unverändert blieb. Die Aktivität dieses Modells gegen pNPA war, außer bei hohen $\mathrm{pH}-$ Werten, nahezu identisch $\mathrm{zu}$ der von $\left[\mathrm{Hg}^{\mathrm{II}}\right]_{\mathrm{s}^{-}}$ $\left[\mathrm{Zn}^{\mathrm{II}}\right]_{\mathrm{N}}$ TRIL9CL23H, was wir auf die verringerte Stabilität durch den Verlust des stabilisierenden $\left[\mathrm{Hg}^{\mathrm{II}}\right]_{\mathrm{S}}$ unter stärker basischen Bedingungen zurückführten.

Um zu untersuchen, ob die spezifische Position der Metallbindungsstelle einen signifikanten Einfluss auf die Aktivität hat, entwickelten wir anschließend CA-Modelle mit modifizierter Position der Zinkbindungsstelle innerhalb der Leucinschicht im Kern unseres 3SCC-Designs. So haben beispielsweise die Orientierung der koordinierenden Histidinreste und die resultierende Position des Zinkions das Potential, den Zugang für Lösungsmittel- wie auch Substratmoleküle sowie die Bildung von Wasserstoffbrücken signifikant zu beeinflussen - Faktoren, die bekanntlich eine wichtige Rolle für die Aktivität nativer CAs spielen. ${ }^{[22]}$ Unsere Gerüststrukturen bieten signifikante Vorteile gegenüber dem

Tabelle 3: Kinetische Parameter der Hydrierung von $\mathrm{CO}_{2}$ durch Enzyme, niedermolekulare Verbindungen und unsere Modellgerüste.

\begin{tabular}{|c|c|c|c|c|c|c|c|}
\hline Enzym/Modell & $\mathrm{p} K_{\mathrm{a}}$ & $\mathrm{pH}$ & $\begin{array}{l}k_{\mathrm{cat}} \\
\left(\mathrm{s}^{-1}\right)\end{array}$ & $\begin{array}{l}K_{\mathrm{M}} \\
(\mathrm{mM})\end{array}$ & $\begin{array}{l}k_{\mathrm{cat}} / K_{\mathrm{M}} \\
\left(\mathrm{L} \mathrm{mol}^{-1} \mathrm{~s}^{-1}\right)\end{array}$ & $\begin{array}{l}k_{2} \\
\left(\mathrm{Lmol}^{-1} \mathrm{~s}^{-1}\right)\end{array}$ & Lit. \\
\hline CAII & $6.8^{[a]}$ & 8.8 & $8.2 \times 10^{5}$ & 8.9 & $9.2 \times 10^{7}$ & & {$[25]$} \\
\hline CAIII & 8.5 & 9.0 & $8 \times 10^{3}$ & 20 & $4 \times 10^{5}$ & & [26] \\
\hline TRIL9CL23H & $8.82^{[b]}$ & 9.5 & $1.8 \times 10^{3}$ & 10.0 & $1.8 \times 10^{5}$ & & [12] \\
\hline$\alpha_{3} \mathrm{DH} 3$ & 9.4 & 9.5 & $1.3 \times 10^{2}$ & 3.5 & $3.8 \times 10^{4}$ & & [24] \\
\hline Zn"([14]aneN4) & 9.8 & & & & & $5040^{[c]}$ & [27] \\
\hline $\mathrm{Zn}^{\prime \prime}([12] \mathrm{aneN} 4)$ & 8.1 & & & & & 3012 & [18a] \\
\hline Zn"(Nitrilotris (2-benzimidazolylmethyl-6-sulfonat) & 8.3 & & & & & 2180 & [28] \\
\hline Zn"(Tris (4,5-di-n-propyl-2-imidazolyl)phosphan) & 8.0 & & & & & 2480 & [29] \\
\hline
\end{tabular}

[a] Aus Lit. [30]. [b] pK $K_{\mathrm{a}}$ der Hydrolyse von pNPA. [c] pH-unabhängige Geschwindigkeitskonstante zweiter Ordnung (maximale Geschwindigkeit), berechnet aus $\mathrm{p} K_{\mathrm{a}} 9.8$ und der gemessenen Geschwindigkeit von $690 \mathrm{M}^{-1} \mathrm{~s}^{-1}$ bei $\mathrm{pH} 9.0$. 
Einbringen von Metallionen in natürliche oder komplexere Strukturen, weil das Einführen der Metallbindungsstelle a) die Geometrie des Gerüsts nicht signifikant verändert, b) durch einfache Änderung der Position der Leucinsubstitution an unterschiedlichen Positionen des 3SCC erfolgen kann und c) infolge der Gegenwart mehrerer Leucinschichten an mehreren geometrisch etwa äquivalenten Position entlang des 3SCC stattfinden kann.

Wir entwickelten das invertierte Gegenstück $\mathrm{zu}\left[\mathrm{Hg}^{\mathrm{II}}\right]_{\mathrm{S}^{-}}$ $\left[\mathrm{Zn}^{\mathrm{II}}\right]_{\mathrm{N}}$ TRIL9CL23H $-\left[\mathrm{Hg}^{\mathrm{II}}\right]_{\mathrm{S}}\left[\mathrm{Zn}^{\mathrm{II}}\right]_{\mathrm{N}}$ TRIL9HL23C -, in dem sich das aktive Zinkzentrum auf der Seite des N-Terminus befindet. ${ }^{[21]}$ Dieses Modell zeigte bei $\mathrm{pH} 7.5$ und $\mathrm{pH} 9$ eine 10mal bzw. 4-mal geringere Zinkbindungsaffinität als TRIL9CL23H und TRIWL23H und unterstreicht so die Bedeutung der Position und Orientierung der Metallbindungsstelle in De-novo-Strukturen. Die kinetische Analyse der pNPA-Hydrolyse unter Michaelis-Menten-Bedingungen ergab, dass das invertierte Modell einen geringeren Wert für $k_{\text {cat }}$ von $0.020 \mathrm{~s}^{-1}$ bei $\mathrm{pH} 9.5$ aufweist (halb so hoch wie für TRIL9CL23H). Diese Abnahme wurde teilweise von einem kleineren $K_{\mathrm{M}}$-Wert kompensiert, sodass $k_{\text {cat }} / K_{\mathrm{M}}$ von 23.3 nur auf $15.8 \mathrm{M}^{-1} \mathrm{~s}^{-1}$ sank (Tabelle 2).

Bereits zuvor konnten wir zeigen, dass die Eigenschaften der Tris(thiolat)-Bindungsstelle für Schwermetalle abhängig von ihrer Positionierung an Position $a$ gegenüber Position $d$ der Heptade variieren. Dabei unterscheiden sich beispielsweise der $\mathrm{p} K_{\mathrm{a}}$-Wert, die Koordinationszahl und die Positionen der Liganden für Cadmium und Quecksilber. ${ }^{[23]}$ Ausgehend von der Annahme, dass ein ähnlicher Effekt auch für Zink in Tris(histidin)-Koordinationsmotiven vorliegen könnte, untersuchten wir TRIWL9CL19H. Dieses Konstrukt zeigte eine fünffach geringere Affinität für Zink und mit $\mathrm{p} K_{\mathrm{a}} 9.6$ einen erhöhten $\mathrm{p} K_{\mathrm{a}}$-Wert für die Hydrolyse von pNPA gegenüber TRIL9CL23H ( $K_{\mathrm{a}}$ 9.2; Abbildung 3$)$. Darüber hinaus zeigte dieses Konstrukt vergleichbare pNPAHydrolysegeschwindigkeiten mit Werten für $k_{\text {cat }} / K_{\mathrm{M}}$ im Bereich der für TRIL9CL23H und TRIL9HL23C ermittelten Werte, allerdings mit einem erhöhten $K_{\mathrm{M}}$-Wert von $2.8 \mathrm{~mm}$. Diese Befunde zeigen das Potential zur gezielten Variation von $K_{\mathrm{M}}$ und $\mathrm{p} K_{\mathrm{a}}$ durch Repositionierung der Metallbindungsstelle, wobei die katalytische Aktivität großteils unbeeinflusst bleibt. Die Position der Metallbindungsstelle in de novo entwickelten Gerüststrukturen sollte daher vor allem berücksichtigen, wie einfach sich sekundäre Wechselwirkungen einbauen lassen, die zu einer Erhöhung der Umsatzgeschwindigkeit führen.

\subsection{Entwicklung eines hydrolytischen Zink-3HB-Proteins}

Wie oben diskutiert, bietet die intrinsische Geometrie unser selbstorganisierten 3SCC-Gerüste eine Vielzahl an Vorteilen. Um jedoch ein funktionales Netzwerk von Wasserstoffbrücken aufzubauen und die Asymmetrie der sekundären Koordinationssphäre in CAII nachzubilden, entwickelten wir im nächsten Schritt ein CA-Modell, das stattdessen auf unserem $\alpha_{3}$ D-Gerüst beruht. ${ }^{[24]}$ Das Ersetzen von drei Leucinresten auf der C-terminalen Seite im Innenraum der ursprünglichen $\alpha_{3} \mathrm{D}$ - und H72V-Mutation zum Ausschluss einer möglichen unerwünschten Koordination von Zink lieferte $\alpha_{3} \mathrm{DH} 3$. In diesem Drei-Helix-Bündel ist Zink mit $K_{\mathrm{d}}=$ $0.15 \mu \mathrm{m}$ bei $\mathrm{pH} 7.5$ und $0.06 \mu \mathrm{m}$ bei $\mathrm{pH} 9$ fester gebunden als in allen 3SCC-Modellen (TRIL9CL23H: $K_{\mathrm{d}}=0.8 \mu \mathrm{M}$ bei $\mathrm{pH} 7$ und $0.22 \mu \mathrm{M}$ bei $\mathrm{pH} 9$ ).

Extended X-ray Absorption Fluorescence Spectroscopy (EXAFS) zufolge besteht die Zink-Koordinationssphäre aus drei Zink-Histidin-Streuern im Abstand von $1.99 \AA$ und einem Zink-Sauerstoff-Streuer im Abstand von $1.90 \AA$ A. Diese Parameter sind nahezu identisch zu denen der nativen CAII.

Wie bereits TRI 3SCC zeigte $\alpha_{3} \mathrm{DH} 3$ eine $\mathrm{pH}$-abhängige $\mathrm{CO}_{2}$-Hydrierungsaktivität. Die Hydrierung wurde bei $\mathrm{pH}$ Werten zwischen 8 und 9.5 analysiert und zeigte eine maximale Effizienz $k_{\mathrm{cat}} / K_{\mathrm{M}}=69000 \mathrm{M}^{-1} \mathrm{~s}^{-1}$ bei höheren $\mathrm{pH}$ Werten. Der katalytische $\mathrm{p} K_{\mathrm{a}}$-Wert betrug 9.4 und lag damit höher als der entsprechende Wert des 3SCC-Modellsystems von 8.8. Der maximale gemessene Wert für $k_{\text {cat }} / K_{\mathrm{M}}$ betrug $38000 \mathrm{M}^{-1} \mathrm{~s}^{-1}$; dies ist 14-mal schneller als das beste molekulare Modell, allerdings 2.5-mal langsamer als das beste TRI3SCC-Modell TRIL9CL23H. Auch dieses Modell zeigte keine Produktinhibierung und ist in dieser Hinsicht den bisher bekannten niedermolekularen Modellen überlegen. Beim Vergleich mit dem nativen Enzym erreicht $\alpha_{3} \mathrm{DH} 3$ die Größenordnung der 2400-fach geringeren Geschwindigkeit des schnellsten Isozyms CAII (Tabelle 3).

\subsection{Zinkkatalysierte Hydrolyse in anderen helikalen Gerüsten}

Wie bereits erwähnt haben andere Gruppen weitere helikale Gerüste entwickelt, die Zinkionen binden und zinkkatalysierte Hydrolyseaktivität aufweisen. Kuhlmann et al. entwickelten ein zinkvermitteltes Homodimer in einem Helix-Turn-Helix-Motiv. Dieses Homodimer enthält zwei vierfach koordinierte Zinkionen, die jeweils in einer $\mathrm{His}_{3} \mathrm{O}$ Umgebung gebunden sind. Ein vierter Histidinrest (der ursprünglich als vierter koordinierender Ligand für das Zinkzentrum vorgesehen war) erzeugt eine Bindungstasche für niedermolekulare Verbindungen. So wie auch in unseren zuletzt beschriebenen CA-Modellen umfasste das rationale Design dabei keine Wechselwirkungen in der sekundären Koordinationssphäre. MID1-Zn zeigte gegenüber unserem TRI-Gerüst eine verbesserte pNPA-Hydrolyseaktivität mit $k_{\text {cat }} / K_{\mathrm{M}}$ von $660 \mathrm{M}^{-1} \mathrm{~s}^{-1}$ bei $\mathrm{pH} 9$, was auf die einfachere $\mathrm{Zu}$ gänglichkeit des aktiven Zentrums im Homodimer zurückgeführt wurde. Vor kurzem beschrieb diese Gruppe die künstliche Evolution des MID1-Katalysators, wodurch dessen Aktivität in der Hydrolyse eines racemischen fluorogenen Esters um das 70000-Fache verbessert wurde. ${ }^{[31]}$ Die Gruppe um Tezcan berichtete vom Design einer Metallo- $\beta$-lactamase bestehend aus einem Tetramer von modifiziertem Cytochrom cb5662, $\mathrm{Zn}_{8}: \mathrm{AB}_{4}{ }^{\left[{ }^{[32]}\right.}$ Das Design dieser Struktur beruht auf einer durch zinkvermittelte Selbstorganisation generierten Grenzfläche, sodass vier der acht Zinkionen eine reine strukturgebende Funktion erfüllen, während die anderen vier katalytisch aktiv sind. Dieses Protein zeigte neben der erwarteten Metallo- $\beta$-lactamaseaktivität auch eine gute Aktivität gegen pNPA mit $k_{\text {cat }} / K_{\mathrm{M}}$ von $32 \mathrm{M}^{-1} \mathrm{~s}^{-1}$ bei pH 9 . In einem ähnlichen Ansatz zeigte die Gruppe um Korendovych, 
dass durch Selbstorganisation kurzer Peptide, ermöglicht über die Bindung von Zinkionen an Histidinreste, zinkverbrückte Amyloidfibrillen mit Esteraseaktivität gebildet werden können. ${ }^{[33]}$ Diese zinkbindenden Amyloidfibrillen, die aus einer beta-Faltblattstruktur anstelle von alpha-Helices bestehen, katalysieren die Hydrolyse von Estern mit $k_{\text {cat }} / K_{\mathrm{M}} \approx 150 \mathrm{M}^{-1} \mathrm{~s}^{-1}$ bei $\mathrm{pH} 9$ und einem maximalen $k_{\text {cat }} / K_{\mathrm{M}}=360 \mathrm{M}^{-1} \mathrm{~s}^{-1}$ bei $\mathrm{pH} 10.3$.

\section{Entwicklung von Kupferzentren als Modelle für die Nitritreduktaseaktivität}

Das De-novo-Design von redoxaktiven Metalloenzymen ist komplizierter als das Design von Modellen mit redoxinaktiven Metallzentren, beispielsweise das der zinkhaltigen CA-Modelle. Eine Änderung des Oxidationszustands des Metallions ändert dabei nicht nur die elektrostatische Ladung der Bindungsstelle; im Allgemeinen werden für unterschiedliche Oxidationszustände des Metallzentrums auch eine unterschiedliche Koordinationsgeometrie und unterschiedliche Liganden bevorzugt. So zeigt beispielsweise $\mathrm{Cu}^{\mathrm{I}}$ eine höhere Präferenz für weichere Liganden und niedrigere Koordinationszahlen als $\mathrm{Cu}^{\mathrm{II}}$. Daher muss beim De-novoDesign von Metalloenzymen zusätzlich zu den oben beschriebenen, bei nicht redoxaktiven Metallen geltenden Kriterien auch die Koordinationsumgebung sowohl der reduzierten als auch der oxidierten Spezies berücksichtigt werden. Unsere De-novo-Gerüststrukturen bieten gegenüber niedermolekularen Modellen einige signifikante Vorteile, da die Geometrie der Metallbindungsstelle durch die stabile Faltung des Gerüsts in Abwesenheit eines Metallions festgelegt ist. Darüber hinaus beobachteten wir in unseren Strukturen bei der Bindung von Metallionen nur geringe Reorganisationsenergien, je nach der Position der Bindungsstelle im Gerüst und der Art des jeweils bindenden Metalls. ${ }^{[34]}$ Wie bereits erwähnt sind die meisten molekularen Modellsysteme nur in organischen Lösungsmitteln löslich und für die Bindung eines einzigen Oxidationszustandes von Kupfer optimiert. Unsere Gerüste sind dementsprechend gut als Modelle für Metalloenzyme mit Redoxaktivität geeignet.

In letzter Zeit berichteten wir von verschiedenen Fortschritten bei der Entwicklung von Modellen mit Kupfernitritreduktase(CuNiR)-Aktivität. CuNiRs katalysieren die Reduktion von Nitrit zu Stickstoffmonoxid über Reaktion 2, den zweiten Schritt der Denitrifikation, d.h. des Abbaus von Nitrat zu molekularem Stickstoff. CuNiR ist ein homotrimeres Kupferenzym mit zwei Kupferzentren, einem $\mathrm{Cu}\left(\mathrm{His}_{2}\right)$ (Cys)(Met)-Typ-1-Kupferzentrum als Elektronentransferzentrum und einem katalytischen $\mathrm{Cu}\left(\mathrm{His}_{3}\right)\left(\mathrm{OH}_{2}\right)$-Typ-2Kupferzentrum. Das katalytische Typ-2-Kupferzentrum liegt dabei in einer verzerrt-tetraedrischen Koordinationsgeometrie vor, die zwischen den von den $\mathrm{Cu}^{\mathrm{I}}$ - und $\mathrm{Cu}^{\mathrm{II}}$-Spezies bevorzugten Koordinationsgeometrien liegt und so die mit dem Oxidationsstufenwechsel verbundene Reorganisationsenergie des Proteins minimiert. ${ }^{[35]}$ Der Mechanismus der Nitritreduktion ist gut untersucht. Das Nitrit bindet im ersten Schritt an das Typ-2-Kupferzentrum, woraufhin im zweiten Schritt ein gerichteter Elektronentransfer vom Typ-1- zum
Typ-2-Kupferzentrum stattfindet. Die Katalyse wird durch einen protonengekoppelten Elektronentransfer unterstützt, der durch Wasserstoffbrücken zwischen einem Histidin (H225) und einem Aspartat (E98) mit Wasser und dem gebundenen Substrat vermittelt wird. ${ }^{[36]}$ Es konnte gezeigt werden, dass diese Aminosäurereste eine entscheidende Rolle für die Aktivität natürlicher CuNiRs spielen und dass die Aktivität des Enzyms in ihrer Abwesenheit um mindestens das 100-Fache abnimmt [Reaktion (2)].

$\mathrm{NO}_{2}^{-}+\mathrm{e}^{-}+2 \mathrm{H}^{+} \rightleftharpoons \mathrm{NO}+\mathrm{H}_{2} \mathrm{O}$

\subsection{CuNiR-Modelle der ersten Generation}

Da die Geometrie der Zinkbindungsstelle unseres CAModells $\mathrm{Hg}_{\mathrm{S}}^{\mathrm{II}} \mathrm{Zn}_{\mathrm{N}}^{\mathrm{II}}$ (TRIL9CL23H) ${ }_{3}$ der Koordinationsumgebung des Typ-2-Kupferzentrums in CuNiR stark ähnelt, untersuchten wir zunächst die Bindung von Kupfer in der Tris(histidin)-Bindungstasche von TRI 3SCC und nutzten dazu das vereinfachte Modell TRIL23H, in dem die schwermetallbindende Tris(cystein)-Umgebung fehlt. ${ }^{[37]}$ Übereinanderlegen des Zinkzentrums in $\mathrm{Hg}^{\mathrm{II}}{ }_{\mathrm{S}} \mathrm{Zn}^{\mathrm{II}}{ }_{\mathrm{N}}$ (TRIL9CL23H) $)_{3}$ und des Kupferzentrums von CuNiRs zeigte ähnliche Koordinationsgeometrien für beide Strukturen, wobei das jeweilige Metallion in beiden Fällen an das $\varepsilon$-Stickstoffatom des Histidins und ein koordiniertes Wassermolekül bindet (Abbildung 4). Die Ladung und der Lewis-saure Charakter von $\mathrm{Zn}^{\mathrm{II}}$ ähneln denen von $\mathrm{Cu}^{\mathrm{II}}$, und die $\mathrm{d}^{10}$-Konfiguration spiegelt die Elektronenkonfiguration des $\mathrm{Cu}^{\mathrm{I}}$-Ions wider. Wir waren daher zuversichtlich, dass dieses Peptid ein geeignetes Modell für das Typ-2-Kupferzentrum in CuNiR darstellen kann und dass es - im Unterschied zu molekularen Modellen - die Möglichkeit bietet, die Reaktion in wässrigem Medium mit den natürlichen Liganden zu untersuchen, und dabei gleichzeitig das komplexe Zusammenspiel der beiden Kupferzentren der natürlichen $\mathrm{CuNiR}$ ausblendet.

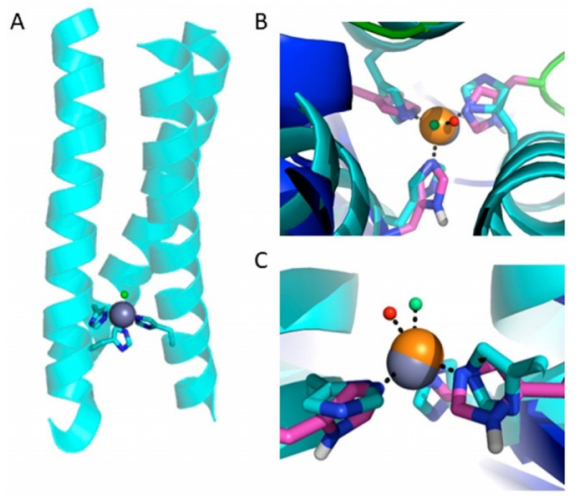

Abbildung 4. A) Modell von Cu-TRIL23H auf Basis der Struktur von $\mathrm{Hg}^{\prime \prime}{ }_{s} \mathrm{Zn}^{\prime \prime}{ }_{N} \mathrm{CSL9CL23H}$. B) Ansicht des $\mathrm{Zn}^{\prime \prime}\left(\mathrm{H}_{2} \mathrm{O}\right)(\mathrm{His})_{3}$-Zentrums entlang der dreifachen Pseudorotationsachse (hellgrau), überlagert mit dem Typ-2-Cu" $\left(\mathrm{H}_{2} \mathrm{O}\right)(\mathrm{His})_{3}$-Zentrum in NiR aus R. sphaeroides (PDB: 2DY2; dunkelgrau). Koordinierte Wassermoleküle sind als Kugeln dargestellt. C) Seitenansicht beider Metallzentren wie in (B). Adaptiert mit Genehmigung aus Lit. [37]. Copyright 2012 Proceedings of the National Academy of Sciences of the United States of America. 
Die Bindung von $\mathrm{Cu}^{1}$ an die Histidinbindungsstellen wurde durch ${ }^{1} \mathrm{H}$-NMR-Spektroskopie bestätigt. ${ }^{[37]}$ Das Spektrum der metallfreien Spezies apo-TRIL23H zeigte zwei Singuletts in der aromatischen Region des ${ }^{1} \mathrm{H}-\mathrm{NMR}$-Spektrums bei $\delta \approx 7.7$ und $7.0 \mathrm{ppm}$, die den Protonen der $\varepsilon$ - und $\delta$ Stickstoffatome zugeordnet werden konnten. Nach Versetzen mit einem Äquivalent $\mathrm{Cu}^{\mathrm{I}}$ wurden diese Singuletts in mehrere Peaks aufgespalten, wodurch die spezifische Bindung des Kupferions an die Histidinreste belegt wurde. Darüber hinaus zeigte eine mittels ${ }^{1} \mathrm{H}-\mathrm{NMR}$-Spektroskopie verfolgte $\mathrm{pH}$-Titration von $\mathrm{Cu}$-TRIL23H, dass, wie für $\mathrm{Cu}^{\mathrm{I}}\left(\mathrm{His}_{3}\right)$ erwartet, nur bei $\mathrm{pH}<4.45$ freie Imidazolprotonen beobachtet werden. XAS-Daten zeigten, dass das $1 \mathrm{~s} \rightarrow 4 \mathrm{p}$-Vorkantensignal, dessen Intensität zur Bestimmung der Koordinationszahl von $\mathrm{Cu}^{\mathrm{I}}$ Spezies genutzt werden kann, ${ }^{[38]}$ ebenfalls mit einer dreifachkoordinierten $\mathrm{Cu}^{\mathrm{I}}$-Spezies in Einklang war. Die beste Angleichung an die EXAFS-Daten von $\mathrm{Cu}^{\mathrm{I}}$ TRIL23H wurde mit drei N/O-Streuern in einem Abstand von $1.93 \AA$ mit zusätzlicher Rückstreuung bei größeren Abständen erhalten, wie sie typischerweise für Histidinkoordination beobachtet wird. Die ungewöhnlich hohen Debye-Waller-Faktoren dieser HisStreuer lassen auf eine trigonal-planare Koordinationsgeometrie schließen. Die Dissoziationskonstante $K_{\mathrm{d}}$ für $\mathrm{Cu}^{\mathrm{I}}$ wurde durch Titration mit Bathocuproindisulfonat $\left(\mathrm{BCS}^{2-}\right)$ bestimmt und betrug $3.1 \mathrm{pm}$ bei $\mathrm{pH} 5.9$ und $0.2 \mathrm{pm}$ bei $\mathrm{pH} 7.5$.

Die Bindung von $\mathrm{Cu}^{\mathrm{II}}$ wurde mit UV/Vis-Spektroskopie untersucht, wobei eine breite Absorptionsbande bei $640 \mathrm{~nm}$ $\left(\varepsilon=135 \mathrm{M}^{-1} \mathrm{~cm}^{-1}\right)$ beobachtet wurde, die in Einklang mit der Bildung eines $\mathrm{Cu}^{\mathrm{II}}(\mathrm{His})_{3}$-Koordinationsmotivs mit entweder einem oder zwei exogenen Wasserliganden ist. ${ }^{[39]}$ Das EPRSpektrum von $\mathrm{Cu}^{\mathrm{II}}$ TRIL23H bestätigte das Vorliegen eines fünffach-koordinierten Typ-2-Kupferzentrums [ $\mathrm{Cu}^{\mathrm{II}}(\mathrm{His})_{3}$ -

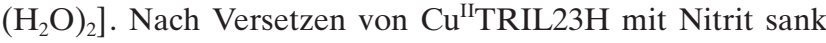
die $z$-Achsen-Hyperfeinkopplungskonstante $A_{\|}$um 9 Gauß und zeigte damit, dass Nitrit auch hier, wie bereits zuvor für die natürliche NiR gezeigt, direkt an das Kupferzentrum bindet. ${ }^{[40]}$ Die Dissoziationskonstante $K_{\mathrm{d}}$ für $\mathrm{Cu}^{\mathrm{II}}$ in diesem Modell wurde durch Trp-Fluoreszenzlöschung bestimmt und betrug $40 \mathrm{~nm}$ bei pH 5.9 und $8.7 \mathrm{~nm}$ bei $\mathrm{pH}$ 7.5.

Das Reduktionspotential des $\mathrm{Cu}^{\mathrm{I}} / \mathrm{Cu}^{\mathrm{II}}$-Paares kann mithilfe der Nernst-Gleichung aus den Affinitäten für $\mathrm{Cu}^{\mathrm{I}}$ und $\mathrm{Cu}^{\mathrm{II}}$ berechnet werden. Das Reduktionspotential dieses Modellsystems liegt mit $400 \mathrm{mV}$ bei pH 5.9 und $430 \mathrm{mV}$ bei pH 7.5 deutlich höher als für Typ-2-Kupferzentren üblich ${ }^{[41]}$ und befindet sich in der Tat näher an den typischerweise für Typ-1-Kupferzentren berichteten Werten. Ein Grund dafür könnte die Stabilisierung der trigonalen Geometrie des $\mathrm{Cu}^{\mathrm{I}}$ Zustandes in der hoch symmetrischen (His) ${ }_{3}$-Koordinationsumgebung sein, die zu einer Erhöhung des Reduktionspotentials führt. Trotz des erhöhten Reduktionspotentials untersuchten wir die NiR-Aktivität von CuTRIL23H. Wir konnten zeigen, dass dieses Modell in der Lage ist, NO aus Nitrit zu erzeugen, indem wir das entstehende NO über die Bildung der farbigen Verbindung $\operatorname{FeEDTA}(\mathrm{NO})$ nachwiesen. ${ }^{[42]}$ Eine FTIR-GC-Analyse aus der Gasphase über der Reaktion zeigte keine nachweisbaren Mengen an $\mathrm{N}_{2} \mathrm{O}$, das in anderen NiR-Modellen häufig als Nebenprodukt entsteht, und belegte so einen weiteren signifikanten Erfolg unserer De-novo-Strategie.
Wir verwendeten Ascorbat als Opfer-Elektronendonor, da dessen Absorption im UV-Bereich bei $265 \mathrm{~nm}$ genutzt werden kann, um den Verlauf der Reaktion zu verfolgen, und konnten unter katalytischen Bedingungen so eine maximale Geschwindigkeitskonstante erster Ordnung von $4.6 \times 10^{-4} \mathrm{~s}^{-1}$ bei pH 5.8 für die NiR-Aktivität bestimmen. Eine signifikante Abnahme der Reaktionsgeschwindigkeit mit steigendem $\mathrm{pH}$-Wert ist wahrscheinlich auf Veränderungen in der $\mathrm{Cu}^{\mathrm{I}} \mathrm{His}_{3}$-Koordinationsumgebung oder die Beteiligung von Protonen an der Nitritreduktion zurückzuführen. Auch wenn diese katalytische Umsatzgeschwindigkeit gegenüber den im natürlichen CuNiR-System erreichten Geschwindigkeiten gering ist, stellt unser Modell das einzige Beispiel eines stabilen, funktionalen $\mathrm{Cu}(\mathrm{His})_{3}$-Zentrums in wässrigem Medium dar, das in der Lage ist, mehrere Turnover dieser Umsetzung zu vermitteln, ohne dass dabei ein Rückgang der Reaktionsgeschwindigkeit beobachtet wurde.

\subsection{Untersuchung des Cu-Zentrums}

Es ist außergewöhnlich, dass unsere De-novo-Enzyme der ersten Generation bereits ohne Modellierung weiterer Koordinationssphären jenseits der ersten metallkoordinierenden Koordinationssphäre gute Aktivitäten zeigen. Daher war deutlich, dass zur weiteren Optimierung der CuNiR-Aktivität vor allem Modifikationen der zweiten Koordinationssphäre sowie der elektrostatischen Wechselwirkungen in der Umgebung des aktiven Kupferzentrums eine entscheidende Rolle spielen werden. ${ }^{[43]}$ Die freie Aktivierungsenthalpie $\left(\Delta G^{+}\right)$und damit die Geschwindigkeitskonstante der katalytischen Umsetzung des Enzyms können durch Veränderungen der elektrostatischen Umgebung des aktiven Zentrums beeinflusst werden, die zu einer Stabilisierung der Ladungsdichte des Übergangszustandes führen. Dynamische Aspekte des aktiven Zentrums, also die im Pico- bis Mikrosekundenbereich ablaufenden Schwingungs- oder Translationsbewegungen im und um das aktive Zentrum, spielen für die Gesamtgeschwindigkeitskonstanten ebenfalls eine Rolle. Die dynamischen und elektrostatischen Faktoren, die für die Katalyse ausschlaggebend sind, können mithilfe von Schwingungssonden in den aktiven Zentren der Enzyme untersucht werden. ${ }^{[4]}$ Diese Arbeiten liefern detaillierte Erkenntnisse zur Flexibilität des aktiven Zentrums, die entscheidend dafür ist, wie Substrate ins aktive Zentrum gelangen und wie der Transport der Produkte verläuft, sowie zu Änderungen der Reaktionsbarriere im Hinblick auf die Moleküldynamik in der Umgebung des aktiven Zentrums. ${ }^{[45]}$

In Zusammenarbeit mit der Gruppe um Kubarych nutzten wir die ultraschnelle Dynamik des an CuTRI-H gebundenen Kohlenmonoxids als Schwingungssonde für das $\mathrm{Cu}-$ (His) ${ }_{3}$-Zentrum zur Untersuchung der Kupferumgebung in unserem CuNiR-Modell. ${ }^{[46]}$ Dabei nutzten wir zweidimensionale IR-Spektroskopie zur In-situ-Untersuchung des aktiven Zentrums, um unser Verständnis der De-novo-Strukturen mit Erkenntnissen zur Chemie niedermolekularer Modelle zu verknüpfen. ${ }^{[4]}$ Das 2D-IR-Spektrum zeigte zwei Banden, die auf Übergängen aus der Anregung des Grundzustands $(v=$ $0 \rightarrow 1,2063 \mathrm{~cm}^{-1}$ ) und Anregung des ersten angeregten $\mathrm{Zu}$ - 
stands $\left(v=1 \rightarrow 2\right.$, rotverschoben nach $2039 \mathrm{~cm}^{-1}$ infolge von CO-Schwingungsanharmonizität) beruhen. Nach der Schwingungsanregung beobachteten wir eine zeitabhängige Anharmonizität der Schwingungsmoden des gebundenen CO-Moleküls mit einer Abklingkonstante von 2 ps. Die Frequenzverschiebung bringt die beiden Banden näher zusammen, da der $v_{01}$-Übergang rot- und der $v_{12}$-Übergang blauverschoben wird. Dabei ist der Betrag der Blauverschiebung des angeregten Zustands größer als die Rotverschiebung des Grundzustands. Wir untersuchten auch das modifizierte Peptid (TRI-HK22Q K24Q), in dem sechs der positiv geladenen Lysinreste in der Nähe des Kupferzentrums durch neutrale Glutaminreste ersetzt wurden. Die ähnliche beobachtete Anharmonizität des Schwingungsübergangs in diesem Protein deutete darauf hin, dass dieses Merkmal auch in anderen Sequenzen reproduzierbar ist und wahrscheinlich unseren anderen 3SCC-Gerüsten ebenfalls gemeinsam ist.

Theoretische Modellierungen des gesamten De-novoProteins wurden zum Verständnis der sterischen und elektrostatischen Wechselwirkungen, die zu diesem Verhalten führen, herangezogen. In einem QM/MMONIOM-Ansatz, mit dem Cu-Zentrum, den Imidazolliganden und dem CO-Addukt im QM-Teil (B3LYP/6$311 \mathrm{G}(\mathrm{d}, \mathrm{p})$ ) beobachteten wir für den schwingungsangeregten Zustand eine Abnahme des Cu-C-O-Bindungswinkels von $>6^{\circ}$. Diese Krümmung ist konsistent mit der im Picosekundenbereich ablaufenden Dynamik, die durch die Frequenzverschiebung in der Schwingungsspektroskopie beobachtet wurde, und stützt so die Annahme, dass das Peptid die Kopplung der CO-Streckschwingung verstärkt. Diese Ergebnisse unterstreichen die Rolle der Peptidumgebung und einen der signifikanten Vorteile unseres De-novo-Ansatzes in der Modellierung von CuNiRs. Weitere Rechnungen ergaben, dass das elektrische Feld des parallelen 3SCC-Peptidgerüsts keinen direkten Einfluss auf den Carbonylliganden ausübt, sondern stattdessen eine Verzerrung der Geometrie der kupferkoordinierenden Histidinliganden bewirkt und so für die $\mathrm{Cu}-\mathrm{C}-\mathrm{O}-\mathrm{Krümmung}$ verantwortlich ist, die an die $\mathrm{CO}$ Streckschwingung des angeregten Zustands gekoppelt ist. Diese Kopplung der Krümmung im angeregten Zustand war stark von der Orientierung der Histidinkoordination am Kupferzentrum abhängig, vermutlich wegen der Lage der Dipolmomente (ca. 3.6 D) jedes einzelnen Histidinliganden (Abbildung 5). Diese Rechnungen zeigen die Bedeutung elektrostatischer Wechselwirkungen für die Moleküldynamik und das Energieprofil der Ligandenkoordination in unserem $\mathrm{Cu}(\mathrm{His})_{3}$-Zentrum. Folglich können unsere CuNiRs durch Modifikation der Elektrostatik der Umgebung weiter verbessert werden, entweder durch Veränderung der Position innerhalb des 3SCC (Coiled-Coil-Dipol) oder durch Positionierung der geladenen Aminosäurereste in größerer Nähe zum aktiven Zentrum.

Um die relativ niedrige CuNiR-Aktivität zu erhöhen, betrachteten wir in der Folge die Rolle der elektrostatischen Umgebung des Kupferzentrums, zunächst durch Modifikation der Aminosäurereste in der äußeren Sphäre, die die Elektrostatik des Kupferzentrums verändern (Abbil-

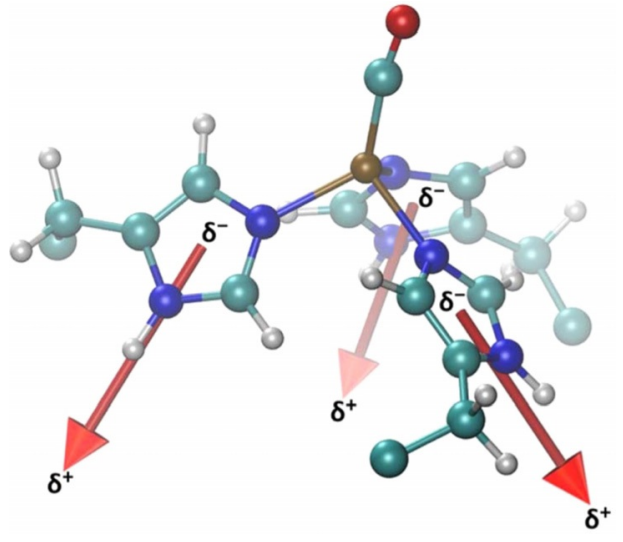

Abbildung 5. Dipolmoment der einzelnen Histidinringe in $\mathrm{Cu}^{\prime}$ $($ TRIL2WL23H)3(CO) + mit einem mittleren Wert von 3.6 D. Diese dipolaren Ketten sind in der Lage, an die durch das Proteingerüst erzeugte elektrostatische Umgebung zu koppeln. Wiedergabe mit Genehmigung aus Lit. [46]. Copyright 2013 American Chemical Society.

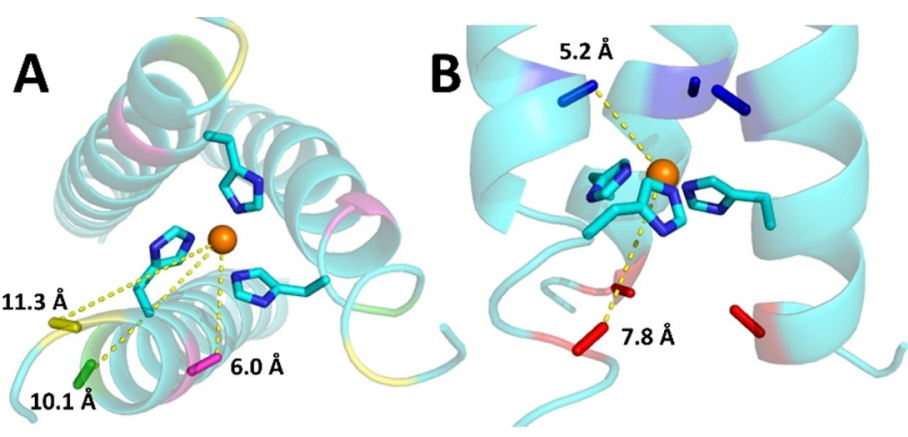

Abbildung 6. Modell für CuNiR mit Fokus auf die Position der substituierten Aminosäurereste der A) äußeren und B) inneren Sphäre in der Umgebung der $\mathrm{Cu}$-Bindungsstelle von TRI-H basierend auf der Kristallstruktur von $\mathrm{Zn}^{11}{ }_{\mathrm{N}} \mathrm{Hg}^{\prime \prime}{ }_{s}\left(\mathrm{CSL}\right.$ 9PenL23H) ${ }_{3}$ (PDB: 3PBJ). Das Kupferion ist als orangefarbene Kugel dargestellt, Abstände zum $\beta$-Kohlenstoffatom des jeweiligen substituierten Aminosäurerests sind für Substitutionen der äußeren Sphäre - K22 (magenta), E24 (grün) und K27 (gelb) - sowie der inneren Sphäre - L19 (blau) und L26 (rot) - angegeben.

dung 6A), und anschließend durch Veränderung von Aminosäureresten der inneren Koordinationssphäre (Abbildung 6B).

\subsection{Modifikation der Ladungsdichte um das Kupferzentrum}

Eine Modifikation der Ladungsdichte um ein redoxaktives Metallzentrum (durch Substitution von Aminosäureresten mit unterschiedlichen Ladungen) hat signifikante Auswirkungen auf die Stabilität und Struktur der verschiedenen Oxidationszustände und damit auch auf das Redoxpotential und schlussendlich auf die katalytische Effizienz oder den Mechanismus redoxaktiver Metalloenzyme. ${ }^{[48]}$ So besitzt die Peptidylglycin- $\alpha$-hydroxylierende Monooxygenase (PHM) ein ähnliches $\left(\mathrm{His}_{3}\right)$-Koordinationsmotiv wie $\mathrm{CuNiR}$, spielt aber eine Rolle im Elektronentransfer und ist im Unterschied zu CuNiR nicht direkt an einer katalytischen Umsetzung 
Tabelle 4: Peptidsequenzen bei der Substitution einzelner Aminosäurerreste in der äußeren (oben) und inneren Sphäre (Mitte) sowie primärer koordinierender Reste (unten) in Arbeiten zur CuNiR-Aktivität. Die Position dieser Modifikationen ist in Abbildung 6 zu sehen.

\begin{tabular}{|c|c|c|c|c|c|c|c|}
\hline Peptid $^{[\mathrm{a}]}$ & & abcdefg & abcdefg & abcdefg & $a b c d e f g$ & & $\Delta_{\text {Ladung }}$ \\
\hline TRI-H & $A C-G$ & WKALEEK & LKALEEK & LKALEEK & HKALEEK & $\mathrm{G}-\mathrm{NH}_{2}$ & \\
\hline TRI-HK22Q & $A_{C}-G$ & WKALEEK & LKALEEK & LKALEEQ & HKALEEK & $\mathrm{G}-\mathrm{NH}_{2}$ & -3 \\
\hline TRI-EH & $A C-G$ & WKALEEK & LKALEEK & LKALEEE & HKALEEK & $\mathrm{G}-\mathrm{NH}_{2}$ & -6 \\
\hline TRI-EHE27K & $A C-G$ & WKALEEK & LKALEEK & LKALEEE & HKAKEEK & $\mathrm{G}-\mathrm{NH}_{2}$ & 0 \\
\hline TRI-EHE27Q & $A C-G$ & WKALEEK & LKALEEK & LKALEEE & HKAQEEK & $\mathrm{G}-\mathrm{NH}_{2}$ & -3 \\
\hline TRI-EHK24Q & $A C-G$ & WKALEEK & LKALEEK & LKALEEE & HQALEEK & $\mathrm{G}-\mathrm{NH}_{2}$ & -9 \\
\hline TRI-EHK24E & $A c-G$ & WKALEEK & LKALEEK & LKALEEE & HEALEEK & $\mathrm{G}-\mathrm{NH}_{2}$ & -12 \\
\hline L19I & $A C-G$ & WKALEEK & LKALEEK & LKAIEEK & HKALEEK & $\mathrm{G}-\mathrm{NH}_{2}$ & 0 \\
\hline $\mathrm{L} 19_{\mathrm{D}} \mathrm{L}$ & $A C-G$ & WKALEEK & LKALEEK & LKA $A_{D}$ LEEK & HKALEEK & $\mathrm{G}-\mathrm{NH}_{2}$ & 0 \\
\hline L19A & $A C-G$ & WKALEEK & LKALEEK & LKAAEEK & HKALEEK & $\mathrm{G}-\mathrm{NH}_{2}$ & 0 \\
\hline L26A & $A C-G$ & WKALEEK & LKALEEK & LKALEEK & HKAAEEK & $\mathrm{G}-\mathrm{NH}_{2}$ & 0 \\
\hline L19D & $A C-G$ & WKALEEK & LKALEEK & LKADEEK & HKALEEK & $\mathrm{G}-\mathrm{NH}_{2}$ & -3 \\
\hline L26D & $A c-G$ & WKALEEK & LKALEEK & LKALEEK & HKADEEK & $\mathrm{G}-\mathrm{NH}_{2}$ & -3 \\
\hline $\mathrm{TRI}_{-{ }_{\mathrm{m}}} \mathrm{H}$ & $A C-G$ & WKALEEK & LKALEEK & LKALEEK & ${ }_{\delta \mathrm{m}} \mathrm{HKALEEK}$ & $\mathrm{G}-\mathrm{NH}_{2}$ & 0 \\
\hline TRI- ${ }_{\varepsilon m} \mathrm{H}$ & $A C-G$ & WKALEEK & LKALEEK & LKALEEK & ${ }_{\mathrm{em}}$ HKALEEK & $\mathrm{G}-\mathrm{NH}_{2}$ & 0 \\
\hline TRI- ${ }_{\varepsilon m} \mathrm{H}$ L19A & $A c-G$ & WKALEEK & LKALEEK & LKAAEEK & ${ }_{\varepsilon m}$ HKALEEK & $\mathrm{G}-\mathrm{NH}_{2}$ & 0 \\
\hline
\end{tabular}

[a] N- und C-Terminus sind acyliert bzw. amidiert.

beteiligt. ${ }^{[49]}$ Historisch wurden diese Studien immer an den nativen Proteinen durchgeführt, die die Komplexität und erschwerenden Faktoren natürlicher Systeme mit sich bringen. Unser Ziel war daher, die Rolle der elektrostatischen Wechselwirkungen in der Umgebung des Kupferzentrums in unserem De-novo-CuNiR-3SCC-Modell TRI-H durch Modifikation der Ladungen der nahegelegenen Aminosäurereste zu untersuchen. Wir entwickelten und synthetisierten dazu mehrere modifizierte Peptide, in denen wie in Tablle 4 (oben) aufgeführt nur Aminosäurereste ersetzt wurden, die weder im hydrophoben Inneren der 3SCCs liegen (was zu einer signifikanten Destabilisierung führen könnte) noch direkt an der Koordination des Kupferzentrums beteiligt sind (Abbildung 6 A) $\cdot{ }^{[50]}$ Der Einfluss des pH-Wertes auf die Bindung des Kupferions in Peptiden mittels modifizierter äußerer Koordinationssphäre wurde mit UV/Vis-Spektroskopie verfolgt. Im nahezu neutralen $\mathrm{pH}$-Bereich zeigte $\mathrm{Cu}^{\mathrm{II}}$-TRI-H eine breite Bande bei 644 nm, die einem d-d-Übergang des Kupfers in der $\mathrm{His}_{3}$-Koordinationsumgebung zugeordnet wurde. Das pH-Profil der Bindung von Kupfer in TRI-H ist infolge mehrerer konkurrierender und einander überlagernder Prozesse, die in Abhängigkeit vom pH-Wert auftreten, kompliziert. Der wichtigste dieser Prozesse ist die Bildung von 3SCCs, die bekanntlich um den $\mathrm{p} K_{\mathrm{a}}$-Wert der Glutamatreste stattfindet, die an der Bildung von Salzbrücken in $e$-Zentren (der fünften Position in der Heptaden-Wiederholungseinheit) beteiligt sind, etwa bei $\mathrm{pH}$ 4.5. Weitere Prozesse sind abhängig von Protonierungsgrad, Ladung und Kupferaffinität des Imidazolliganden (bei $\mathrm{pH}$ 5.5-8) sowie vom Protonierungsgrad von koordinierenden Wassermolekülen $(\mathrm{pH}>8)$. Dementsprechend zeigt das UV/Vis-Spektrum zwei wesentliche Änderungen: einen Übergang bei niedrigen $\mathrm{pH}-$ Werten, der auf der Bildung der 3SCC-Struktur und der Bindung von Kupfer im (His) $)_{3}$-Koordinationsmotiv beruht und bei etwa pH 5 abgeschlossen ist; sowie die Deprotonierung des an das Kupferzentrum gebundenen Wassers unter Bildung einer Hydroxidspezies mit $\mathrm{p} K_{\mathrm{a}}$ ca. 8.5 (Abbildung 7). Modifikatio- nen der äußeren Koordinationssphäre mit anderen Ladungen hatten ähnliche $\mathrm{pH}$-abhängige Profile für die Bindung von Kupfer bei niedrigen $\mathrm{pH}-$ Werten zur Folge, führten aber zu signifikant abweichenden Profilen im Bereich höherer $\mathrm{pH}$ Werte wegen des Zusammenspiels verschiedener $\mathrm{pH}$-abhängiger Effekte. So findet beispielsweise die Deprotonierung des gebundenen Wassers in TRI-EH bei deutlich höheren $\mathrm{pH}$-Werten statt ( $\mathrm{p} K_{\mathrm{a}}$ 9.86). XAS-Messungen der $\mathrm{Cu}^{\mathrm{I}}$-Form und EPR-Messungen der $\mathrm{Cu}{ }^{\mathrm{II}}$-Form von TRI-H und TRI-EH zeigten bei pH 5.8 keine signifikanten Unterschiede in der Geometrie des Kupferzentrums in beiden Gerüsten. Geringfügige Abweichungen in der Intensität der Vorkantenstruktur und niedrigere Debye-Waller-Werte für die $\mathrm{Cu}-\mathrm{N}$-Streuer in der EXAFS-Region lassen auf eine etwas symmetrischere trigonal-planare Geometrie für TRI-EH gegenüber einer etwas stärker verzerrten T-förmigen Geometrie im ursprünglichen TRI-H schließen.

Für diese Serie von Modellen mit modifizierten äußeren Koordinationssphären wurden die Dissoziationskonstanten für die jeweiligen $\mathrm{Cu}^{\mathrm{I}}$ - und $\mathrm{Cu}^{\mathrm{II}}$-Spezies ermittelt. Die Dissoziationskonstante $K_{\mathrm{d}}$ für $\mathrm{Cu}^{\mathrm{I}}$ nahm infolge der Verringerung der Ladung von 0 auf -12 um zwei Größenordnungen $\mathrm{ab}$, wohingegen dieselben Modifikationen für die $\mathrm{Cu}^{\mathrm{II}}$-Spezies nur eine geringe Abnahme der Affinität und eine nur leicht niedrigere Dissoziationskonstante $K_{\mathrm{d}}$ zur Folge hatten. Diese Werte wurden anschließend zur Berechnung der Reduktionspotentiale über die Nernst-Gleichung genutzt und als Funktion der Ladungsdifferenz zum ursprünglichen TRI-HSystem bei zwei spezifischen $\mathrm{pH}$-Werten aufgetragen (Abbildung $8 \mathrm{~A}$ ). Die Werte zeigen darüber hinaus eine lineare Abnahme als Funktion einer steigenden negativen Ladung sowohl bei $\mathrm{pH} 5.8$ als auch bei $\mathrm{pH} 7.5$ mit einer Steigung von $100 \mathrm{mV}$ je $1.6 \mathrm{pH}$-Einheiten, was einem Proton je Elektron entspricht. Diese Abnahme des berechneten Reduktionspotentials spiegelt vor allem die Destabilisierung der $\mathrm{Cu}^{\mathrm{I}}$-Spezies in einer stärker negativ geladenen Umgebung und weniger die Stabilisierung der $\mathrm{Cu}^{\mathrm{II}}$-Spezies wider, die $\mathrm{zu}$ einem 

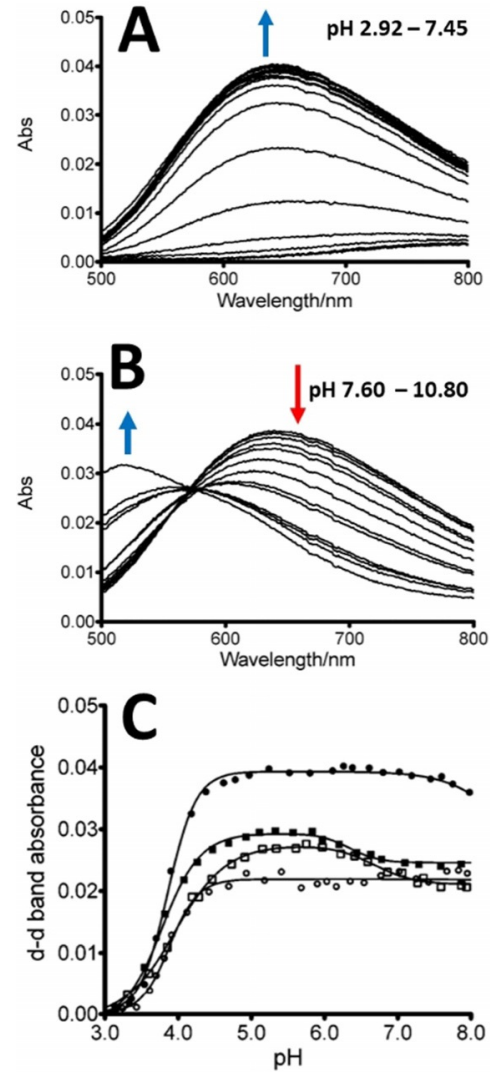

Abbildung 7. pH-Titration von $\left.\mathrm{Cu}^{\prime \prime}(\mathrm{TRI}-\mathrm{H})_{3} \mathrm{~A}\right)$ unterhalb und $\mathrm{B}$ ) ober-

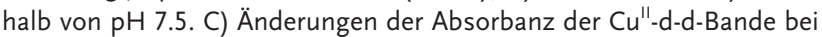
Bindung von $\mathrm{Cu}^{\prime \prime}$ an TRI-H $\left(\bullet ; \Delta_{\text {Ladung }}=0\right)$, TRI-EHE27K ( $\circ ; \Delta_{\text {La. }}$ dung $=0)$, TRIE-H ( $\left.\square ; \Delta_{\text {Ladung }}=-6\right)$ und TRI-EHK24E ( $\left.\square ; \Delta_{\text {Ladung }}=-12\right)$. Adaptiert mit Genehmigung aus Lit. [50]. Copyright 2013 American Chemical Society.

weniger positiven Reduktionspotential führt. Die unterschiedlichen Bindungsaffinitäten der $\mathrm{Cu}^{\mathrm{I}}$ - und $\mathrm{Cu}^{\mathrm{II}}$-Spezies in jedem unserer Modelle liegen etwa $100 \mathrm{mV}$ auseinander, wobei bei niedrigen $\mathrm{pH}$-Werten jeweils das positivere $\mathrm{Re}$ duktionspotential gefunden wird.

Das ursprüngliche Ziel unseres Designs von CuNiR-Modellen mit zunehmend negativer Ladung bestand in der Stabilisierung der positiv geladenen $\mathrm{Cu}^{\mathrm{II}}$-Spezies als Strategie, um das Reduktionspotential zu senken. Obwohl wir innerhalb dieser Serie in der Tat die erwartete Abnahme des Reduktionspotentials beobachten konnten, war dies eine Folge der Destabilisierung der $\mathrm{Cu}^{\mathrm{I}}$-Spezies und nicht der erwünschten Stabilisierung der $\mathrm{Cu}^{\mathrm{II}}$-Spezies. Die erhöhte Affinität für $\mathrm{Cu}^{\mathrm{I}}$ beim Übergang von einer negativ geladenen Umgebung des Metallzentrums zu stärker positiv geladenen Umgebungen legt nahe, dass hierbei Effekte infolge der Bildung von Wasserstoff- und Salzbrücken zum Tragen kommen. Wir schlugen daher vor, dass das Kupferion in unseren Modellen in einer starren Ligandenmatrix („rack-induced“) koordiniert ist, ähnlich der in blauen Kupferproteinen, die als Elektronentransferproteine fungieren. ${ }^{[51]}$ In diesem Modell schränkt die Proteinmatrix die Geometrie der Koordinationsumgebung des Metallzentrum derart ein, dass sich für die verschiedenen Oxidationszustände eine veränderte Stabilität ergibt, die
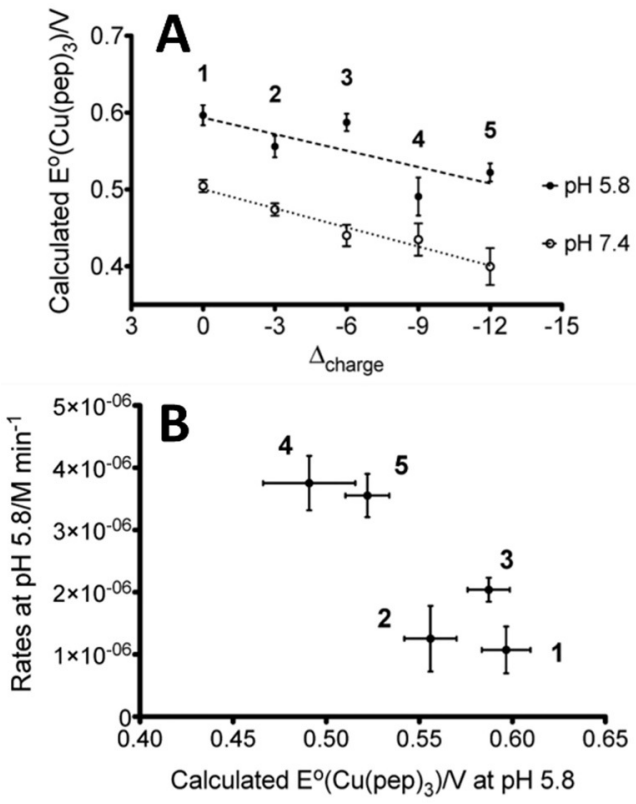

Abbildung 8. A) Berechnete Reduktionspotentiale bei Änderung der lokalen Ladung bei pH 5.8 und 7.4. B) Geschwindigkeit der NiR-Reaktion gegen berechnetes Reduktionspotential bei $\mathrm{pH}$ 5.8. Peptide: 1) TRIEHE27K, 2) TRI-EHE27Q, 3) TRI-EH, 4) TRI-EHK24Q, 5) TRIE-HK24E. Adaptiert mit Genehmigung aus Lit. [50]. Copyright 2013 American Chemical Society.

wiederum zur Einstellung des Redoxpotentials des Kupferzentrums genutzt wird. Unsere Ergebnisse lassen darauf schließen, dass dieser Effekt der starren Proteinmatrix in unseren $\mathrm{CuNiR}-M o d e l l e n$ für die $\mathrm{Cu}^{\mathrm{I}}$-Form stärker ausgeprägt ist. Wir nahmen an, dass eine Wasserstoffbrücke zwischen Glu22 und His23 für die Orientierung des Imidazolliganden verantwortlich ist.

Schließlich ermittelten wir über den oben beschriebenen Ascorbat-Assay auch die Geschwindigkeitskonstanten der CuNiR-Aktivität unserer Modelle mit modifizierter äußerer Sphäre. Bei einer von 0 auf -12 verringerten Ladung beobachteten wir für die gesamte Serie eine vierfache Erhöhung der NiR-Aktivität und eine Korrelation mit dem jeweiligen Reduktionspotential (Abbildung 8B). Bei pH 5.8 gilt für diese Modelle, dass bei höherem Reduktionspotenial eine niedrigere Geschwindigkeitskonstante erhalten wird. Obwohl diese Befunde dafür zu sprechen scheinen, dass die Reaktionsgeschwindigkeit linear vom Reduktionspotential abhängt, widerlegen die Bedingungen des verwendeten Assays (in dem Ascorbat in signifikantem Überschuss zugesetzt wird) die Schlussfolgerung, dass dieses Verhalten in der Geschwindigkeit des Elektronentransfers begründet ist, denn wir konnten zeigen, dass die Reduktion von $\mathrm{Cu}^{\mathrm{II}} \mathrm{zu} \mathrm{Cu}^{\mathrm{I}}$ durch Ascorbat nicht der geschwindigkeitsbestimmende Schritt der Umsetzung ist. Wir nehmen stattdessen an, dass die Reorganisationsenergie bei der Oxidation (von trigonalem $\mathrm{Cu}^{\mathrm{I}} \mathrm{zu}$ pseudo-tetraedrischem $\mathrm{Cu}^{\mathrm{II}}$ ) die beobachteten Geschwindigkeiten begrenzt. Diese Arbeit zeigte, dass Veränderungen der Ladung in der Umgebung des aktiven Zentrums durch Substitution nahegelegener Aminosäurereste zur Modifikation von Eigenschaften genutzt werden können, die das Redukti- 
onspotential und die NiR-Aktivität auf systematische Weise beeinflussen.

\subsection{Modifikation des sterischen Anspruchs und Einführung potentieller Wasserstoffbrücken in der inneren Sphäre}

Nachdem wir den Einfluss von Modifikationen in der äußeren Sphäre auf die CuNiR-Aktivität untersucht hatten, richteten wir unser Augenmerk auf die Auswirkungen von Modifikationen der inneren Sphäre. Es ist bekannt, dass die Aminosäurereste der inneren Sphäre eine signifikante Rolle in der Katalyse spielen, und es wurde bereits gezeigt, dass Mutationen in der inneren Sphäre die katalytische Effizienz und Umsatzgeschwindigkeiten signifikant verändern. Daher nutzten wir unsere rationale Designstrategie und identifizierten zwei Positionen innerhalb des 3SCC, in denen eine Substitution der Leucinschicht durch andere Aminosäurereste zu Modifikationen der Koordinationsumgebung des Kupferzentrums oder der kupfergebundenen Wassermoleküle führen könnte (Abbildung 6B). Wir hatten in vorangegangen Arbeiten bereits zeigen können, dass die Koordinationszahl von $\mathrm{Cd}$ in Tris(cystein)-Koordinationsmotiven durch Modifikation des sterischen Anspruchs der hydrophoben Schicht im Innenraum der Struktur oberhalb oder unterhalb des $\mathrm{Cd}\left(\mathrm{S}_{3}\right)$-Zentrums gesteuert werden kann. ${ }^{[16,52]}$ Dementsprechend sollte sich durch Modifikation des sterischen Anspruchs der Aminosäurereste in der Umgebung der Bindungsstelle des katalytisch aktiven Metallions der Substrat- und Lösungsmittelzugang zum aktiven Zentrum einstellen lassen. Wir nutzten diesen Ansatz für unsere $\mathrm{Cu}\left(\mathrm{His}_{3}\right)$ NiR-Systeme und substituierten die Leucinreste in den Positionen 19 und 26, also in den Leucinschichten direkt ober- und unterhalb des aktiven $\mathrm{Cu}(\mathrm{NiR})$-Zentrums (Tabelle 4 und Abbildung 6B). ${ }^{[53]}$ Wir erhöhten den sterischen Anspruch oberhalb des Kupferzentrums durch Substitution mit Isoleucin oder D-Leucin, da wir annahmen, dass in unserem CuNiRModell der ersten Generation eine Fünffach-Koordination des $\mathrm{Cu}^{\mathrm{II}}$-Zustands erfolgt, während in nativem $\mathrm{CuNiR}$ eine Vierfach-Koordination vorliegt. Wir nahmen an, dass eine Erhöhung des sterischen Anspruchs oberhalb des Metallzentrums den Zugang für Lösungsmittelmoleküle erschweren und so zu einer niedrigeren Koordinationszahl des Kupfers führen würde. Wir untersuchten anschließend auch den Effekt eines verringerten sterischen Anspruchs ober- oder unterhalb des Metallzentrums durch Substitution mit Alanin, da Kristallstrukturen unserer schwermetallbindenden Strukturen gezeigt hatten, dass ein verringerter sterischer Anspruch die Bindung von bis zu vier weiteren Wassermolekülen ermöglicht. ${ }^{[34]}$ Um den Einfluss von Wasserstoffbrücken zum kupfergebundenen Wasser oder den Histidin-Imidazolliganden und/oder des Hinzufügens weiterer $\mathrm{Cu}$-koordinierender Aminosäurereste zu untersuchen, entwickelten wir Gerüste, in denen sich Aspartatreste direkt unter- oder oberhalb des Kupferzentrums befinden.

Wir studierten die CuNiR-Aktivität in dieser Serie von CuNiR-Modellen und beobachteten Geschwindigkeitskonstanten, die die Serie in zwei identifizierbare Gruppen aufteilten (Abbildung 9, grün): eine Gruppe, in der die An-

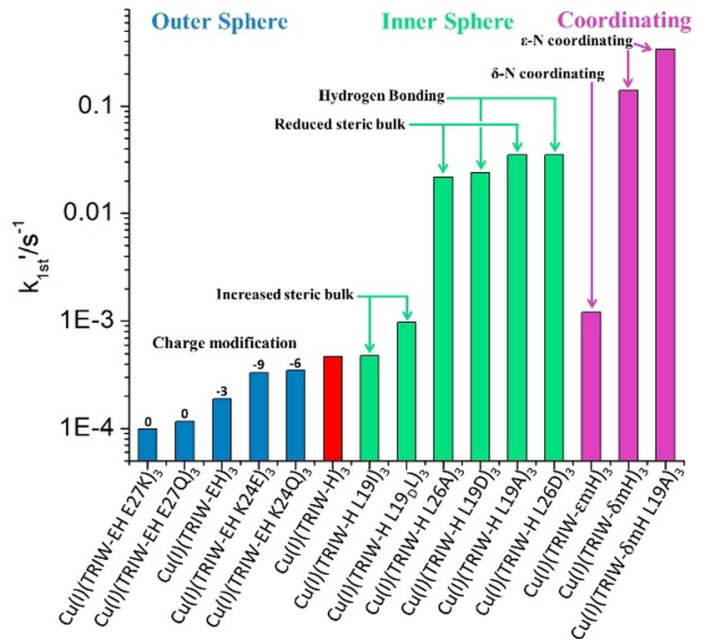

Abbildung 9. Geschwindigkeitskonstanten pseudo-erster Ordnung des ursprünglichen TRIW-H-Konstrukts (rot) aus Lit. [37] im Vergleich zu denen der Aminosäurereste des helikalen Kontakts der äußeren Sphäre (blau) aus Lit. [50], der inneren Aminosäurreste (grün) aus Lit. [53], und der primären koordinierenden Aminosäurereste (magenta) aus Lit. [56]. Adaptiert mit Genehmigung aus Lit. [56]. Copyright 2019 American Chemical Society.

fangsgeschwindigkeitskonstanten denen des ursprünglichen TRI-H ähnelten (L19I und L19 $\mathrm{D}$ L), und eine Gruppe, in der die Geschwindigkeit der CuNiR-Reaktivität 60-75-mal höher lag (Ala- und Asp-substituierte Modelle). Wir nahmen an, dass dieser Trend der unterschiedlichen Reaktionsgeschwindigkeiten auf Strukturunterschiede in der Ruheform der $\mathrm{Cu}^{\mathrm{I}-}$ Spezies zurückzuführen war, da wir bereits gezeigt hatten, dass die Reduktion der $\mathrm{Cu}^{\mathrm{II}}$-Spezies unter den Bedingungen unserer Assays extrem schnell verläuft. Daher nahmen wir Röntgenabsorptionsdaten auf und verglichen die $1 \mathrm{~s} \rightarrow 4 \mathrm{p}$ Energien der XANES-Region (Abbildung 10) und die aus EXAFS-Daten ermittelten Bindungslängen.

Die höhere Intensität der $\mathrm{Cu}^{\mathrm{I}}$-Vorkantenstruktur und die Zunahme der Kupfer-Ligand-Bindungslängen gemäß den EXAFS-Daten, die für Modelle mit zunehmendem sterischem Anspruch erhalten wurden, lassen darauf schließen, dass ein verringerter sterischer Anspruch nicht die Bindung weiterer Liganden ermöglicht, sondern stattdessen eine Entspannung am $\mathrm{Cu}^{\mathrm{I}}$-Zentrum unter Verringerung der Koordinationszahl von 3 auf 2 erlaubt. Dieser Befund war gegensätzlich zu den Ergebnissen, die wir zuvor bei der Modifikation der Sterik in der Umgebung von Schwermetallzentren erhalten hatten, in denen ein verringerter sterischer Anspruch zu einer Erhöhung der Koordinationszahl führte. Die unterschiedlichen XANES-1s $\rightarrow 4 \mathrm{p}$-Energien konnten zur Abgrenzung der beiden Gruppen genutzt werden, wobei die aktiveren Modelle eine höhere Energie als das TRI-H-Vorbild aufweisen und diejenigen Modelle, die eine TRI-Hähnliche Aktivität zeigen, auch ähnliche $1 \mathrm{~s} \rightarrow 4 \mathrm{p}$-Energien haben. Diese Verschiebung, die Informationen über die Elektronendichte am Kupferzentrum und dementsprechend über seine Verfügbarkeit für redoxchemische Prozesse liefert, scheint mit einer erhöhten NiR-Aktivität zu korrelieren und würde auch einen Einfluss auf die Potentialfläche des Über- 


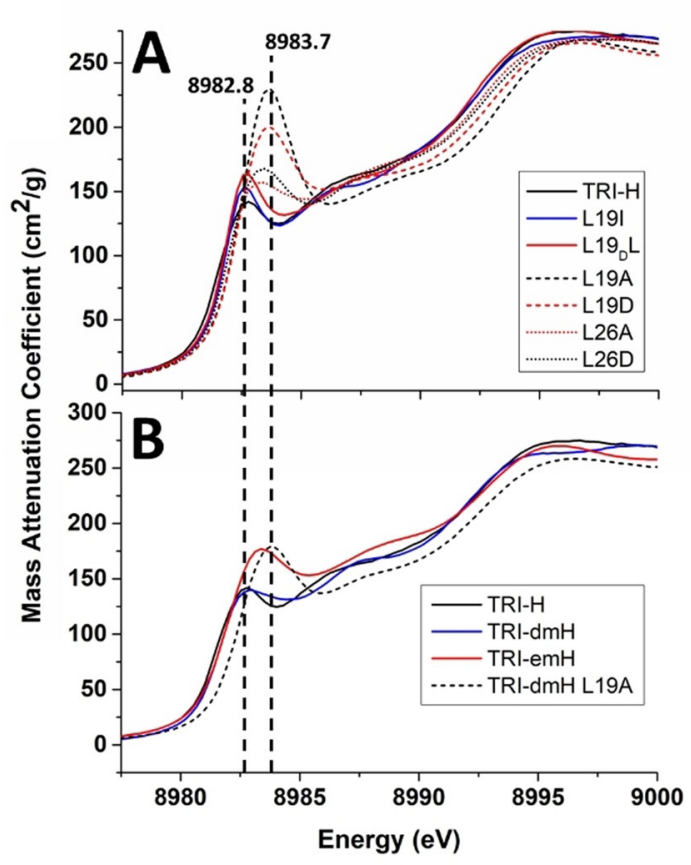

Abbildung 10. $\mathrm{Cu}^{\prime}$-XANES bei $\mathrm{pH} 5.8$ von Gerüsten mit Modifikation A) der inneren Sphäre und B) der primären koordinierenden Aminosäurereste im Vergleich zu den Daten für TRIW-H. Adaptiert mit Genehmigung aus Lit. [53] und [56]. Copyright 2018 Wiley-VCH und 2019 American Chemical Society.

gangszustands während der Katalyse haben (siehe Abschnitt 3.2). Native CuNiRs enthalten sowohl im oxidierten als auch im reduzierten Zustand vierfach-koordinierte $\mathrm{Cu}$ $(\mathrm{His})_{3}\left(\mathrm{H}_{2} \mathrm{O}\right)$-Zentren, was darauf hindeutet, dass die Reorganisation in unseren Modellsystemen einen limitierenden Faktor für die Verbesserung der Aktivität darstellt.

\subsection{Die Rolle von Histidin-Koordinationsisomeren für die CuNiR- Aktivität}

Eine weitere wichtige Eigenschaft von Imidazoleinheiten ist ihre Fähigkeit, über jedes der beiden Imidazol-Stickstoffatome als Ligand zu koordinieren. Wie bereits in unserer Diskussion von PHM und CuNiR erwähnt, zeigen diese beiden Enzyme eine deutlich unterschiedliche Kupferchemie, obwohl es sich in beiden Fällen um ein $\mathrm{Cu}(\mathrm{His})_{3}$-Zentrum handelt. Eine genaue Betrachtung der Strukturen von CuNiR (PDB: 4YSE ${ }^{[54]}$ ) und PHM (PDB: $1 \mathrm{PHM}^{[55]}$ ) ergibt, dass darin unterschiedliche tautomere Koordinationsisomere vorliegen, wobei die Koordination an das Kupferzentrum im ersten Fall über das $\mathrm{N}_{\varepsilon}$ - und im zweiten Fall über das $\mathrm{N}_{\delta}$-Atom des Imidazols erfolgt. Dieser Unterschied in der Koordination $\left(\mathrm{N}_{\varepsilon}\right.$ gegenüber $\left.\mathrm{N}_{\delta}\right)$ ist allen Typ-1-Kupferzentren, die dem Elektronentransfer dienen, gegenüber katalytischen Typ-2Kupferzentren gemeinsam. Um die Orientierung der Histidinkoordination in unserem CuNiR-Modell TRI-H zu bestimmen, entwickelten wir Gerüste, die N-methyliertes Histidin als primäre koordinierende Liganden enthielten (Sequenzen in Tabelle 4). ${ }^{[56]}$ So war es möglich, $N_{\varepsilon}$-Methyl- histidin (TRI- ${ }_{\varepsilon m} \mathrm{H}$, Koordination über $\mathrm{N}_{\delta}$ ) mit $N_{\delta}$-Methylhistidin $\left(\mathrm{TRI}_{-\mathrm{m}} \mathrm{H}\right.$, Koordination über $\mathrm{N}_{\varepsilon}$ ) mit unserem ursprünglichen Design zu vergleichen und so nicht nur den genauen Koordinationsmodus zu bestimmen, sondern auch die Auswirkungen des umgekehrten Koordinationsmodus zu betrachten und so direkt den Einfluss der verschiedenen Kupfer-Histidin-Koordinationsisomere auf die Eigenschaften unseres gut verstandenen Metalloenzyms zu untersuchen.

Dabei ist es wichtig zu erwähnen, dass die Methylierung des Imidazols die Eigenschaften dieses Liganden fundamental, und nicht nur beschränkt auf die N-Koordination, verändert. Das Ersetzen einer der N-H-Einheiten durch N-Me entfernt auch eine Möglichkeit der Wasserstoffbrückenbindung und verändert sowohl den $\mathrm{p} K_{\mathrm{a}}$-Wert als auch die zugängliche Ladung dieses Liganden. Zudem ist die Methylgruppe ein stärkerer Elektronendonor und verändert die elektronischen Eigenschaften des Imidazolliganden auf oft schwer vorhersagbare Weise. ${ }^{[57]}$ Nicht zuletzt sind $\mathrm{N}$-Methylimidazole sterisch anspruchsvoller als Histidine, was die Stabilität und Geometrie der Kupferzentren signifikant beeinflussen kann. Dementsprechend müssen bei Substitutionen mit $N$-Methylhistidin mehrere Faktoren berücksichtigt werden.

Wir untersuchten die Auswirkungen erzwungener $\varepsilon$ - oder $\delta$-Stickstoffbindung (durch Methylierung des jeweils anderen Imidazol-Stickstoffatoms) auf die Geometrie, das Redoxpotential und die katalytische Aktivität des Kupferzentrums. EPR-, XAS- und UV/Vis-Spektroskopie deuten darauf hin, dass TRI- ${ }_{\varepsilon m} \mathrm{H}$ sowohl in der $\mathrm{Cu}^{\mathrm{I}}$ - als auch in der $\mathrm{Cu}^{\mathrm{II}}$-Form eine kleinere Zahl koordinierender Imidazolliganden aufweist als TRI- ${ }_{\delta \mathrm{m}} \mathrm{H}$ (Abbildung 11). TRI- ${ }_{\delta \mathrm{m}} \mathrm{H}$ zeigte eine sehr ähnlich Geometrie wie das Original (TRI-H), während in TRI- ${ }_{\varepsilon m} \mathrm{H}$ eine eher tetraedrische $\mathrm{Cu}^{\mathrm{II}}$-Spezies vorlag $\left(\mathrm{N}_{3} \mathrm{O}\right.$ Koordination im Unterschied zur $\mathrm{N}_{2} \mathrm{O}_{2}$-Koordination in TRI$\mathrm{H}$ und $\mathrm{TRI}_{\left.-{ }_{\delta \mathrm{m}} \mathrm{H}\right)}$ und ein eher zweifach-koordinierter Charakter für die $\mathrm{Cu}^{\mathrm{I}}$-Spezies, im Unterschied zur Dreifach-Koordination in den beiden anderen Strukturen, gefunden wurde. Diese Befunde legen nahe, dass die Koordination in TRI-H über das $\varepsilon$-Stickstoffatom erfolgt. Wie auch bei unseren Modifikationen der inneren Koordinationssphäre be-

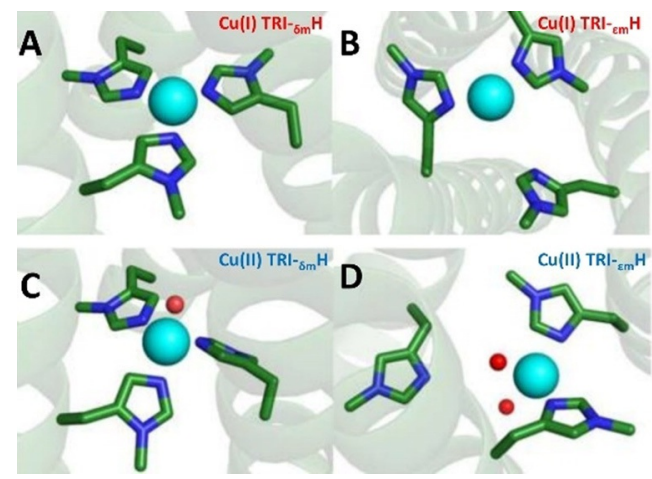

Abbildung 11. Modelle der Metallbindungsstelle in A) Cu'-TRIW- $\delta m H$ und B) Cu'-TRIW- $\varepsilon m H$, C) Cu"-TRIW- $\delta m H$ und D) Cu"-TRIW- $\varepsilon m H$. Modelle erstellt mit PyMol auf Basis des $\mathrm{Zn}^{\prime \prime}(\mathrm{His})_{3}$-Zentrums in $\mathrm{Hg}^{\prime \prime}{ }_{5} \mathrm{Zn}^{\prime \prime}{ }_{\mathrm{N}}$ $(\mathrm{CSL9CL23H})_{3}$ [PDB: 3PB $)^{[12]}$. Adaptiert mit Genehmigung aus Lit. [56] Copyright 2019 American Chemical Society. 
obachteten wir für diese Systeme eine Verschiebung der Energie des $1 \mathrm{~s} \rightarrow 4 \mathrm{p}$-Übergangs in der XANES-Region, wobei diese in TRI- ${ }_{\delta \mathrm{m}} \mathrm{H}$ der des Originals TRI-H entsprach, während sie in TRI- ${ }_{\varepsilon m} \mathrm{H}$ zu etwas höheren Werten verschoben war (Abbildung 10B).

Zum Schluss verglichen wir die NiR-Aktivität der $\mathrm{N}$ Methylhistidin-substituierten Modelle mit der unserer früheren Designs (Abbildung 9, magenta). Die größte Steigerung der NiR-Aktivität wurde durch Modifikation der primären Liganden erreicht. Interessanterweise wurde die gröBere Aktivitätssteigerung durch Methylierung des $\delta$-Stickstoffatoms erreicht, die eine $\varepsilon$-Koordination wie in TRI-H erzwingt. Wir schlossen daraus, dass ein induktiver Effekt bei der N-Alkylierung, der mit einer Erhöhung der HOMOEnergien durch elektronenreichere Liganden einhergeht, für die unterschiedliche Aktivität dieser Systeme verantwortlich ist. Wir versuchten nun, diejenigen Eigenschaften, die in den vorangegangenen Modifikationen der inneren Koordinationssphäre zu den höchsten NiR-Aktivitäten geführt hatten (Reduktion des sterischen Anspruchs durch L19A-Mutation, 75-fache Steigerung der Reaktionsgeschwindigkeit gegenüber der von TRI-H) mit der besten primären Koordinationsumgebung (TRI- ${ }_{\delta \mathrm{m}} \mathrm{H}, 260$-fache Aktivitätssteigerung) zu kombinieren und synthetisierten TRI- ${ }_{\delta \mathrm{m}} \mathrm{H}-\mathrm{L} 19 \mathrm{~A}$. Zwar führte diese Kombination nur zu einer 2.5-fachen Erhöhung der Reaktionsgeschwindigkeit gegenüber jener von TRI- ${ }_{\delta \mathrm{m}} \mathrm{H}$, jedoch ist dieses Gerüst bis heute das beste CuNiR-Modell in einem wässrigen System, mit einer 640-fach höheren Aktivität als unser CuNiR-Modell der ersten Generation (TIR-H). Auch wenn dieses System den bisher besten synthetischen homogenen Katalysator für die CuNiR-Aktivität darstellt, bleibt seine Aktivität um das 400000-Fache hinter der des natürlichen Systems zurück.

Die Michaelis-Menten-Kinetik der CuNiR-Aktivität unserer Modelle zeigte, dass die niedrigere Aktivität eine Folge verschiedener Faktoren ist, die sowohl die maximale katalytische Umsatzgeschwindigkeit als auch die Bindung und den Zugang der Substrate zum aktiven Zentrum beeinflussen (Tabelle 5). $V_{\max }$ erreicht ein Plateau, während die Katalyseleistung am stärksten durch $K_{\mathrm{M}}$-Effekte beeinflusst wird. Dabei haben wir in unseren CuNiR-Modellen bisher den entscheidenden Säure-Base-Katalysator außer Acht gelassen, einen Aspartatrest, der für die Aktivität des nativen Proteins wichtig ist. Wir haben bereits Versuche unternom- men, einen nahegelegenen Aspartatrest einzufügen. Die erzwungene dreifache Symmetrie bedeutete allerdings, dass dabei drei Aspartatreste in der Nähe des $\mathrm{CuHis}_{3}$-Zentrums positioniert waren, und wir nehmen an, dass diese Aspartatreste miteinander statt mit dem Kupferzentrum wechselwirkten. ${ }^{[53]}$ Zusätzlich beobachteten wir einen signifikant niedrigeren $K_{\mathrm{M}}$-Wert als bei niedermolekularen Modellen, was darauf schließen lässt, dass die Substraterkennung und der Substratzugang zum aktiven Zentrum durch unser Gerüstdesign eingeschränkt werden. Dieser Unterschied kann sich auch in der Bindung von $\mathrm{NO}_{2}{ }^{-}$an $\mathrm{Cu}^{\mathrm{I}}$ gegenüber $\mathrm{Cu}^{\mathrm{II}}$ widerspiegeln. Dies bedeutet, dass weitere Modifikationen an unseren Gerüststrukturen nötig sind, die die Substratbindung verbessern, beispielsweise neue Gerüste, die asymmetrische Modifikationen ermöglichen. Wir haben kürzlich ein solches Gerüst entwickelt, über das wir in Kürze berichten wollen. ${ }^{[63]}$

\section{Design von Elektronentransferzentren in De-novo-Gerüsten}

Wir wenden uns nun unseren aktuellen Arbeiten zum Denovo-Design von Elektronentransferzentren in unseren alpha-helikalen Gerüstsystemen zu. Metallzentren, die dem Transport von Elektronen über Membranen hinweg, zwischen Metallzentren oder gekoppelt an Protonentransfers dienen, müssen Bindungsmotive aufweisen, die die unterschiedlichen jeweils bevorzugten Geometrien und Liganden der verschiedenen Oxidationszustände unterstützen, wie es auch für Metallzentren wie in CuNiR der Fall ist, die an katalytischen Redoxprozessen beteiligt sind. Wie bereits oben im Detail beschrieben, erfordert dies eine sorgfältige Betrachtung der Koordinationszahl und -geometrie sowie eine dementsprechende Positionierung der Liganden in der Gerüststruktur. Wir betrachten in der Folge die Entwicklung unserer Modelle für eisenhaltige Rubredoxine und kupferhaltige Cupredoxine.

\subsection{Entwicklung von Nicht-Häm-Eisen-Rubredoxinmodellen}

FeS-Cluster-Proteine sind eine Klasse von Proteinen mit Kofaktoren unterschiedlicher Komplexität, die von einem einzelnen, an vier Cysteinreste gebundenen Eisenzentrum

Tabelle 5: Kinetische Parameter der CuNiR-Aktivität ausgewählter 3SCCs und niedermolekularer Modellkomplexe bei pH 5.8.

\begin{tabular}{|c|c|c|c|c|c|}
\hline Konstrukt & $\begin{array}{l}\text { Reaktionsgeschw. }{ }^{[\mathrm{a}]} \\
\qquad\left[\mathrm{s}^{-1}\right]\end{array}$ & $\begin{array}{c}V_{\max } \\
{\left[\mathrm{M} \mathrm{s}^{-1}\right]}\end{array}$ & $\begin{array}{l}K_{\mathrm{M}} \\
{[\mathrm{M}]}\end{array}$ & $\begin{array}{l}k_{\text {cat }} \\
{\left[\mathrm{s}^{-1}\right]}\end{array}$ & $\begin{array}{c}k_{\text {cat }} / K_{\mathrm{M}} \\
{\left[\mathrm{s}^{-1} \mathrm{M}^{-1}\right]}\end{array}$ \\
\hline TRIW-H $\mathrm{H}^{[58]}$ & $4.6 \times 10^{-4}$ & $\mathrm{~N} / \mathrm{A}$ & $\mathrm{N} / \mathrm{A}$ & $\mathrm{N} / \mathrm{A}$ & $\mathrm{N} / \mathrm{A}$ \\
\hline TRIW-H L19A ${ }^{[59]}$ & $3.5 \times 10^{-2}$ & $2.3 \pm 0.3 \times 10^{-6}$ & $0.24 \pm 0.05$ & $0.23 \pm 0.03$ & $1.0 \pm 0.3$ \\
\hline TRIW- ${ }_{-m} \mathrm{H}$ & 0.12 & $1.5 \pm 0.1 \times 10^{-5}$ & $0.18 \pm 0.02$ & $1.5 \pm 0.1$ & $8.2 \pm 0.1$ \\
\hline TRIW- ${ }_{-m} \mathrm{H}$ L19A & 0.30 & $1.5 \pm 0.1 \times 10^{-5}$ & $0.13 \pm 0.01$ & $1.5 \pm 0.1$ & $11.3 \pm 0.1$ \\
\hline TRIW- ${ }_{\varepsilon m} \mathrm{H}$ & $1.2 \times 10^{-3}$ & $\mathrm{~N} / \mathrm{A}$ & $\mathrm{N} / \mathrm{A}$ & $\mathrm{N} / \mathrm{A}$ & $\mathrm{N} / \mathrm{A}$ \\
\hline$\left[\mathrm{CuMe}_{2} \mathrm{bpa}\left(\mathrm{H}_{2} \mathrm{O}\right)\left(\mathrm{ClO}_{4}\right)\right]^{+}$auf der Elektrode bei pH 5.5 $5^{[60]}$ & $\mathrm{N} / \mathrm{A}$ & $\mathrm{N} / \mathrm{A}$ & $1.1 \times 10^{-3}$ & 0.063 & 57.3 \\
\hline$\left[\mathrm{CuMe}_{2} \mathrm{bpa}\left(\mathrm{H}_{2} \mathrm{O}\right)\left(\mathrm{ClO}_{4}\right)\right]^{+}$in Lösung bei $\mathrm{pH} 5.5^{[60]}$ & $\mathrm{N} / \mathrm{A}$ & $\mathrm{N} / \mathrm{A}$ & $2.5 \times 10^{-3}$ & $5.3 \times 10^{-5}$ & 0.02 \\
\hline AfCuNiR pH $6.5^{[61]}$ & $\mathrm{N} / \mathrm{A}$ & $\mathrm{N} / \mathrm{A}$ & $1.5 \times 10^{-4}$ & 620 & $4.1 \times 10^{6}$ \\
\hline AxCuNiR pH 7.0, $4{ }^{\circ} \mathrm{C}^{[62]}$ & $\mathrm{N} / \mathrm{A}$ & $\mathrm{N} / \mathrm{A}$ & $2.7 \times 10^{-3}$ & 89 & $3.3 \times 10^{5}$ \\
\hline
\end{tabular}

[a] Der Wert für die Reaktionsgeschwindigkeit bezieht sich auf die Geschwindigkeitskonstante pseudo-erster Ordnung der metallopeptidkatalysierten Reduktion von Nitrit durch Ascorbat in Lösungen mit $30 \mathrm{~mm}$ Nitrit und $1.2 \mathrm{~mm}$ Ascorbat. N/A= nicht verfügbar. ${ }^{[58]}$ 
(z.B. Rubredoxin) $)^{[64]}$ bis zu mehratomigen Kofaktoren reicht, die von einer separaten Proteinmaschinerie aufgebaut werden müssen, bevor sie in das jeweilige Zielprotein inseriert werden können (beispielsweise der P-Cluster der Nitrogenase) ${ }^{[65]}$ Die relativ einfache Struktur des aktiven Zentrums und die umfangreiche Literatur, die zu ihrer Geometrie und Spektroskopie verfügbar ist, machen Rubredoxine $\mathrm{zu}$ einem vielversprechenden Ziel im Design von Metalloproteinen. ${ }^{[3 b]}$

Frühere Arbeiten zum Design von Rubredoxinen konzentrierten sich auf die Nachbildung der Haarnadelstruktur der natürlichen Bindungsstelle und zeigten, dass mit einer De-novo-Proteinsequenz dieselbe Sekundärstruktur und Metallbindungsstelle reproduziert werden konnten. ${ }^{[66]]}$ Farinas und Regan nutzten das Programm Metal Search, um ein tetraedrisches $\mathrm{Cys}_{4}$-Motiv in die B1-Domäne des IgG-bindenden Proteins $\mathrm{G}$ einzubauen. Obwohl dieses System die spektroskopischen Eigenschaften der Fe ${ }^{\mathrm{III}}$-Form von Rubredoxin nachbildete, war es kein funktionales Redoxzentrum. ${ }^{[66 \mathrm{~d}]}$ DeGrado et al. entwickelten ein Rubredoxinmodell, indem sie die sekundäre lokale Geometrie des Eisenzentrums im natürlichen Protein nachbildeten und das umgebende Protein auf die zur Erhaltung dieser Geometrie notwendigen 40 Aminosäuren minimierten. ${ }^{[66]}$ Dieses System bildete nicht nur erfolgreich die spektroskopischen Eigenschaften des natürlichen Fe $\mathrm{F}^{\mathrm{III}}$-Rubredoxins nach, sondern war auch das erste de novo entworfene Rubredoxinmodell, das in der Lage war, zuverlässig bis zu 16 Redoxzyklen zu durchlaufen. Die wohl erfolgreichste Vereinfachung von Rubredoxin wurde von Sénèque et al. in einem Peptid aus 18 Aminosäuren entwickelt, das aus einem zyklischen und einem linearen Abschnitt bestand. ${ }^{[66]}$ Auch wenn dieses System weniger Redoxzyklen durchlief als das von DeGrado et al. beschriebene Modell (7 anstelle von 16), bildete es die spektroskopischen Eigenschaften des natürlichen Rubredoxins in der $\mathrm{Fe}^{\mathrm{II}}$ - und $\mathrm{Fe}^{\mathrm{III}}$ Form mit weniger als der halben Anzahl von Aminosäuren nach.

Wir konzentrierten unsere eigenen Arbeiten darauf $\mathrm{zu}$ evaluieren, ob die Haarnadelschleife der Sekundärstruktur zur Nachbildung der spektroskopischen Eigenschaften von Rubredoxin notwendig ist. Dazu brachten wir eine Rubredoxin-ähnliche $\mathrm{Cys}_{4}$-Bindungsstelle in ein alpha-Helix-Bündel ein (Abbildung 12). ${ }^{[67]}$ Basierend auf dem schwermetallbindenden $\mathrm{Cys}_{3}$-Peptid $\alpha_{3}$ DIV hatte unsere Gruppe in vorangegangenen Arbeiten bereits zwei Cys -Proteine $\left(\alpha_{3}\right.$ DIV H72C oder L21C) als Modelle für das Cd-Zentrum in CadC entwickelt. ${ }^{[68]}$ Mittels ${ }^{113} \mathrm{Cd}-\mathrm{NMR}-$ Spektroskopie hatten wir gezeigt, dass die $\mathrm{H} 72 \mathrm{C}$-Variante, in der sich der vierte Cysteinrest in einer nahegelegenen Schlaufe befand, $\mathrm{CDS}_{3} \mathrm{O}$ bildete, wohingegen $\mathrm{L} 21 \mathrm{C}$, in dem der vierte Cysteinrest Teil des CXXC-Chelatmotivs war, $\mathrm{CDS}_{4}$ bildete. Wir testeten daher sowohl $\alpha_{3}$ DIVH72C als auch L21C als mögliche Rubredoxinmodelle.

Wenn $\alpha_{3}$ DIVH72C und L21C in Medien exprimiert wurden, die zusätzliches Fe enthielten, war die L21C-Variante rot gefärbt, was auf einen gewissen Grad an Eisenbindung in vivo hindeutete. Ähnliche Exprimierung entweder von $\alpha_{3}$ DIV allein oder seiner H72C-Variation ergaben die standardmäßige gelbliche Farbe. Daher konzentrierten wir unsere

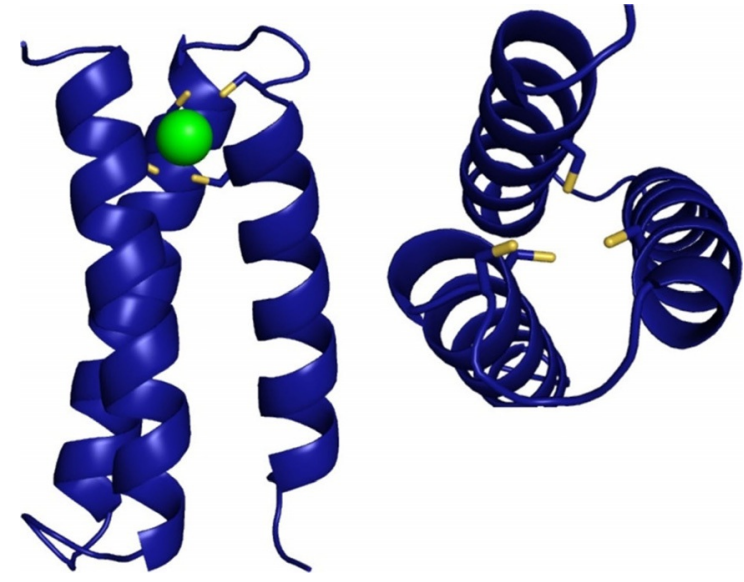

Abbildung 12. Modell des synthetischen Rubredoxins Fe- $\alpha_{3}$ DIV L21C, erzeugt mit PyMol auf Basis der NMR-Struktur von $\alpha_{3}$ DIV (PDB 2MTQ). Wiedergabe mit Genehmigung aus Lit. [67]. Copyright 2018 American Chemical Society.

Charakterisierung auf $\alpha_{3}$ DIVL21C als mögliches Rubredoxinmodell und nutzten dazu UV/Vis-, Mößbauer-, EPR-, Magnetocirculardichroismus(MCD)- und Röntgenabsorptionsspektroskopie. Aufgereinigtes Peptid wurde mit Fe rekonstituiert, indem $\mathrm{Fe}^{\mathrm{II}}$ zugesetzt wurde, bevor durch Oxidation an Luft die $\mathrm{Fe}^{\mathrm{III}}$-Form erhalten wurde. Die optischen Absorptionsspektren von $\mathrm{Fe}^{\mathrm{III}}-\alpha_{3}$ DIV L21C zeigten LigandMetall-Charge-Transfer(LMCT)-Peaks bei ähnlichen Wellenlängen, wie für das natürliche Rubredoxin berichtet (Tabelle 6), allerdings nur mit etwa $30 \%$ der erwarteten Intensität, in Übereinstimmung mit anderen spektroskopischen Befunden, die auf einen gewissen Anteil eisenfreier Spezies hindeuteten (siehe unten). ${ }^{[69]}$

Die MCD-Analyse des optischen Spektrums von $\mathrm{Fe}^{\mathrm{III}}$ $\alpha_{3}$ DIV L21C lieferte neun Peaks, die energetisch den in natürlichem Rubredoxin beobachteten Peaks entsprachen. Weitere Untersuchungen der optischen Spektren durch MCD-Spektroskopie bei variabler Temperatur und variablem Feld ergaben ein Sättigungsverhalten, das mit dem des natürlichen Rubredoxins konsistent war. Bei $4.2 \mathrm{~K}$ aufgenommene Mößbauer-Spektren von $\mathrm{Fe}^{\mathrm{II}}-\alpha_{3}$ DIVL21C ähnelten denen natürlicher Rubredoxine. Hochfeldspektren zeigten allerdings das Vorliegen zweier unabhängiger Spezies: $60 \%$ $\mathrm{FeS}_{4}$ und $40 \% \mathrm{FeS}_{3} \mathrm{O}^{[70 a]}$ Ähnliche Ergebnisse wurden aus den Mößbauer-Spektren von Fe $\mathrm{F}^{\mathrm{III}}-\alpha_{3}$ DIV L21C erhalten, die denen von Rubredoxin ähneln, allerdings $25 \%$ Verunreinigungen von Eisen(III)-oxiden und -hydroxiden enthielten. Diese Verunreinigung wurde auch im X-Band-EPR-Spektrum beobachtet, das jedoch im Allgemeinen mit dem Spektrum des natürlichen Rubredoxins übereinstimmte. EXAFSAnalysen zeigten darüber hinaus, dass in $\mathrm{Fe}^{\mathrm{II}}-\alpha_{3} \mathrm{DIV}$ L21C nur eine einzige Fe-S-Streuer-Bindung von $2.32 \AA$ vorliegt.

Wir betrachteten das elektrochemische Verhalten von $\mathrm{Fe}^{\mathrm{II} / \mathrm{III}}-\alpha_{3} \mathrm{DIV}$ L21C, um Informationen über seine Aktivität als Elektronentransferzentrum zu gewinnen, und beobachteten dabei einen Ein-Elektronen-Transfer, der mit einem Potential von $-75 \mathrm{mV}$ im Bereich natürlicher Rubredoxine $(-90$ bis $50 \mathrm{mV})$ liegt. $^{[64 a, f, 70 b, 71]} \mathrm{pH}$-Abhängige Messungen des Redoxpotentials ergaben, dass es sich hierbei um einen ge- 
Tabelle 6: Physikalische Eigenschaften der in Lit. [67] beschriebenen Konstrukte.

\begin{tabular}{|c|c|c|c|c|}
\hline Protein & $\begin{array}{l}\text { UV/Vis: } \lambda[\mathrm{nm}] \\
\left(\varepsilon\left[\mathrm{M}^{-1} \mathrm{~cm}^{-1}\right]\right)\end{array}$ & $\begin{array}{l}\text { Redoxpotential } \\
\text { (gegen } \\
\text { NHE) }[\mathrm{mV}]\end{array}$ & $\begin{array}{l}\mathrm{Fe}^{\prime \prime \prime}-\mathrm{Mößbauer}\left(\delta \text { und } \triangle E Q\left[\mathrm{~mm} \mathrm{~s}^{-1}\right]\right. \\
\left.D\left[\mathrm{~cm}^{-1}\right], A[T]\right)\end{array}$ & $\begin{array}{l}\text { Fe"-Mößbauer }\left(\delta \text { und } \triangle E Q\left[\mathrm{~mm} \mathrm{~s}^{-1}\right] \text {, }\right. \\
\left.D\left[\mathrm{~cm}^{-1}\right], A[T]\right)\end{array}$ \\
\hline Rubredoxin ${ }^{[69,70]}$ & $\begin{array}{l}750(350) \\
570(3200) \\
490(6600) \\
370(7710)\end{array}$ & -90 bis +50 & $\begin{array}{l}\delta / \triangle E Q=0.24 /-0.5, \eta=0.2 \\
D=+1.9, E / D=0.23 \\
A_{x x, y y, z z}=(-16,-15.9,-16.9)\end{array}$ & $\begin{array}{l}\delta / \triangle E Q=0.70 /-3.25, \eta=0.65 \\
D=+7.4, E / D=0.28 \\
A_{x x, y y, z z}=(-20.1,-8.3,-30.1)\end{array}$ \\
\hline$\alpha_{3}$ DIV L21C & $\begin{array}{l}595(1200) \\
491(2700) \\
345(5000)\end{array}$ & $-75(\mathrm{pH} 8.5)$ & $\begin{array}{l}\delta / \triangle E Q=0.26 /-0.5, \eta=0.0 \\
D=+0.5, E / D=0.15 \\
A_{x x, y y, z z}=(-15.9,-16,-17)\end{array}$ & $\begin{array}{l}\delta / \triangle E Q=0.73 /-3.40, \eta=0.9 \\
D=+7, E / D=0.26 \\
A_{x x, y y, z z}=(-16,-7.3,-25)\end{array}$ \\
\hline
\end{tabular}

koppelten 2-Protonen-1-Elektron-Prozess handelt. Damit unterscheidet sich unser System von natürlichen Rubredoxinen, deren Redoxpotential pH-unabhängig ist. Wir nehmen an, dass dieser Effekt in unserem Modell durch geladene Aminosäurereste in der Nähe der Metallbindungsstelle verursacht wird. Bis zu drei Zyklen aus chemischer Reduktion mit Dithionit und nachfolgender Oxidation mit Luftsauerstoff konnten durchgeführt werden, bevor ein irreversibles Ausbleichen der Probe beobachtet wurde, das vermutlich auf die Oxidation von Cysteinresten zurückzuführen ist.

Diese Arbeit stellte die umfassendste berichtete Charakterisierung eines de novo entworfenen Rubredoxins dar und zeigte, dass es möglich ist, ein tetraedrisches $\mathrm{FeS}_{4}$-Zentrum in einem starren Gerüst zu konstruieren, das nicht von der Sekundärstruktur des nativen Proteins abgeleitet ist. Wir konnten auch belegen, dass das CXXC-Motiv des nativen Rubredoxins ein wichtiger Baustein zur Erhaltung der Geometrie der Metallbindungsstelle in einem Protein ist, da unser Gerüst ohne dieses Motiv nicht in der Lage war, die spektroskopischen Eigenschaften eines tetraedrischen $\mathrm{FeS}_{4}$-Zentrums nachzubilden. Ein Vergleich der MCD-Daten mit den Ergebnissen der Mößbauer- und EPR-Spektren ergab, dass unser Modell auch das kontroverse Vorzeichen des Parameters $D$ im natürlichen Rubredoxin reproduziert, für den aus MCD-Experimenten negative Werte, aus EPR- und Mößbauer-Spektroskopie aber positive Werte erhalten werden. ${ }^{[70 a, 72]}$ In Zukunft können Hochfeld-EPR-Spektroskopie und weiteres Proteindesign dazu beitragen, diesen scheinbaren Widerspruch aufzulösen.

\subsection{Entwicklung von Cupredoxinmodellen}

Typ-1-Kupferproteine sind Elektronentransferproteine mit einem Greek-Key-beta-Fass und einer $\mathrm{CuHis}_{2} \mathrm{Cys} \mathrm{Xxx}-$ Bindungsstelle, in der Xxx zwischen Met, Gln und (in einem Fall) Glu variieren kann. Diese Proteine faszinieren Bioanorganiker wegen ihrer rigiden Geometrie, ihrer einzigartigen optischen Eigenschaften, die zu intensiv blauen, grünen oder roten Lösungen führen, und der verringerten Hyperfeinkopplungskonstante in ihren EPR-Spektren seit vielen Jahren. ${ }^{[73]}$ Blaue Typ-1-Kupferzentren zeigen einen intensiven LMCT bei $600 \mathrm{~nm}$, der auf dem Cys-Cu- $\pi-\mathrm{d}_{x^{2}-y^{2}}$-Übergang beruht, eine kurze Cu-Cys-Bindung von 2.1-2.2 $\AA$ und eine verkleinerte Hyperfeinkopplungskonstante $\mathrm{A}_{\|}$von unter $100 \times 10^{-4} \mathrm{~cm}^{-1} .{ }^{[74}$ Grüne Typ-1-Kupferzentren haben eine zusätzliche LMCT-Bande bei $450 \mathrm{~nm}$, die zu einem Cys-Cu- $\sigma-$ $\mathrm{d}_{x^{2}-y^{2}}$-Übergang gehört, wobei das Intensitätsverhältnis beider Übergänge etwa 1 beträgt, eine etwas längere $\mathrm{Cu}-\mathrm{Cys}-$ Bindung von $2.2 \AA$ und eine ähnliche Hyperfeinkopplungskonstante $A_{\|} \cdot{ }^{[75]}$ Rote Typ-1-Kupferzentren schließlich haben eine deutlich intensivere $\sigma$-LMCT-Bande bei $390 \mathrm{~nm}$, einen blauverschobenen und abgeschwächten $\mathrm{Cys}-\mathrm{Cu}-\pi-\mathrm{d}_{x^{2}-y^{2}-}$ Übergang bei $500 \mathrm{~nm}$ mit einem $\varepsilon_{\mathrm{o}} / \pi$-Verhältnis von ca. 3 , einen $\mathrm{Cu}$-Cys-Abstand von fast $2.3 \AA$ und ein EPR-Spektrum, das dem für Typ-2-Kupferzentren beobachteten EPR-Spektrum ähnelt. ${ }^{[76]}$

Frühere Versuche, Typ-1-Kupferzentren in Gerüsten zu entwerfen, die nicht vom natürlichen Gerüst abgeleitet waren, lieferten meist grüne Kupferproteine. ${ }^{[77]}$ Valentine et al. gelang die Nachbildung der spektroskopischen Eigenschaften eines grünen Kupferproteins in einer H80C-Variante der $\mathrm{Cu} / \mathrm{Zn}$-Superoxid-Dismutase, während Hellinga eine Serie von Thioredoxinvarianten entwickelte, die nach Hinzufügen eines exogenen Azidliganden ebenfalls die spektroskopischen Eigenschaften grüner Kupferproteine nachbildeten. ${ }^{[77 a, b]}$ In einem kombinatorischen Ansatz synthetisierten und analysierten Hildebrandt et al. 180 verschiedene VierHelix-Bündel-Proteine, die das $\mathrm{His}_{2} \mathrm{Cys}$-Motiv enthielten, und berichteten, dass mehrere dieser Proteine die charakteristischen Spektren grüner Kupferproteine zeigten. ${ }^{[77 c]}$ Die erfolgreichste Arbeit in der Entwicklung von blauen Denovo-Kupferproteinen gelang Tanaka et al., die ein $\mathrm{His}_{2} \mathrm{Glu}-$ Kupfer-bindendes Protein in einem Vier-Helix-Bündel zu einer $\mathrm{His}_{2} \mathrm{Cys}$-Bindungsstelle modifizierten und so durch rationales Design ein grünes Kupferprotein erhielten. ${ }^{[77 d]}$ Interessanterweise ließ sich durch Zugabe verschiedener exogener Liganden wie Chlorid, Sulfat, Acetat und Phosphat dieses grüne Kupferprotein spektroskopisch in ein blaues Kupferprotein überführen. ${ }^{[78]}$ Wenngleich all diese Arbeiten beeindruckende Beiträge zur Weiterentwicklung des Forschungsgebiets leisteten, zeigt die benötigte Zugabe exogener Liganden zur Nachbildung der Spektren blauer Kupferzentren, dass die Frage nach der Synthese eines eigenständigen blauen Kupferzentrums in De-novo-Gerüststrukturen noch immer unbeantwortet blieb.

Wir konnten bereits zuvor zeigen, dass eine $\mathrm{His}_{3^{-}}$oder $\mathrm{Cys}_{3}$-Metallbindungsstelle in das 3HB-Protein $\alpha_{3} \mathrm{D}$ eingebaut werden kann, aber diese Arbeit stellte unseren ersten Versuch zum Design einer gemischten Koordinationssphäre dar. ${ }^{[2,80]}$ Vier unterschiedliche mögliche Cupredoxine wurden in diesem $\alpha_{3}$ D-Gerüst entworfen: $\mathrm{CR} 1, \mathrm{CH} 3, \mathrm{CH} 4$ und $\mathrm{ChC} 2$ 

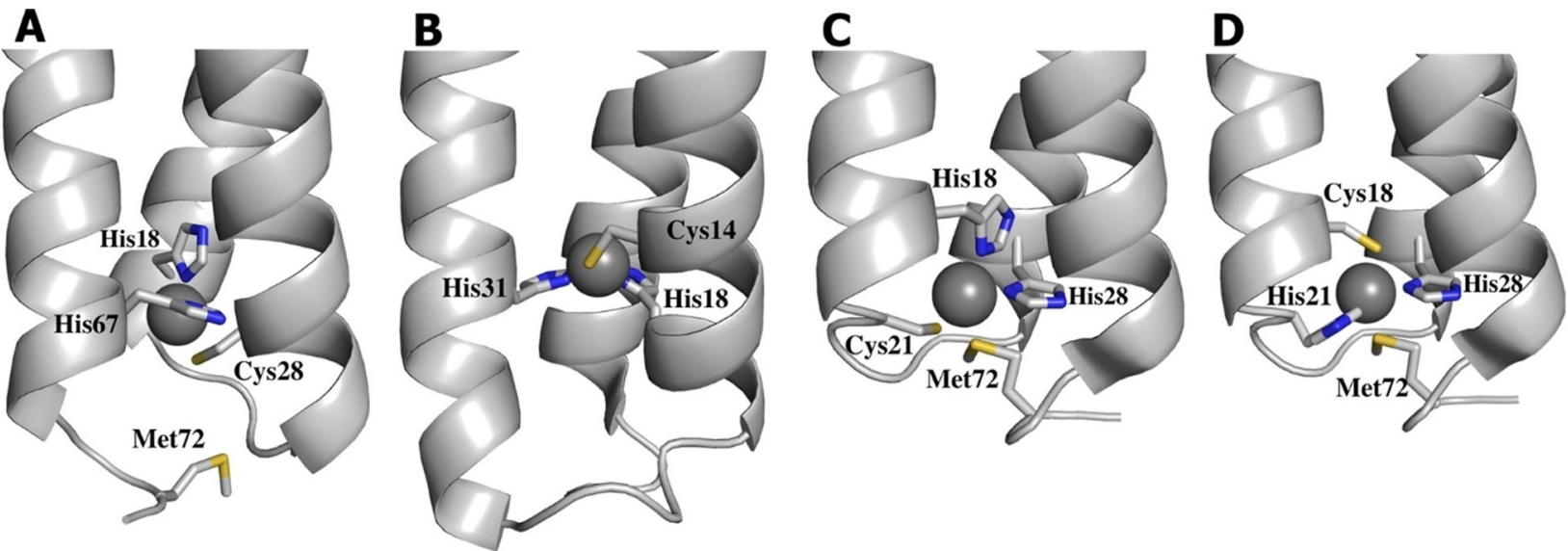

Abbildung 13. Modelle der reduzierten Form der entworfenen Cupredoxine auf Basis von EXAFS-Daten. A) Cu' $\alpha_{3}$ DCR1, B) Cu' $\alpha_{3}$ DChC2, C) $\mathrm{Cu}^{\prime} \alpha_{3} \mathrm{DCH}$, D) $\mathrm{Cu}^{\prime} \alpha_{3} \mathrm{DCH} 4$. Wiedergabe mit Genehmigung aus Lit. [79]. Copyright 2015 American Chemical Society.

(Abbildung 13 und Tabelle 7). ${ }^{[79]} \quad \alpha_{3}$ DCR1 enthält ein $\mathrm{His}_{2}$ Cys-Bindungsmotiv, das die drei Helices an den Aminosäureresten 18, 28 und 67 umspannt (denselben Positionen, die zuvor in $\alpha_{3}$ DIV und $\alpha_{3} \mathrm{DH} 3$ genutzt wurden), sowie einen nahegelegenen Met-Rest an Position 72. Das Design von $\alpha_{3} \mathrm{DCH} 3$ und $\alpha_{3} \mathrm{DCH} 4$ enthielt die Chelatmotive CXXH oder HCCX auf Helix 1, wobei His- und Met-Liganden auf die beiden verbleibenden Helices aufgeteilt wurden. Zuletzt repositioniert das Design von $\alpha_{3} \mathrm{DChC} 2$ die Metallbindungsstelle von $\alpha_{3} \mathrm{DCH} 4$ weiter in Richtung des N-Terminus des Peptids und in Richtung des Zentrums des hydrophoben Kerns und schließt es so in einer „Box“ aus hydrophoben Resten ein. Dadurch wurde versucht, einen entatischen $\mathrm{Zu}$ stand ähnlich dem der natürlichen Typ-1-Kupferzentren zu erzwingen.

Denaturierung mit $\mathrm{GuHCl}$ und nachfolgende Circulardichroismus-Spektroskopie zeigten, dass alle vier Systeme, mit Ausnahme von $\alpha_{3}$ DChC2, alpha-helikal und in Lösung stabil gefaltet vorlagen. Die UV/Vis- und EPR-Spektren wurden für die $\mathrm{Cu}^{\mathrm{II}}$-Formen dieser Modelle aufgenommen, um $\mathrm{zu}$ analysieren, wie gut die $\mathrm{Cu}^{\mathrm{II}}$-Geometrie eines Typ-1-Kupferproteins in jedem einzelnen dieser Modelle nachgebildet wird. Für $\alpha_{3}$ DCR1 wurden Spektren erhalten, die mit einer intensiven LMCT-Bande bei $380 \mathrm{~nm}$ und einer Schulter bei $550 \mathrm{~nm}$ im Verhältnis $\varepsilon_{\sigma / \pi}=3.6$ und einer Hyperfeinkopplungskonstante von $163 \times 10^{-4} \mathrm{~cm}^{-1}$ denen von Typ-2-Kupferthiolatspezies ähneln. $\alpha_{3} \mathrm{DCH} 3$ lag als gelbe Spezies mit einer intensiven Absorptionsbande bei $400 \mathrm{~nm}$ und einer breiten Bande zwischen 600 und $800 \mathrm{~nm}$ im besonders hohen Verhältnis von $\varepsilon_{\sigma / \pi}=11.9$ sowie einer Hyperfeinkopplungskonstante von $152 \times 10^{-4} \mathrm{~cm}^{-1}$ vor. Für $\alpha_{3} \mathrm{DCH} 4$ wurden Absorptionsbanden bei 377,450 und $520 \mathrm{~nm}$ mit $\varepsilon_{\sigma / \pi}=3.3$ sowie eine Hyperfeinkopplungskonstante $\mathrm{A}_{\|}$von $185 \times$ $10^{-4} \mathrm{~cm}^{-1}$ beobachtet. Interessanterweise reichte eine einfache Umkehr des Chelatmotivs von $\mathrm{CH} 3$ zu CH4 aus, um drastische Änderungen der spektroskopischen Eigenschaften der $\mathrm{Cu}^{\mathrm{II}}$-Spezies herbeizuführen. Wir nahmen an, dass dieser Unterschied dadurch zustande kommt, dass der Cysteinrest der Metallbindungstasche bei einer Umkehrung des Chelatmotivs tiefer im Proteingerüst liegt. Daher entwickelten wir in der Folge $\alpha_{3} \mathrm{DChC} 2$, in dem der Cysteinrest, im Versuch eine hydrophobe Box um das gebundene Kupfer zu erzeugen, noch tiefer im Proteingerüst gelegen ist. $\alpha_{3} \mathrm{DChC} 2$ zeigt zwei intensive Banden bei 401 und $499 \mathrm{~nm}$ im Verhältnis $\varepsilon_{\sigma / \pi}=2.2$ und eine leicht verringerte Hyperfeinkopplungskonstante $130 \times$ $10^{-4} \mathrm{~cm}^{1}$ und liegt folglich als rotbraune Kupferspezies vor. Damit erinnert die optische Spektroskopie dieses Systems sowohl an blaue Kupferproteinvarianten wie M121E Azurin oder M148 Rusticyanin als auch an das native rote Kupferprotein Nitrosocyanin. ${ }^{[82,83]}$

Eines der bemerkenswertesten Ergebnisse dieser Arbeit war, dass alle vier konstruierten Proteine in 
der $\mathrm{Cu}^{1}$-Form die Geometrie blauer Kupferproteine nachbildeten, unabhängig davon, wie erfolgreich die Geometrie und Spektroskopie in der $\mathrm{Cu}^{\mathrm{II}}$-Form nachgebildet wurden. EXAFS-Daten der $\mathrm{Cu}^{\mathrm{I}}$-Spezies aller vier Strukturen zeigten kurze Cu-Cys-Bindungen zwischen 2.18 und $2.22 \AA$ mit weiteren Streuern aus den Histidinliganden in größeren Abständen. Die Analyse des $\mathrm{Cu}^{\mathrm{I}}$-XANES-1s $\rightarrow 4 \mathrm{p}$-Übergangs bei $8984 \mathrm{eV}$ in allen vier Strukturen teilte diese Modelle in zwei Gruppen: Die Kupferzentren in Ch2 und CR1 sind eher dreifach-koordiniert, während in $\mathrm{CH} 3$ und $\mathrm{CH} 4$ eher eine Vierfach-Koordination vorliegt. Mittels Protein-Film-Voltammetrie konnten wir darüber hinaus zeigen, dass alle vier Modelle mit Potentialen zwischen 364 und $462 \mathrm{mV}$ auch das Redoxpotential blauer Kupferproteinen nachbildeten, das üblicherweise zwischen 300 und $700 \mathrm{mV}$ liegt. ${ }^{[81 b, 83 b, 84]}$

Diese Arbeiten zeigten, dass das Design von Cupredoxinzentren in 3HB-Strukturen drastische Auswirkungen auf die spektroskopischen Eigenschaften des gebundenen $\mathrm{Cu}^{\text {II }}$ Ions haben kann. Unsere Designstrategie mündete schließlich in die Entwicklung von $\alpha_{3} \mathrm{DChC} 2$, das die Spektroskopie eines roten Kupferproteins sowie die Geometrie und das Redoxpotential eines blauen Kupferproteins nachbildet. Wir gingen davon aus, dass ein vollständigeres Verständnis der in $\alpha_{3}$ DChC2 vorliegenden Metallbindungsstelle es uns ermöglichen würde, die spektroskopischen Eigenschaften der $\mathrm{Cu}^{\mathrm{II}}$ Spezies derart zu beeinflussen, dass sie denen einer grünen oder blauen Kupferspezies entsprechen. Die gleichbleibende Geometrie und das Redoxpotential der $\mathrm{Cu}^{\mathrm{I}}$-Form in allen vier Modellen zeigen, dass bei einer erfolgreichen Abstimmung der $\mathrm{Cu}^{\mathrm{II}}$-Spektroskopie hin $\mathrm{zu}$ jener eines blauen Kupferproteins alle anderen Eigenschaften bereits passen würden.

Unser Erfolg in der Nachbildung einer roten Kupferproteins mit $\alpha_{3} \mathrm{DChC} 2$ gab uns Anlass, dieses Gerüst erneut zu betrachten, um Anhaltspunkte zu gewinnen, wie sich dieses Gerüst als ein Modell für grüne oder blaue Kupferproteine abstimmen lassen könnte. Eine Möglichkeit bestand darin, dass die über chemische Denaturierung bestimmte relative Instabilität von $\alpha_{3} \mathrm{DChC} 2$ die hydrophobe Box-Struktur schwächt, die zur Erzwingung eines entatischen Zustandes eingebaut wurde. Diese Instabilität machte auch Einzelmutationsstudien zur Untersuchung dieses Gerüsts unmöglich und somit die Entwicklung einer stabileren Variante nötig. Unsere Erfahrung mit dreisträngigen Coiled-Coil-Systemen führte uns zu der Strategie, die $\alpha_{3} D$ alpha-Helix im Gerüstprotein zu verlängern und so die thermische Stabilität zu erhöhen. ${ }^{[85]}$ Das ursprüngliche Design des $\alpha_{3} \mathrm{D}-\mathrm{Ge}$ rüsts in der Gruppe um De Grado umfasste mehrere iterative Designprozesse, die sich hauptsächlich auf die Schleifenregion konzentrierten, die jede Helix verbindet. In unserem Design von $G R \alpha_{3} D$ versuchten wir, diesen komplexen Prozess zu vermeiden, indem wir die Helices von der Mitte ausgehend verlängerten und die zentrale Heptade jeder Helix duplizierten. GuHCl-
Denaturierung von $\mathrm{GR}_{3} \mathrm{D}$ zeigte, dass diese Strategie erfolgreich war und ein Gerüst mit einer freien Enthalpie für die Entfaltung von $11.4 \mathrm{kcal} \mathrm{mol}^{-1}$, gegenüber $5.9 \mathrm{kcal} \mathrm{mol}^{-1}$ in $\alpha_{3} \mathrm{D}$, lieferte. Dank der so erhöhten Stabilität gelang es uns, zur Röntgendiffraktometrie geeignete Kristalle zu gewinnen und die Struktur des Gerüsts mit einer Auflösung von $1.34 \AA$ zu lösen (Tabelle 8).

Durch Einführen eines ChC2-Bindungszentrums in $\mathrm{GR} \alpha_{3} \mathrm{D}$ entwickelten wir $\mathrm{GR} \alpha_{3} \mathrm{DChC} 2$ und beobachteten, dass dieses Gerüst, entgegen dem als Vorbild fungierenden Peptid, in Lösung vollständig gefaltet vorlag (Abbildung 14). Die spektroskopischen Eigenschaften der $\mathrm{Cu}^{\mathrm{II}}$-Form blieben jedoch weiterhin deutlich im Bereich derer von roten Kupferproteinen und widerlegten so die Hypothese, dass thermodynamische Instabilität die Ursache der anomalen spektralen Eigenschaften von $\alpha_{3} \mathrm{DChC} 2$ waren. Eine MCD-Analyse des optischen Spektrums von $\mathrm{GR} \alpha_{3} \mathrm{DChC} 2$ bestätigte die Zuordnung zu roten Kupferproteinen weiter und stimmte mit den d-d-Übergängen in nativem Nitrosocyanin überein. ${ }^{[76]}$ Das $\mathrm{His}_{2} \mathrm{CysGlu-Bindungsmotiv} \mathrm{von} \mathrm{Nitrosocyanin} \mathrm{war} \mathrm{nicht}$ Teil unseres ursprünglichen $\alpha_{3} \mathrm{DChC} 2$-Designs, und so blieb die Frage offen, warum dieses Gerüst Nitrosocyanin so stark ähnelte, obwohl sein Design nur auf einem $\mathrm{His}_{2} \mathrm{Cys}$-Motiv beruhte.

Die Modellierung der $\mathrm{Cu}$-Bindungsstelle von $\mathrm{GR} \alpha_{3} \mathrm{DChC} 2$ in die $\mathrm{GR} \alpha_{3} \mathrm{D}$-Röntgenkristallstruktur ließ darauf schließen, dass infolge des Designs der Metallbindungsstelle, die zwei der drei Helices umspannte, das Kupferzentrum außerhalb des Zentrums des hydrophoben Inneren und näher an der Helix-Helix-Schnittfläche positioniert war. Diese Positionierung bringt das Kupferzentrum in einen Abstand von ca. $5 \AA$ zum Aminosäurerest Glu41, der im GR $\alpha_{3}$ D-Gerüst als Teil einer Salzbrücke mit Arg24 vorkommt. Diese Möglichkeit war besonders faszinierend, da das Absorptionsspektrum von $\mathrm{GR} \alpha_{3} \mathrm{DChC} 2$ nicht nur dem von Nitrosocyanin, sondern auch dem der Varianten blauer Kupferproteine M121E Azurin und M148E Rusticyanin glich. Es war demzufolge denkbar, dass es durch das Ausschalten der Cu-Glu41-Wechselwirkung über eine E41AMutation oder Abstimmung mit E41Q möglich sein könnte, die spektroskopischen Eigenschaften von $\mathrm{GR} \alpha_{3} \mathrm{DChC} 2$ in Richtung grüner oder blauer Kupferproteine zu lenken. ${ }^{[22,83]}$

Tabelle 8: Physikalische Eigenschaften der in Lit. [11] beschriebenen Konstrukte.

\begin{tabular}{|c|c|c|c|}
\hline Protein & UV/Vis: $\lambda[\mathrm{nm}]\left(\varepsilon\left[\mathrm{M}^{-1} \mathrm{~cm}^{-1}\right]\right)$ & EPR: $A_{\|} \times 10^{-4} \mathrm{~cm}^{-1}$ & $\begin{array}{l}\text { Redoxpotential } \\
\text { (gegen NHE) [mV] }\end{array}$ \\
\hline $\mathrm{GR} \alpha_{3} \mathrm{DChC2}$ & $\begin{array}{l}400(3760), 490(1600) \\
\varepsilon_{\sigma / \pi}=2.3\end{array}$ & 142 & +530 \\
\hline $\mathrm{GR} \alpha_{3} \mathrm{DChC2} \mathrm{R} 24 \mathrm{~A}$ & $\begin{array}{l}399(2520), 490(1150) \\
\varepsilon_{\sigma / \pi}=2.2\end{array}$ & 142 & - \\
\hline $\mathrm{GRO}_{3} \mathrm{DChC2} \mathrm{R} 24 \mathrm{M}$ & $\begin{array}{l}399(3480), 493(1450) \\
\varepsilon_{\sigma / \pi}=2.4\end{array}$ & 138 & - \\
\hline $\mathrm{GR \alpha _{3 }} \mathrm{DChC2} \mathrm{E} 41 \mathrm{Q}$ & $\begin{array}{l}377(5120), 490(970) \\
\varepsilon_{\sigma / \pi}=5.3\end{array}$ & 154 & +510 \\
\hline $\mathrm{GR} \alpha_{3} \mathrm{DChC2} \mathrm{E} 41 \mathrm{~A}$ & $\begin{array}{l}373(4090), 490(720) \\
\varepsilon_{\sigma / \pi}=5.7\end{array}$ & 160 & +510 \\
\hline Nitrosocyanin ${ }^{[76,82]}$ & $\begin{array}{l}390(7000), 490(2200) \\
\varepsilon_{\sigma / \pi}=3.2\end{array}$ & 142 & +85 \\
\hline
\end{tabular}




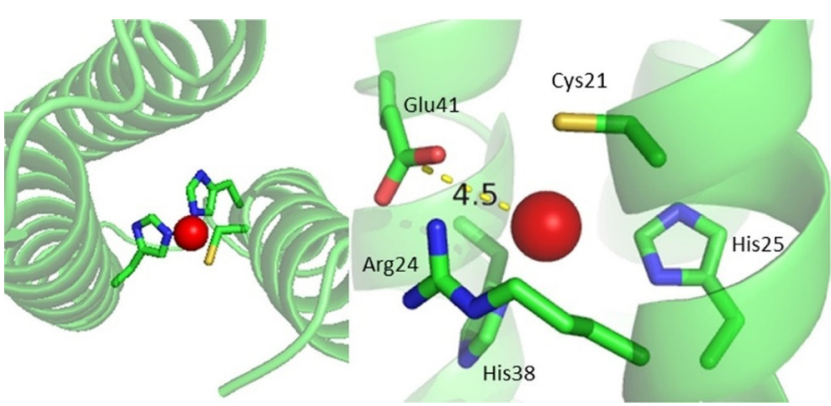

Abbildung 14. PyMol-Illustrationen der erwarteten Position der Metallbindungsstelle in $\mathrm{GR} \alpha_{3} \mathrm{DChC2}$ (links) und des erwarteten Glu41-Cu-Abstands bei Bindung von $\mathrm{Cu}^{\prime \prime}$ an dieser Position. Wiedergabe mit Genehmigung aus Lit. [11]. Copyright 2018 American Chemical Society.

Mutationsstudien in der Umgebung des Glu41-Arg24Paares ergaben, dass E41A und E41Q drastische Veränderungen des Absorptionsprofils zur Folge hatten. Dabei wurde der $\sigma$-LMCT-Übergang blauverschoben, und das Verhältnis $\varepsilon_{\sigma / \pi}$ stieg auf 5.3 bzw. 5.7, während die Hyperfeinkopplungskonstante auf 160 bzw. $154 \times 10^{-4} \mathrm{~cm}^{-1}$ anstieg. Diese Änderungen zeigten einen Wechsel von einem roten Kupferprotein zu einem Typ-2-Kupferprotein an. Um zu untersuchen, ob die Effekte der E41-Mutation auf den Verlust einer Salzbrücke und einen besseren Lösungsmittelzugang statt den Verlust der direkten $\mathrm{Cu}-\mathrm{E} 41-W e c h s e l w i r k u n g$ zurückzuführen waren, entwickelten wir R24A- und R24M-Konstrukte. Die R24Varianten zeigten keine Änderung der UV/Vis- und EPRSpektren der $\mathrm{Cu}^{\mathrm{II}}$-Form und bestätigten so, dass die E41Aund E41Q-Mutationen spezifisch eine E41-Cu-Wechselwirkung störten. Dieser Befund verdeutlichte, dass unser GR $\alpha_{3}$ DChC2-Konstrukt am besten als Nitrosocyanin-Mimetikum anstatt als blaues Kupferprotein mit einem axialen GluLiganden zu beschreiben ist. Dies bedeutet, dass zur Nachahmung der spektroskopischen Eigenschaften blauer Kupferproteine mit diesem Konstrukt wahrscheinlich größere Veränderungen des aktiven Zentrums nötig sein werden. Diese könnten ausgehend von der kürzlich von $\mathrm{Lu}$ et al. veröffentlichten Arbeit erfolgen, in der das blaue Kupferprotein Azurin durch Rotation des aktiven Zentrums und Substitution des vierten $\mathrm{Cu}$-Liganden in ein Nitrosocyaninähnliches, rotes Kupferprotein umgewandelt wurde. ${ }^{[86]}$ Die Geometrie der $\mathrm{Cu}^{\mathrm{I}}$-Spezies und das Redoxpotential waren in allen Mutationen unserer Studie unverändert. Dies bestätigt die vorherige Annahme, dass sich eine Abstimmung auf die spektroskopischen Eigenschaften der $\mathrm{Cu}^{\mathrm{II}}$-Spezies konzentrieren kann und es wohl keine Auswirkungen auf das Redoxpotential und die Geometrie der $\mathrm{Cu}^{\mathrm{I}}$-Spezies geben wird. Wir nutzten die so gewonnenen Erkenntnisse zur Struktur unserer Modelle seitdem zur Entwicklung von Varianten, die spektroskopisch grünen Kupferproteinen gleichen und ähnlich wie in der Arbeit von Tanaka et al. - durch Hinzufügen exogener Chloridliganden in blaue Kupferproteine überführt werden können, sowie einer Variante, die die spektroskopischen Eigenschaften blauer Kupferproteinen auch ohne Hinzufügen exogener Liganden nachbildet. ${ }^{[77 d]}$ Ein Manuskript, in dem wir von dieser Arbeit berichten, wird derzeit vorbereitet. ${ }^{[87]}$

\subsection{Messung der Elektronentransferaktivität}

Eines der übergeordneten Ziele der Arbeit unserer Gruppe war die Entwicklung einer vollständig funktionalen und eigenständigen $\mathrm{Cu}$-Nitritreduktase mit einem aktiven Typ-2-Kupferzentrum sowie einem Elektronentransferzentrum. Für dieses Ziel ist ein Verständnis des Elektronentransfers durch unsere Peptidgerüste sowie der Geschwindigkeit des Elektronentransfers an ihren redoxaktiven Metallzentren nötig. Bisher haben wir zwei verschiedene Methoden zur Beantwortung dieser Fragen genutzt, indem wir intermolekulare Elektronentransfers zur Untersuchung von $\alpha_{3} \mathrm{DCH} 3$ nutzten und intramolekularen Elektronentransfer betrachteten, um zu verstehen, wie Elektronen durch unsere Gerüste transportiert werden können. ${ }^{[8]}$

Um die Elektronentransfereigenschaften eines unserer Cupredoxinmodelle zu untersuchen, wurden Lösungen von $\alpha_{3}$ DCH3 durch Bestrahlung von Ruthenium(II)-trisbipyridin, $\left[\mathrm{Ru}^{\mathrm{II}}(\text { bipy })_{3}\right]^{3+}$, mit einem 460-nm-Laser in Gegenwart von $\left[\mathrm{Ru}^{\mathrm{III}}\left(\mathrm{NH}_{3}\right)_{6}\right]^{3+}$ zur Erzeugung von $\left[\mathrm{Ru}^{\mathrm{III}}(\text { bipy })_{3}\right]^{3+}$, einem starken Oxidationsmittel mit einem Potential von $1.3 \mathrm{~V}$, photooxidiert. Der Elektronentransfer zwischen unterschiedlichen Spezies wurde danach durch optische Spektroskopie verfolgt (Abbildung 15 und Tabelle 9). In dieser Reaktion wird das $\left[\mathrm{Ru}^{\mathrm{II}}(\text { bipy })_{3}\right]^{3+}$-Radikal nach $100 \mathrm{~ns}$ gebildet und reagiert anschließend mit dem Elektronenakzeptor unter Bildung von $\left[\mathrm{Ru}^{\mathrm{III}}(\mathrm{bipy})_{3}\right]^{3+}$ nach $1 \mu \mathrm{s}$. Eine positive Absorptionsbande bei $400 \mathrm{~nm}$ nach $100 \mu$ s wurde der Bildung von $\mathrm{Cu}^{\mathrm{II}} \alpha_{3} \mathrm{DCH} 3$ ausgehend von der spektroskopisch nicht detektierbaren $\mathrm{Cu}^{\mathrm{I}} \alpha_{3} \mathrm{DCH} 3-$ Spezies zugeordnet. Diese $\mathrm{Cu}^{\mathrm{II}} \alpha_{3} \mathrm{DCH} 3-$ Spezies reagierte nach $10 \mathrm{~ms}$ mit dem Elektronenakzeptor und lieferte so erneut $\mathrm{Cu}^{\mathrm{I}} \alpha_{3} \mathrm{DCH} 3$. Aufgrund der Absorptionsänderungen konnten wir berechnen, dass

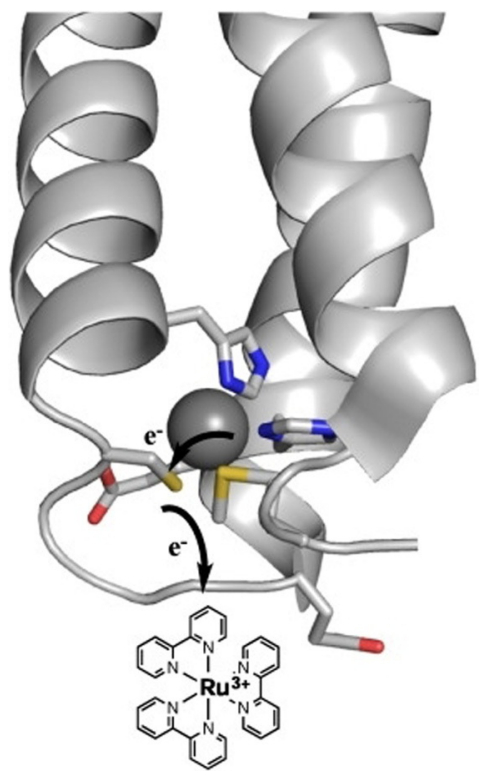

Abbildung 15. Vorgeschlagener Elektronentransfer (ET)-Pfad. In $\mathrm{Cu}_{3} \mathrm{DCH} 3$ kann der Cys-Rest einen Superaustauschpfad für den ET zwischen dem Kupferzentrum und dem Photooxidationsmittel eröffnen. Wiedergabe mit Genehmigung aus Lit. [88b]. Copyright 2018 Elsevier B.V. 
Tabelle 9: Kennzahlen des intermolekularen Elektronentransfers durch $\alpha_{3} \mathrm{DCH}$.

\begin{tabular}{|c|c|c|c|}
\hline Probe & $k_{1 \mathrm{app}} \times 10^{5} \mathrm{~s}^{-1}$ & $k_{\text {2app }} \times 10^{8} \mathrm{M}^{-1} \mathrm{~s}^{-1}$ & Triebkraft $[\mathrm{eV}]$ \\
\hline Apo $\alpha_{3} \mathrm{DCH} 3+\mathrm{Ru}$ (bipy) ${ }_{3}$ & 0.39 & 3.9 & \\
\hline $\mathrm{Cu}_{3} \mathrm{DCH} 3+\mathrm{Ru}(\text { bipy })_{3}$ & 1.15 & 6.3 & 1.18 \\
\hline $\mathrm{Cu}_{3} \mathrm{DCH} 3+\mathrm{Ru}(\text { phen })_{3}$ & 1.07 & 10.7 & 0.88 \\
\hline $\mathrm{Cu}_{3} \mathrm{DCH} 3+(\mathrm{COOEt})_{4} \mathrm{Ru}$ (bipy) $)_{3}$ & 1.08 & 10.8 & 1.51 \\
\hline $\mathrm{Cu}_{3} \mathrm{DCH} 3+(\mathrm{COOEt})_{2} \mathrm{Ru}(\text { bipy })_{3}$ & 1.05 & 10.5 & 1.24 \\
\hline $\mathrm{Cu \alpha}_{3} \mathrm{DCH} 3+\mathrm{ZnTMPyP}$ & 0.79 & 7.9 & 0.84 \\
\hline
\end{tabular}

dig. ${ }^{[90]}$ Diese Transferprozesse über große Distanzen erfolgen in einer Serie von Schritten, die den Abstand, der in einer einzelnen Elektronenübertragung überwunden werden muss, verkleinern und damit die Geschwindigkeit des Gesamtprozesses erhöhen. ${ }^{[91]}$ In Proteinen werden solche schrittweisen Transportprozesse durch redoxaktive Aminosäurereste wir Tyr und Trp ermöglicht. ${ }^{[92]}$ Die Bildung von Tyrosinradikalen ist ein wesentlicher Bestandteil von Photosystem II, der Ribonukleotid-Reduktase und der Cytochrom-c-Oxidase. ${ }^{[90]}$ Der Elektronentransfer durch Bildung eines Tyrosinradikals ist dabei wegen der großen Unterschiede im $\mathrm{p} K_{\mathrm{a}}$-Wert von Tyr (10) und dem entsprechenden Radikal (-2) an einen Protonentransfer gekoppelt. ${ }^{[3]}$ Die Analyse natürlicher Systeme, die Tyrosinreste nutzen, wird meist durch die Komplexität solcher Systeme behindert. Frühere Arbeiten zur Bildung von Tyrosinradikalen in einem künstlichen Protein ergaben, dass ein einziges Tyrosinradikal in einem alpha-Helixbündel dadurch stabilisiert werden kann, dass es tief im hydrophoben Inneren des Peptids positioniert wird. ${ }^{[94]]}$ Wir verankerten ein $\mathrm{Ru}^{\mathrm{II}}$ (bipy) ${ }_{3}{ }^{-}$ Photooxidationsmittel kovalent am C-Terminus unseres $\alpha_{3} \mathrm{DH}_{3}$-Carboanhydrasekonstrukts, um $\alpha_{3} \mathrm{DH}_{3}$-Rubpymal zu erzeugen und zu untersuchen, wie die schrittweise Übertragung von Elektronen auf Tyrosinreste in unseren Systemen zum Elektronentransfer über weite Strecken genutzt werden kann (Abbildung 16). ${ }^{[88 b]}$ Auf Grundlage der Struktur von $\alpha_{3} \mathrm{D}$ in Lösung schätzten wir $\mathrm{ab}$, dass das gebundene $\mathrm{Ru}$ und Tyr70 (das nächstgelegene Tyr) etwa $16 \AA$ voneinander entfernt lagen.

Zur Untersuchung der auf ns-Zeitskala ablaufenden Elektronentransferprozesse und der Reaktionskinetik zwischen dem gebundenen $\mathrm{Ru}$ und Tyr70 nutzten wir LaserFlash-Photolyse. Der intermolekulare Elektronentransfer zwischen radikalischem $\mathrm{Ru}^{\mathrm{II}}$ (bipy) ${ }_{3}$ und dem Elektronenakzeptor $\mathrm{Ru}^{\mathrm{III}}\left(\mathrm{NH}_{3}\right)_{6}$ lieferte oxidiertes $\mathrm{Ru}^{\mathrm{II}}(\text { bipy })_{3}$ mit einer

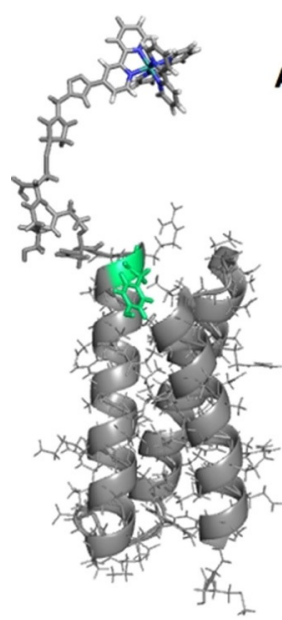

A

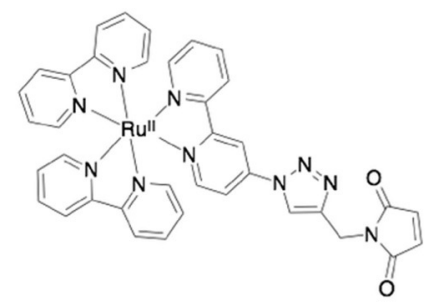

Peptide Sequence

MGS WAEFKQR LAAIKTR HQAL GG SEAEHAAFEKE IAAFESE LQAY KGKC NPE VEALRKE AAAIRDE HQAY RHN GSGC

Abbildung 16. A) Struktur von $\alpha_{3} \mathrm{DH}_{3}$-Rubpymal basierend auf der mittels NMR-Spektroskopie in Lösung bestimmten Struktur eines eng verwandten Gerüsts (PDB: 2MTQ). Der Tyrosinrest ist grün markiert. B) Struktur von Rubpymal (oben) und Sequenz von $\alpha_{3} \mathrm{DH}_{3}$ (unten). Wiedergabe mit Genehmigung aus Lit. [88b]. Copyright 2017 Wiley$\mathrm{VCH}$. 
Geschwindigkeitskonstante zweiter Ordnung von $1.1 \times$ $10^{9} \mathrm{M}^{-1} \mathrm{~s}^{-1}$ (Halbwertszeit $40 \mathrm{~ns}$ ). Die zweite Phase der Reaktion mit einer Geschwindigkeitskonstante von $3.3 \times 10^{5} \mathrm{~s}^{-1}$ wurde anhand der beobachteten Absorptionsmaxima bei 390 und $410 \mathrm{~nm}$ der Bildung des Tyrosinradikals zugeordnet. ${ }^{[94 a, 95]}$ Die beobachtete Geschwindigkeit ist in Einklag mit der für einen Elektronentransfer über $16 \AA$ erwarteten Geschwindigkeit, die aus einem vereinfachten Elektronentunnelmodell in Peptiden erhalten werden kann. ${ }^{[96]}$ Schließlich wurde eine dritte Reaktionsphase mit einer Halbwertszeit von $210 \mu \mathrm{s}$ beobachtet, in der das Tyrosinradikal mit dem Elektronenakzeptor $\mathrm{Ru}^{\mathrm{III}}\left(\mathrm{NH}_{3}\right)_{6}$ kombiniert. Die $\mathrm{pH}$-Abhängigkeit der zweiten Phase zeigte, dass es sich bei diesem Prozess um einen Protonen-gekoppelten Elektronentransfer (PCET) handelt, da diese Phase bei pH 9.5 viermal schneller ablief als bei $\mathrm{pH}$ 5.0. Die Bildung des Tyr-Radikals wurde mittels X-BandEPR-Spektroskopie einer Reaktion in Gegenwart des nichtreversiblen Elektronenakzeptors $\left[\mathrm{Co}^{\mathrm{III}}\left(\mathrm{NH}_{3}\right)_{5} \mathrm{Cl}\right]^{2+}$ bestätigt. Zukünftige Arbeiten an diesem Modell werden wasserstoffbrückenbindende Aminosäuren in der Umgebung von Tyr70 einbringen, um deren Einfluss auf die beobachtete PCETGeschwindigkeit und die Abstandsabhängigkeit der entworfenen Elektronentransferrelais zu bestimmen. Die Verfeinerung des Designs von ET-Relais in Gerüsten aus alpha-Helixbündeln wird uns unserem Ziel eines selbständigen Denovo-NiR-Modells einen großen Schritt näher bringen.

\section{Zusammenfassung und Ausblick}

Dieser Aufsatz fasst unsere aktuellen Arbeiten zur Entwicklung aktiver Metalloproteinzentren in De-novo-Peptiden und -Proteinen aus drei $\alpha$-Helices zusammen. Wir haben mehrere Modelle von Metallbindungsstellen entwickelt, die moderate bis exzellente Aktivitäten in der Reaktivität ihrer nativen Vorbilder aufweisen. Als Ziele setzten wir uns dabei bisher bereits die Hydrolyseaktivität von Zink in symmetrischen (His) ${ }_{3}$-Koordinationsumgebungen, die Kupfernitritreduktaseaktivität und Elektronentransferzentren in unseren $\alpha$ Helixgerüsten.

Unser Ansatz zur Erzeugung von Hydrolyseaktivität in De-novo-Gerüsten, die die Aktivität der CA nachbilden, indem wir ein Tris(histidin)-Metallbindungsmotiv in unsere definierten Gerüste einbrachten, offenbarte interessante Eigenschaften dieses Enzyms. Zunächst wurde klar, dass ein Großteil der Aktivität darauf beruht, dass sich die symmetrische primäre Koordinationssphäre in einer Peptidumgebung befindet. Unsere Modelle übertrafen die CA-Aktivität niedermolekularer Modelle, indem wir die natürlich koordinierten Liganden in einem dem natürlichen System ähnlichen Gerüst verwendeten, wobei wir zugleich die Abhängigkeit der Aktivität von der Proteinfaltung untersuchen konnten. Obwohl natürliche CA vorrangig aus beta-Faltblatt- und Schleifenstrukturen besteht, zeigte das hier beschriebene, strukturell nicht verwandte alpha-Helixgerüst mittlere bis ausgezeichnete Umsatzgeschwindigkeiten bei der $\mathrm{CO}_{2}$-Hydrierung und pNPA-Hydrolyse. Die nächste Generation unserer Modelle mit hydrolytischer Aktivität wird eine asymmetrische sekundäre Koordinationssphäre aufweisen, indem entweder Heterotrimere unserer 3SCC-Systeme gebildet ${ }^{[63]}$ oder in einem rationalen Designansatz wasserstoffbrückenbindende Aminosäurereste in unser $\alpha_{3} \mathrm{DH}_{3}$-System eingeführt werden. Darüber hinaus können wir die Orientierung der Aminosäurereste in der Nähe der Metallbindungsstelle durch Einführung nichtnatürlicher Aminosäuren oder nichtkanonischer Wiederholungseinheiten, wie Stutter-and-Stammer-Inserts, in den Heptaden kontrollieren.

Wie auch die Arbeiten zu $\mathrm{Zn}(\mathrm{His})_{3}$-Zentren mit Hydrolyseaktivität umfasste die Nachbildung der CuNiR-Aktivität bisher nur die explizite Modellierung der primären Koordinationssphäre, nämlich der $\left(\mathrm{His}_{3}\right)$-Bindungsstelle. Ähnlich wie $\mathrm{CA}$ enthält auch $\mathrm{CuNiR}$ einen entscheidenden SäureBase-abhängigen Aminosäurerest, Asp98, der Wasserstoffbrücken eingehen kann und für einen effizienten Protonentransfer benötigt wird. Wir unternahmen bereits erste Versuche, Asp im Inneren unserer 3SCC-Struktur in der Nähe des Kupferzentrums einzubauen. Die experimentellen Befunde zu L19D- oder L26D-Modifikationen ließen allerdings darauf schließen, dass die Carboxygruppen miteinander statt mit dem Kupferzentrum wechselwirkten. Als Folge der Arbeit mit unseren selbstassoziierenden 3SCCs sind unsere Modifikationen bisher in jedem Fall symmetrisch. Möglicherweise lassen sich bessere CuNiR-Aktivitäten erhalten, wenn nur ein einziger Asp-Rest ober- oder unterhalb des Kupferzentrums eingeführt wird. Wir haben kürzlich ein System vorgestellt, in dem es möglich sein sollte, diese asymmetrischen Modifikationen durch Bildung heterotrimerer 3SCCs in unser 3SCC-System einzubauen. ${ }^{[63]}$ Die Einführung nichtnatürlicher Aminosäuren jenseits einfacher methylierter Histidine sollte es möglich machen, das Reduktionspotential und die Lewis-Acidität unserer Metallbindungsstellen gezielt zu variieren.

Abschließend wollen wir erwähnen, dass sowohl Rubredoxin als auch Cupredoxin Bindungsstellen aufweisen, die aus Proteinschleifen bestehen. Dadurch kann die Geometrie der Bindung großteils durch das Metall statt durch das Proteingerüst bestimmt werden. Die Nachbildung der gleichen Metallkoordination in einem starreren Gerüst wie unserem Helixbündel erfordert wahrscheinlich ein exaktes Design, was für unsere Strategie einen limitierenden Faktor darstellt: Indem wir Leucinreste im hydrophoben Inneren des Gerüsts ersetzen, schränken wir die Zahl geometrischer Anordnungen der koordinierenden Aminosäurereste stark ein. Daher wird eine weitere Verbesserung der Aktivität unserer Elektronentransferzentren das spezifische Design der Schleifenregionen, die die Helices in $\alpha_{3} \mathrm{D}$ oder $\mathrm{GR} \alpha_{3} \mathrm{D}$ verbinden, oder die Entwicklung eines neuen Gerüsts mit zusätzlicher inhärenter Flexibilität oder Sekundärstrukturelementen erfordern, die modifizierbar sind.

Das Design von Proteinen ist ein leistungsstarkes Mittel, um sowohl unser Verständnis von Metalloenzymen auf die Probe zu stellen als auch unser Wissen zur metalloenzymatischen Aktivität zu verbessern. Die Möglichkeit, die natürliche Funktion von Metalloproteinen sowohl für katalytische als auch für Elektronentransferzentren in signifikant abweichenden Proteinstrukturen nachzubilden, zeigt einen möglichen Pfad für die evolutionäre Entwicklung der verschiede- 
nen Metalloproteine, die essentiell für so viele Zellfunktionen sind.

\section{Danksagung}

T.B.J.P dankt dem National Science Research Council of Canada für finanzielle Unterstützung in Form eines PostdocStipendiums. V.L.P. dankt den National Institutes of Health für finanzielle Unterstützung dieser Arbeit (ES012236). Die Nutzung der Stanford Synchrotron Radiation Lightsource, SLAC National Accelerator Laboratory, wurde durch das U.S. Department of Energy, Office of Science, Office of Basic Energy Sciences unterstützt (Contract No. DE-AC0276SF00515). Das SSRL Structural Molecular Biology Program wird unterstützt durch das DOE Office of Biological and Environmental Research und die National Institutes of Health, National Institute of General Medical Sciences (einschließlich P41GM103393). Der Inhalt dieser Publikation liegt ausschließlich in der Verantwortung der Autoren und spiegelt nicht notwendigerweise die offiziellen Standpunkte des NIGMS oder der NIH wider.

\section{Interessenkonflikt}

Die Autoren erklären, dass keine Interessenkonflikte vorliegen.

Zitierweise: Angew. Chem. Int. Ed. 2020, 59, 7678-7699 Angew. Chem. 2020, 132, 7750-7773

[1] a) K. J. Waldron, J. C. Rutherford, D. Ford, N. J. Robinson, Nature 2009, 460, 823; b) I. Bertini, A. Sigel, Handbook on Metalloproteins, CRC Press, Boca Raton, 2001; c) C. Andreini, I. Bertini, G. Cavallaro, G. L. Holliday, J. M. Thornton, J. Biol. Inorg. Chem. 2008, 13, 1205-1218.

[2] C. Andreini, I. Bertini, A. Rosato, Acc. Chem. Res. 2009, 42, $1471-1479$.

[3] a) P.-S. Huang, S. E. Boyken, D. Baker, Nature 2016, 537, 320; b) F. Yu, V. M. Cangelosi, M. L. Zastrow, M. Tegoni, J. S. Plegaria, A. G. Tebo, C. S. Mocny, L. Ruckthong, H. Qayyum, V. L. Pecoraro, Chem. Rev. 2014, 114, 3495-3578; c) Y. Lu, S. M. Berry, T. D. Pfister, Chem. Rev. 2001, 101, 3047-3080; d) Y. Lu, N. Yeung, N. Sieracki, N. M. Marshall, Nature 2009, 460, 855 e) F. Nastri, D. D'Alonzo, L. Leone, G. Zambrano, V. Pavone, A Lombardi, Trends Biochem. Sci 2019, 44, 1022-1040.

[4] B. A. Smith, M. H. Hecht, Curr. Opin. Chem. Biol. 2011, 15, $421-426$.

[5] J. Kaplan, W. F. DeGrado, Proc. Natl. Acad. Sci. USA 2004, 101 , $11566-11570$

[6] D. N. Woolfson, G. J. Bartlett, A. J. Burton, J. W. Heal, A. Niitsu, A. R. Thomson, C. W. Wood, Curr. Opin. Struct. Biol. 2015, 33 , $16-26$.

[7] a) J. P. Schneider, A. Lombardi, W. F. DeGrado, Fold. Des. 1998, 3, R29-R40; b) E. Moutevelis, D. N. Woolfson, J. Mol. Biol. 2009, 385, 726-732.

[8] B. Lovejoy, S. Choe, D. Cascio, D. McRorie, W. F. DeGrado, D. Eisenberg, Science 1993, 259, $1288-1293$.

[9] R. S. Hodges, A. K. Saund, P. C. Chong, S. A. St-Pierre, R. E. Reid, J. Biol. Chem. 1981, 256, 1214-1224.
[10] G. R. Dieckmann, D. K. McRorie, D. L. Tierney, L. M. Utschig, C. P. Singer, T. V. O'Halloran, J. E. Penner-Hahn, W. F. DeGrado, V. L. Pecoraro, J. Am. Chem. Soc. 1997, 119, 6195-6196.

[11] K. J. Koebke, L. Ruckthong, J. L. Meagher, E. Mathieu, J. Harland, A. Deb, N. Lehnert, C. Policar, C. Tard, J. E. Penner-Hahn, Inorg. Chem. 2018, 57, 12291-12302.

[12] M. L. Zastrow, A. F. Peacock, J. A. Stuckey, V. L. Pecoraro, Nat. Chem. 2012, 4, 118.

[13] J. S. Plegaria, S. P. Dzul, E. R. Zuiderweg, T. L. Stemmler, V. L. Pecoraro, Biochemistry 2015, 54, 2858 - 2873.

[14] R. H. Holm, P. Kennepohl, E. I. Solomon, Chem. Rev. 1996, 96 , 2239-2314.

[15] a) J. Liu, S. Chakraborty, P. Hosseinzadeh, Y. Yu, S. Tian, I. Petrik, A. Bhagi, Y. Lu, Chem. Rev. 2014, 114, 4366-4469; b) S. Shaik, A. W. Munro, S. Sen, C. Mowat, W. Nam, E. Derat, T. Bugg, D. A. Proshlyakov, R. P. Hausinger, G. D. Straganz, Ironcontaining enzymes: Versatile catalysts of hydroxylation reactions in nature, Royal Society of Chemistry, London, 2011; c) R. Lill, Nature 2009, 460, 831; d) C. Andreini, V. Putignano, A. Rosato, L. Banci, Metallomics 2018, 10, 1223-1231.

[16] a) K.-H. Lee, M. Matzapetakis, S. Mitra, E. N. G. Marsh, V. L. Pecoraro, J. Am. Chem. Soc. 2004, 126, 9178-9179; b) L. Ruckthong, A. Deb, L. Hemmingsen, J. E. Penner-Hahn, V. L. Pecoraro, J. Biol. Inorg. Chem. 2018, 23, 123-135; c) A. F. Peacock, L. Hemmingsen, V. L. Pecoraro, Proc. Natl. Acad. Sci. USA 2008, 105, 16566-16571; d) A. F. Peacock, J. A. Stuckey, V. L. Pecoraro, Angew. Chem. Int. Ed. 2009, 48, 7371-7374; Angew. Chem. 2009, 121, 7507-7510.

[17] K. Håkansson, M. Carlsson, L. A. Svensson, A. Liljas, J. Mol. Biol. 1992, 227, 1192-1204.

[18] a) E. Kimura, T. Shiota, T. Koike, M. Shiro, M. Kodama, J. Am. Chem. Soc. 1990, 112, 5805-5811; b) C. P. Olmo, K. Böhmerle, H. Vahrenkamp, Inorg. Chim. Acta 2007, 360, 1510-1516; c) T. B. Koerner, R. Brown, Can. J. Chem. 2002, 80, 183-191.

[19] a) L. L. Kiefer, S. A. Paterno, C. A. Fierke, J. Am. Chem. Soc. 1995, 117, 6831-6837; b) J. F. Krebs, J. Ippolito, D. Christianson, C. Fierke, J. Biol. Chem. 1993, 268, 27458-27466; c) Z. Liang, Y. Xue, G. Behravan, B. H. Jonsson, S. Lindskog, Eur. J. Biochem. 1993, 211, 821-827.

[20] B. S. Der, D. R. Edwards, B. Kuhlman, Biochemistry 2012, 51, $3933-3940$.

[21] M. L. Zastrow, V. L. Pecoraro, J. Am. Chem. Soc. 2013, 135, $5895-5903$.

[22] A. E. Eriksson, T. A. Jones, A. Liljas, Proteins Struct. Funct. Bioinf. 1988, 4, 274-282.

[23] M. Matzapetakis, B. T. Farrer, T.-C. Weng, L. Hemmingsen, J. E. Penner-Hahn, V. L. Pecoraro, J. Am. Chem. Soc. 2002, 124, $8042-8054$.

[24] V. M. Cangelosi, A. Deb, J. E. Penner-Hahn, V. L. Pecoraro, Angew. Chem. Int. Ed. 2014, 53, 7900-7903; Angew. Chem. 2014, 126, 8034-8037.

[25] J. E. Jackman, K. M. Merz, C. A. Fierke, Biochemistry 1996, 35 , $16421-16428$.

[26] D. A. Jewell, C. Tu, S. R. Paranawithana, S. M. Tanhauser, P. V. LoGrasso, P. J. Laipis, D. N. Silverman, Biochemistry 1991, 30, $1484-1490$

[27] L. Koziol, C. A. Valdez, S. E. Baker, E. Y. Lau, W. C. Floyd III, S. E. Wong, J. H. Satcher, Jr, F. C. Lightstone, R. D. Aines, Inorg. Chem. 2012, 51, 6803-6812.

[28] K. Nakata, N. Shimomura, N. Shiina, M. Izumi, K. Ichikawa, M. Shiro, J. Inorg. Biochem. 2002, 89, 255-266.

[29] H. Slebocka-Tilk, J. Cocho, Z. Frackman, R. Brown, J. Am. Chem. Soc. 1984, 106, 2421-2431.

[30] C. A. Fierke, T. L. Calderone, J. F. Krebs, Biochemistry 1991, 30 , $11054-11063$ 
[31] S. Studer, D. A. Hansen, Z. L. Pianowski, P. R. Mittl, A. Debon, S. L. Guffy, B. S. Der, B. Kuhlman, D. Hilvert, Science 2018, 362 , $1285-1288$.

[32] a) W. J. Song, F. A. Tezcan, Science 2014, 346, 1525-1528; b) J. D. Brodin, A. Medina-Morales, T. Ni, E. N. Salgado, X. I Ambroggio, F. A. Tezcan, J. Am. Chem. Soc. 2010, 132, 8610 8617.

[33] C. M. Rufo, Y. S. Moroz, O. V. Moroz, J. Stöhr, T. A. Smith, X. Hu, W. F. DeGrado, I. V. Korendovych, Nat. Chem. 2014, 6, 303.

[34] L. Ruckthong, M. L. Zastrow, J. A. Stuckey, V. L. Pecoraro, J. Am. Chem. Soc. 2016, 138, 11979-11988.

[35] a) H. Iwasaki, S. Noji, S. Shidara, J. Biochem. 1975, 78, 355-361; b) E. Libby, B. A. Averill, Biochem. Biophys. Res. Commun 1992, 187, 1529-1535; c) M. Kukimoto, M. Nishiyama, M. E. Murphy, S. Turley, E. T. Adman, S. Horinouchi, T. Beppu, Biochemistry 1994, 33, 5246-5252; d) M. E. Murphy, S. Turley, E. T. Adman, J. Biol. Chem. 1997, 272, 28455-28460.

[36] a) S. V. Antonyuk, R. W. Strange, G. Sawers, R. R. Eady, S. S. Hasnain, Proc. Natl. Acad. Sci. USA 2005, 102, 12041-12046; b) K. Kataoka, H. Furusawa, K. Takagi, K. Yamaguchi, S Suzuki, J. Biochem. 2000, 127, 345-350; c) M. J. Boulanger, M. Kukimoto, M. Nishiyama, S. Horinouchi, M. E. Murphy, J. Biol. Chem. 2000, 275, 23957-23964.

[37] M. Tegoni, F. Yu, M. Bersellini, J. E. Penner-Hahn, V. L. Pecoraro, Proc. Natl. Acad. Sci. USA 2012, 109, 21234-21239.

[38] L. S. Kau, D. J. Spira-Solomon, J. E. Penner-Hahn, K. O. Hodgson, E. I. Solomon, J. Am. Chem. Soc. 1987, 109, 6433-6442.

[39] E. Prenesti, P. G. Daniele, M. Prencipe, G. Ostacoli, Polyhedron 1999, 18, 3233-3241.

[40] K. Olesen, A. Veselov, Y. Zhao, Y. Wang, B. Danner, C. P. Scholes, J. P. Shapleigh, Biochemistry 1998, 37, 6086-6094.

[41] a) F. Jacobson, A. Pistorius, D. Farkas, W. De Grip, Ö. Hansson, L. Sjölin, R. Neutze, J. Biol. Chem. 2007, 282, 6347-6355; b) S. Suzuki, K. Yamaguchi, K. Kataoka, K. Kobayashi, S. Tagawa, T. Kohzuma, S. Shidara, H. Iwasaki, J. Biol. Inorg. Chem. 1997, 2 , $265-274$.

[42] E. Monzani, G. A. A. Koolhaas, A. Spandre, E. Leggieri, L. Casella, M. Gullotti, G. Nardin, L. Randaccio, M. Fontani, P. Zanello, J. Biol. Inorg. Chem. 2000, 5, 251-261.

[43] A. Warshel, P. K. Sharma, M. Kato, Y. Xiang, H. Liu, M. H. Olsson, Chem. Rev. 2006, 106, 3210-3235.

[44] S. D. Fried, S. Bagchi, S. G. Boxer, Science 2014, 346, 1510-1514.

[45] a) R. Zwanzig, J. Chem. Phys. 1992, 97, 3587-3589; b) W. Min, B. P. English, G. Luo, B. J. Cherayil, S. Kou, X. S. Xie, Acc. Chem. Res. 2005, 38, 923-931.

[46] M. R. Ross, A. M. White, F. Yu, J. T. King, V. L. Pecoraro, K. J. Kubarych, J. Am. Chem. Soc. 2015, 137, 10164-10176.

[47] M. Lim, P. Hamm, R. M. Hochstrasser, Proc. Natl. Acad. Sci. USA 1998, 95, 15315-15320.

[48] a) A. Churg, A. Warshel, Biochemistry 1986, 25, 1675-1681; b) D. Kuila, J. A. Fee, J. Biol. Chem. 1986, 261, 2768-2771; c) R. Varadarajan, T. E. Zewert, H. B. Gray, S. G. Boxer, Science 1989 $243,69-72$.

[49] E. E. Chufán, S. T. Prigge, X. Siebert, B. A. Eipper, R. E. Mains, L. M. Amzel, J. Am. Chem. Soc. 2010, 132, 15565-15572.

[50] F. Yu, J. E. Penner-Hahn, V. L. Pecoraro, J. Am. Chem. Soc. 2013, 135, 18096-18107.

[51] H. B. Gray, B. G. Malmström, Comments Inorg. Chem. 1983, 2 , $203-209$.

[52] a) O. Iranzo, C. Cabello, V. L. Pecoraro, Angew. Chem. Int. Ed. 2007, 46, 6688-6691; Angew. Chem. 2007, 119, 6808-6811; b) K. H. Lee, C. Cabello, L. Hemmingsen, E. N. G. Marsh, V. L. Pecoraro, Angew. Chem. Int. Ed. 2006, 45, 2864-2868; Angew. Chem. 2006, 118, 2930-2934.

[53] K. J. Koebke, F. Yu, E. Salerno, C. Van Stappen, A. G. Tebo, J. E. Penner-Hahn, V. L. Pecoraro, Angew. Chem. Int. Ed. 2018, 57, 3954-3957; Angew. Chem. 2018, 130, 4018-4021.
[54] Y. Fukuda, K. M. Tse, T. Nakane, T. Nakatsu, M. Suzuki, M. Sugahara, S. Inoue, T. Masuda, F. Yumoto, N. Matsugaki, Proc. Natl. Acad. Sci. USA 2016, 113, 2928-2933.

[55] S. T. Prigge, A. S. Kolhekar, B. A. Eipper, R. E. Mains, L. M. Amzel, Science 1997, 278, 1300-1305.

[56] K. J. Koebke, F. Yu, C. Van Stappen, T. B. Pinter, A. Deb, J. E. Penner-Hahn, V. L. Pecoraro, J. Am. Chem. Soc. 2019, 141, $7765-7775$

[57] M. Tanokura, Biochim. Biophys. Acta Protein Struct. Mol. Enzymol. 1983, 742, 576-585.

[58] M. Tegoni, F. Yu, M. Bersellini, J. E. Penner-Hahn, V. L. Pecoraro, Proc. Natl. Acad. Sci. USA 2012, 109, 21234-21239.

[59] K. J. Koebke, F. Yu, E. Salerno, C. V. Stappen, A. G. Tebo, J. E. Penner-Hahn, V. L. Pecoraro, Angew. Chem. Int. Ed. 2018, 57, 3954-3957; Angew. Chem. 2018, 130, 4018-4021.

[60] N. Isoda, H. Yokoyama, M. Nojiri, S. Suzuki, K. Yamaguchi, Bioelectrochemistry 2010, 77, 82-88.

[61] E. I. Tocheva, L. D. Eltis, M. E. P. Murphy, Biochemistry 2008, $47,4452-4460$

[62] N. G. H. Leferink, C. Han, S. V. Antonyuk, D. J. Heyes, S. E. J. Rigby, M. A. Hough, R. R. Eady, N. S. Scrutton, S. S. Hasnain, Biochemistry 2011, 50, 4121-4131.

[63] A. E. Tolbert, C. S. Ervin, L. Ruckthong, T. J. Paul, V. M. Jayasinghe-Arachchige, K. P. Neupane, J. A. Stuckey, R. Prabhakar, V. L. Pecoraro, Nat. Chem. 2019, im Druck.

[64] a) W. Lovenberg, B. E. Sobel, Proc. Natl. Acad. Sci. USA 1965, 54,193-199; b) P. Bertrand, J.-P. Gayda, Biochim. Biophys. Acta Protein Struct. Mol. Enzymol. 1988, 954, 347-350; c) R. G. Shulman, P. Eisenberger, W. E. Blumberg, N. A. Stombaugh, Proc. Natl. Acad. Sci. USA 1975, 72, 4003-4007; d) B. Bunker, E. A. Stern, Biophys. J. 1977, 19, 253 -264; e) N. M. Atherton, K. Garbett, R. D. Gillard, R. Mason, S. J. Mayhew, J. L. Peel, J. E. Stangroom, Nature 1966, 212, 590-593; f) H. Bönisch, C. L. Schmidt, P. Bianco, R. Ladenstein, J. Biol. Inorg. Chem. 2007, 12, $1163-1171$

[65] a) S. C. Lee, W. Lo, R. H. Holm, Chem. Rev. 2014, 114, 35793600 ; b) D. L. Gerlach, D. Coucouvanis, J. Kampf, N. Lehnert, Eur. J. Inorg. Chem. 2013, 5253-5264.

[66] a) A. Jacques, M. Clémancey, G. Blondin, V. Fourmond, J.-M. Latour, O. Sénèque, Chem. Commun. 2013, 49, 2915 - 2917; b) V. Nanda, M. M. Rosenblatt, A. Osyczka, H. Kono, Z. Getahun, P. L. Dutton, J. G. Saven, W. F. DeGrado, J. Am. Chem. Soc. 2005, 127, 5804-5805; c) A. Jacques, J.-M. Latour, O. Sénèque, Dalton Trans. 2014, 43, 3922-3930; d) E. Farinas, L. Regan, Protein Sci. 1998, 7, 1939-1946; e) D. E. Benson, M. S. Wisz, W. Liu, H. W. Hellinga, Biochemistry 1998, 37, 7070-7076.

[67] A. G. Tebo, T. B. J. Pinter, R. García-Serres, A. L. Speelman, C. Tard, O. Sénéque, G. Blondin, J.-M. Latour, J. Penner-Hahn, N. Lehnert, V. L. Pecoraro, Biochemistry 2018, 57, 2308-2316.

[68] A. G. Tebo, L. Hemmingsen, V. L. Pecoraro, Metallomics 2015, 7, $1555-1561$

[69] Z. Xiao, M. J. Lavery, M. Ayhan, S. D. B. Scrofani, M. C. J. Wilce, J. M. Guss, P. A. Tregloan, G. N. George, A. G. Wedd, J. Am. Chem. Soc. 1998, 120, 4135-4150.

[70] a) P. Wegner, M. Bever, V. Schünemann, A. X. Trautwein, C. Schmidt, H. Bönisch, M. Gnida, W. Meyer-Klaucke, Hyperfine Interact. 2004, 156, 293-298; b) J. M. Meyer, in Handbook of Metalloproteins (Hrsg.: A. H. Messerschmidt, R. Poulat, T. Wieghardt), Wiley, Hoboken, 2006.

[71] a) I. Moura, A. V. Xavier, R. Cammack, M. Bruschi, J. Le Gall, Biochim. Biophys. Acta Protein Struct. 1978, 533, 156-162; b) F. E. Jenney, M. W. W. Adams, in Methods Enzymol., Vol. 334, Academic Press, San Diego, 2001, S. 45-55.

[72] a) V. S. Oganesyan, S. J. George, M. R. Cheesman, A. J. Thomson, J. Chem. Phys. 1999, 110, 762-777; b) S. J. Yoo, J. Meyer, C. Achim, J. Peterson, M. P. Hendrich, E. Münck, J. Biol. Inorg. Chem. 2000, 5, 475-487; c) B. Börger, D. Suter, J. Chem. Phys. 
2001, 115, 9821 - 9826; d) J. Peisach, W. E. Blumberg, E. T. Lode, M. J. Coon, J. Biol. Chem. 1971, 246, 5877-5881.

[73] E. I. Solomon, Inorg. Chem. 2006, 45, 8012-8025.

[74] A. A. Gewirth, E. I. Solomon, J. Am. Chem. Soc. 1988, 110, $3811-3819$.

[75] L. B. LaCroix, S. E. Shadle, Y. Wang, B. A. Averill, B. Hedman, K. O. Hodgson, E. I. Solomon, J. Am. Chem. Soc. 1996, 118 $7755-7768$.

[76] L. Basumallick, R. Sarangi, S. DeBeer George, B. Elmore, A. B. Hooper, B. Hedman, K. O. Hodgson, E. I. Solomon, J. Am. Chem. Soc. 2005, 127, 3531-3544.

[77] a) H. W. Hellinga, J. Am. Chem. Soc. 1998, 120, 10055-10066; b) Y. Lu, L. B. LaCroix, M. D. Lowery, E. I. Solomon, C. J. Bender, J. Peisach, J. A. Roe, E. B. Gralla, J. S. Valentine, J. Am. Chem. Soc. 1993, 115, 5907-5918; c) R. Schnepf, W. Haehnel, K Wieghardt, P. Hildebrandt, J. Am. Chem. Soc. 2004, 126, $14389-$ 14399; d) D. Shiga, D. Nakane, T. Inomata, Y. Funahashi, H. Masuda, A. Kikuchi, M. Oda, M. Noda, S. Uchiyama, K. Fukui, K. Kanaori, K. Tajima, Y. Takano, H. Nakamura, T. Tanaka, J. Am. Chem. Soc. 2010, 132, 18191-18198.

[78] D. Shiga, Y. Hamano, M. Kamei, Y. Funahashi, H. Masuda, M. Sakaguchi, T. Ogura, T. Tanaka, J. Biol. Inorg. Chem. 2012, 17, $1025-1031$.

[79] J. S. Plegaria, M. Duca, C. Tard, T. J. Friedlander, A. Deb, J. E. Penner-Hahn, V. L. Pecoraro, Inorg. Chem. 2015, 54, $9470-$ 9482.

[80] S. Chakraborty, J. Y. Kravitz, P. W. Thulstrup, L. Hemmingsen, W. F. DeGrado, V. L. Pecoraro, Angew. Chem. Int. Ed. 2011, 50 2049-2053; Angew. Chem. 2011, 123, 2097-2101.

[81] a) K. W. Penfield, R. R. Gay, R. S. Himmelwright, N. C. Eickman, V. A. Norris, H. C. Freeman, E. I. Solomon, J. Am. Chem. Soc. 1981, 103, 4382 - 4388; b) G. P. Anderson, D. G. Sanderson C. H. Lee, S. Durell, L. B. Anderson, E. L. Gross, Biochim Biophys. Acta 1987, 894, 386-398.

[82] D. M. Arciero, B. S. Pierce, M. P. Hendrich, A. B. Hooper, Biochemistry 2002, 41, 1703-1709.

[83] a) B. G. Karlsson, L.-C. Tsai, H. Nar, J. Sanders-Loehr, N. Bonander, V. Langer, L. Sjölin, Biochemistry 1997, 36, $4089-$ 4095; b) J. F. Hall, L. D. Kanbi, R. W. Strange, S. S. Hasnain, Biochemistry 1999, 38, 12675-12680.

[84] a) T. Pascher, B. G. Karlsson, M. Nordling, B. G. Malmstom, T. Vanngard, Eur. J. Biochem. 1993, 212, 289-296; b) A. G. Lappin C. A. Lewis, W. J. Ingledew, Inorg. Chem. 1985, 24, 1446-1450; c) F. Xu, R. M. Berka, J. A. Wahleithner, B. A. Nelson, J. R Shuster, S. H. Brown, A. E. Palmer, E. I. Solomon, Biochem. J. 1998, 334, 63-70.
[85] a) B. T. Farrer, N. P. Harris, K. E. Balchus, V. L. Pecoraro, Biochemistry 2001, 40, 14696-14705; b) J. Y. Su, R. S. Hodges, C. M. Kay, Biochemistry 1994, 33, 15501-15510.

[86] S. Tian, J. Liu, R. E. Cowley, P. Hosseinzadeh, N. M. Marshall, Y. Yu, H. Robinson, M. J. Nilges, N. J. Blackburn, E. I. Solomon, Y. Lu, Nat. Chem. 2016, 8, 670-677.

[87] K. J. Koebke, T. B. J. Pinter, A. Deb, C. Tard, J. Penner-Hahn, V. L. Pecoraro, unveröffentlichte Ergebnisse.

[88] a) J. S. Plegaria, C. Herrero, A. Quaranta, V. L. Pecoraro, Biochim. Biophys. Acta Bioenerg. 2016, 1857, 522-530; b) A. G. Tebo, A. Quaranta, C. Herrero, V. L. Pecoraro, A. Aukauloo, ChemPhotoChem 2017, 1, 89-92.

[89] a) J. R. Winkler, P. Wittung-Stafshede, J. Leckner, B. G. Malmström, H. B. Gray, Proc. Natl. Acad. Sci. USA 1997, 94, 42464249; b) A. J. Di Bilio, M. G. Hill, N. Bonander, B. G. Karlsson, R. M. Villahermosa, B. G. Malmström, J. R. Winkler, H. B. Gray, J. Am. Chem. Soc. 1997, 119, 9921-9922; c) L. K. Skov, T. Pascher, J. R. Winkler, H. B. Gray, J. Am. Chem. Soc. 1998, 120, $1102-1103$; d) K. Sigfridsson, M. Ejdebäck, M. Sundahl, Ö. Hansson, Arch. Biochem. Biophys. 1998, 351, 197-206; e) T. M. McCleskey, J. R. Winkler, H. B. Gray, J. Am. Chem. Soc. 1992, 114, 6935-6937.

[90] J. L. Dempsey, J. R. Winkler, H. B. Gray, Chem. Rev. 2010, 110, $7024-7039$

[91] a) H. B. Gray, J. R. Winkler, Chem. Phys. Lett. 2009, 483, 1-9; b) H. B. Gray, J. R. Winkler, $Q$. Rev. Biophys. 2003, 36, 341-372; c) C. C. Moser, J. M. Keske, K. Warncke, R. S. Farid, P. L. Dutton, Nature 1992, 355, 796-802.

[92] B. A. Barry, J. Photochem. Photobiol. B 2011, 104, 60-71.

[93] W. T. Dixon, D. Murphy, J. Chem. Soc. Faraday Trans. 2 1976, 72, $1221-1230$.

[94] a) B. W. Berry, M. C. Martínez-Rivera, C. Tommos, Proc. Natl. Acad. Sci. USA 2012, 109, 9739-9743; b) S. D. Glover, C. Jorge, L. Liang, K. G. Valentine, L. Hammarström, C. Tommos, J. Am. Chem. Soc. 2014, 136, 14039-14051.

[95] a) L. P. Candeias, S. Turconi, J. H. A. Nugent, Biochim. Biophys. Acta Bioenerg. 1998, 1363, 1-5; b) A. A. Pizano, D. A. Lutterman, P. G. Holder, T. S. Teets, J. Stubbe, D. G. Nocera, Proc. Natl. Acad. Sci. USA 2012, 109, 39-43.

[96] C. C. Moser, P. L. Dutton, Biochim. Biophys. Acta Bioenerg. 1992, 1101, 171-176

Manuskript erhalten: 16. Juni 2019

Akzeptierte Fassung online: 22. August 2019

Endgültige Fassung online: 2. März 2020

Übersetzt von Dr. Marie Bergner, Göttingen 